\title{
Modes of exercise training for intermittent claudication
}

Citation for published version (APA):

Jansen, S. C. P., Abaraogu, U. O., Lauret, G. J., Fakhry, F., Fokkenrood, H. J. P., \& Teijink, J. A. W. (2020). Modes of exercise training for intermittent claudication. Cochrane Database of Systematic Reviews, (8), [009638]. https://doi.org/10.1002/14651858.CD009638.pub3

Document status and date:

Published: 01/01/2020

DOI:

10.1002/14651858.CD009638.pub3

Document Version:

Publisher's PDF, also known as Version of record

Document license:

Taverne

Please check the document version of this publication:

- A submitted manuscript is the version of the article upon submission and before peer-review. There can be important differences between the submitted version and the official published version of record.

People interested in the research are advised to contact the author for the final version of the publication, or visit the DOI to the publisher's website.

- The final author version and the galley proof are versions of the publication after peer review.

- The final published version features the final layout of the paper including the volume, issue and page numbers.

Link to publication

\footnotetext{
General rights rights.

- You may freely distribute the URL identifying the publication in the public portal. please follow below link for the End User Agreement:

www.umlib.nl/taverne-license

Take down policy

If you believe that this document breaches copyright please contact us at:

repository@maastrichtuniversity.nl

providing details and we will investigate your claim.
}

Copyright and moral rights for the publications made accessible in the public portal are retained by the authors and/or other copyright owners and it is a condition of accessing publications that users recognise and abide by the legal requirements associated with these

- Users may download and print one copy of any publication from the public portal for the purpose of private study or research.

- You may not further distribute the material or use it for any profit-making activity or commercial gain

If the publication is distributed under the terms of Article $25 \mathrm{fa}$ of the Dutch Copyright Act, indicated by the "Taverne" license above, 
[Intervention Review]

\section{Modes of exercise training for intermittent claudication}

Sandra CP Jansen 1,2 , Ukachukwu Okoroafor Abaraogu ${ }^{3,4}$, Gert Jan Lauret ${ }^{5}$, Farzin Fakhry ${ }^{6}$, Hugo JP Fokkenrood ${ }^{7}$, Joep AW Teijink ${ }^{1,8}$

1Department of Vascular Surgery, Catharina Hospital, Eindhoven, Netherlands. 2CAPHRI School for Public Health and Primary Care, Maastricht University Medical Centre, Maastricht, Netherlands. ${ }^{3}$ Department of Physiotherapy and Paramedicine, School of Health and Life Sciences, Glasgow Caledonian University, Glasgow, UK. ${ }^{4}$ Department of Medical Rehabilitation, University of Nigeria, Nsukka, Nigeria. ${ }^{5}$ Department of Vascular Surgery, Slingeland Hospital, Doetinchem, Netherlands. ${ }^{6}$ Department of Cardiology, Haga Teaching Hospital, The Hague, Netherlands. ${ }^{7}$ Department of Vascular Surgery, Radboud University Medical Center, Radboud Institute for Health Sciences, Nijmegen, Netherlands. ${ }^{8}$ CAPHRI School for Public Health and Primary Care, Maastricht University Medical Centre, Maastricht, Netherlands

Contact address: Joep AW Teijink, joep.teijink@catharinaziekenhuis.nl.

Editorial group: Cochrane Vascular Group.

Publication status and date: New search for studies and content updated (no change to conclusions), published in Issue 8, 2020.

Citation: Jansen SCP, Abaraogu UO, Lauret GJ, Fakhry F, Fokkenrood HJP, Teijink JAW. Modes of exercise training for intermittent claudication. Cochrane Database of Systematic Reviews 2020, Issue 8. Art. No.: CD009638. DOI: 10.1002/14651858.CD009638.pub3.

Copyright ( 2020 The Cochrane Collaboration. Published by John Wiley \& Sons, Ltd.

\section{A B S T R A C T}

\section{Background}

According to international guidelines and literature, all patients with intermittent claudication should receive an initial treatment of cardiovascular risk modification, lifestyle coaching, and supervised exercise therapy. In the literature, supervised exercise therapy often consists of treadmill or track walking. However, alternative modes of exercise therapy have been described and yielded similar results to walking. This raises the following question: which exercise mode produces the most favourable results? This is the first update of the original review published in 2014.

\section{Objectives}

To assess the effects of alternative modes of supervised exercise therapy compared to traditional walking exercise in patients with intermittent claudication.

\section{Search methods}

The Cochrane Vascular Information Specialist searched the Cochrane Vascular Specialised Register, CENTRAL, MEDLINE, Embase and CINAHL databases and World Health Organization International Clinical Trials Registry Platform and ClinicalTrials.gov trials registers to 4 March 2019. We also undertook reference checking, citation searching and contact with study authors to identify additional studies. No language restriction was applied.

\section{Selection criteria}

We included parallel-group randomised controlled trials comparing alternative modes of exercise training or combinations of exercise modes with a control group of supervised walking exercise in patients with clinically determined intermittent claudication. The supervised walking programme needed to be supervised at least twice a week for a consecutive six weeks of training.

\section{Data collection and analysis}

Two review authors independently selected studies, extracted data, and assessed the risk of bias for each study. As we included studies with different treadmill test protocols and different measuring units (metres, minutes, or seconds), the standardised mean difference (SMD) approach was used for summary statistics of mean walking distance (MWD) and pain-free walking distance (PFWD). Summary estimates were obtained for all outcome measures using a random-effects model. We used the GRADE approach to assess the certainty of the evidence. 


\section{Main results}

For this update, five additional studies were included, making a total of 10 studies that randomised a total of 527 participants with intermittent claudication (IC). The alternative modes of exercise therapy included cycling, lower-extremity resistance training, upper-arm ergometry, Nordic walking, and combinations of exercise modes. Besides randomised controlled trials, two quasi-randomised trials were included. Overall risk of bias in included studies varied from high to low. According to GRADE criteria, the certainty of the evidence was downgraded to low, due to the relatively small sample sizes, clinical inconsistency, and inclusion of three studies with risk of bias concerns.

Overall, comparing alternative exercise modes versus walking showed no clear differences for MWD at 12 weeks (standardised mean difference (SMD) -0.01, 95\% confidence interval ( $\mathrm{Cl}$ ) -0.29 to $0.27 ; \mathrm{P}=0.95 ; 6$ studies; 274 participants; low-certainty evidence); or at the end of training (SMD - $0.11,95 \% \mathrm{Cl}-0.33$ to $0.11 ; \mathrm{P}=0.32 ; 9$ studies; 412 participants; low-certainty evidence). Similarly, no clear differences were detected in PFWD at 12 weeks (SMD -0.01, 95\% Cl -0.26 to 0.25; P = 0.97; 5 studies; 249 participants; low-certainty evidence); or at the end of training (SMD $-0.06,95 \% \mathrm{Cl}-0.30$ to $0.17 ; \mathrm{P}=0.59 ; 8$ studies, 382 participants; low-certainty evidence). Four studies reported on health-related quality of life (HR-QoL) and three studies reported on functional impairment. As the studies used different measurements, meta-analysis was only possible for the walking impairment questionnaire (WIQ) distance score, which demonstrated little or no difference between groups (MD -5.52, 95\% $\mathrm{Cl}-17.41$ to $6.36 ; \mathrm{P}=0.36 ; 2$ studies; 96 participants; low-certainty evidence).

\section{Authors' conclusions}

This review found no clear difference between alternative exercise modes and supervised walking exercise in improving the maximum and pain-free walking distance in patients with intermittent claudication. The certainty of this evidence was judged to be low, due to clinical inconsistency, small sample size and risk of bias concerns. The findings of this review indicate that alternative exercise modes may be useful when supervised walking exercise is not an option. More RCTs with adequate methodological quality and sufficient power are needed to provide solid evidence for comparisons between each alternative exercise mode and the current standard of supervised treadmill walking. Future RCTs should investigate outcome measures on walking behaviour, physical activity, cardiovascular risk, and HRQoL, using standardised testing methods and reporting of outcomes to allow meaningful comparison across studies.

\section{PLAIN LANGUAGE SUMMARY}

\section{How effective are supervised exercise programmes compared to supervised walking programmes for treating intermittent claudication?}

\section{Why this question is important}

Intermittent claudication is the medical term for pain in the lower leg (or both legs) that develops during exercise (for example, walking) and usually goes away after a few minutes' rest. This pain is produced by a restriction of blood flow to the leg muscles. This restriction in blood flow is caused by the partial blockage of arteries (vessels that deliver oxygen-rich blood around the body) by a build-up of fatty deposits (atherosclerosis). This results in a reduced oxygen supply reaching the leg muscles.

International guidelines recommend that people with intermittent claudication should exercise by walking (for example, on a treadmill) while supervised by a physical or exercise therapist. The goal of these exercises is to increase the distance people can walk, and to limit the impact of intermittent claudication on their quality of life.

Supervised walking programmes are not the only type of supervised exercise available. There are other options, such as strength training, Nordic walking (walking with specially designed poles to exercise the upper as well as the lower body) or cycling. To find out how effective other types of supervised exercise programmes are compared to supervised walking programmes, we reviewed the evidence from research studies.

\section{How we identified and assessed the evidence}

First, we searched for all relevant studies in the medical literature. We then compared the results, and summarised the evidence from all the studies. Finally, we assessed how certain the evidence was. We considered factors such as the way studies were conducted, study sizes, and consistency of findings across studies. Based on our assessments, we categorised the evidence as being of very low, low, moderate or high certainty.

\section{What we found}

We found ten studies on a total of 527 people with intermittent claudication. The studies compared supervised walking programmes against:

* exercises to strengthen the leg muscles (four studies);

* Nordic walking (three studies);

* cycling (one study); 
* arm ergometry (pedalling with the arms on an exercise machine - one study);

* a combination of different types of exercise (four studies).

The programmes lasted between six and 24 weeks.

The evidence suggests that there may be little to no difference between supervised walking and other types of supervised exercise in terms of:

* the average maximum distance that people can walk after 12 weeks of exercise, or once they have completed the exercise programme;

* the average distance that people can walk without feeling pain after 12 weeks of exercise, or once they have completed the exercise programme; or

* disability (after 12 to 24 weeks of exercise).

We do not know if there is a difference in quality of life, since the studies that investigated this used different measurement tools to assess it, and we could not compare the results.

\section{What this means}

This review suggests that supervised walking and other types of supervised exercise programmes may have similar effects on how far people with intermittent claudication can walk, and how far they can walk without pain. However, our confidence in this finding is limited, mainly because:

${ }^{*}$ the studies we reviewed were small;

* the types of supervised walking exercises that were evaluated varied across studies; and

* concerns about how some studies were conducted.

Future studies that use robust methods and include large numbers of people are needed to provide stronger evidence for comparing different types of supervised exercise programmes for intermittent claudication.

\section{How-up-to date is this review?}

The evidence in this Cochrane Review is current to March 2019. 
SUMMARY OF FINDINGS

\section{Summary of findings 1 . Alternative modes of exercise compared to walking exercise for people with intermittent claudication}

Alternative modes of exercise compared to walking exercise in people with intermittent claudication (IC)

Patient or population: patients with IC

Setting: hospital or community-based (supervised exercise therapy)

Intervention: alternative modes of exercise

Comparison: walking exercise

\begin{tabular}{|c|c|c|c|c|c|c|}
\hline \multirow[t]{2}{*}{ Outcomes } & \multicolumn{2}{|c|}{$\begin{array}{l}\text { Anticipated absolute effects }{ }^{\star}(95 \% \\
\mathrm{Cl})\end{array}$} & \multirow[t]{2}{*}{$\begin{array}{l}\text { Relative effect } \\
(95 \% \mathrm{CI})\end{array}$} & \multirow{2}{*}{$\begin{array}{l}\text { № of partici- } \\
\text { pants } \\
\text { (studies) }\end{array}$} & \multirow{2}{*}{$\begin{array}{l}\text { Certainty of } \\
\text { the evidence } \\
\text { (GRADE) }\end{array}$} & \multirow[t]{2}{*}{ Comments } \\
\hline & $\begin{array}{l}\text { Risk with } \\
\text { walking exer- } \\
\text { cise }\end{array}$ & $\begin{array}{l}\text { Risk with alter- } \\
\text { native modes of } \\
\text { exercise }\end{array}$ & & & & \\
\hline $\begin{array}{l}\text { Maximum walking dis- } \\
\text { tance } \\
\text { (12 weeks) }\end{array}$ & - & $\begin{array}{l}\text { SMD } 0.01 \text { lower } \\
\text { (0.29 lower to } \\
0.27 \text { higher) }\end{array}$ & - & $\begin{array}{l}274 \\
\text { (6 studies) }\end{array}$ & $\begin{array}{l}\oplus \oplus \ominus \ominus \\
\text { LOW } 123\end{array}$ & $\begin{array}{l}\text { This translates to no clear difference in MWD } \\
\text { after } 12 \text { weeks of training when comparing al- } \\
\text { ternative modes of exercise with walking ex- } \\
\text { ercise. }\end{array}$ \\
\hline $\begin{array}{l}\text { Maximum walking dis- } \\
\text { tance } \\
\text { (at end of training, rang- } \\
\text { ing from } 6 \text { to } 24 \text { weeks) }\end{array}$ & - & $\begin{array}{l}\text { SMD } 0.11 \text { lower } \\
(0.33 \text { lower to } \\
0.11 \text { higher) }\end{array}$ & - & $\begin{array}{l}412 \\
\text { (9 studies) }\end{array}$ & $\begin{array}{l}\oplus \oplus \Theta \Theta \\
\text { LOW } 123\end{array}$ & $\begin{array}{l}\text { This translates to no clear difference in MWD } \\
\text { at the end of training when comparing alter- } \\
\text { native modes of exercise with walking exer- } \\
\text { cise. }\end{array}$ \\
\hline $\begin{array}{l}\text { Pain-free walking dis- } \\
\text { tance } \\
\text { (12 weeks) }\end{array}$ & - & $\begin{array}{l}\text { SMD } 0.01 \text { lower } \\
(0.26 \text { lower to } \\
0.25 \text { higher) }\end{array}$ & - & $\begin{array}{l}249 \\
\text { (5 studies) }\end{array}$ & $\begin{array}{l}\oplus \oplus \ominus \ominus \\
\text { LOW } 123\end{array}$ & $\begin{array}{l}\text { This translates to no clear difference in PFWD } \\
\text { after } 12 \text { weeks of training when comparing al- } \\
\text { ternative modes of exercise with walking ex- } \\
\text { ercise. }\end{array}$ \\
\hline $\begin{array}{l}\text { Pain-free walking dis- } \\
\text { tance } \\
\text { (at end of training, rang- } \\
\text { ing from } 6 \text { to } 24 \text { weeks) }\end{array}$ & - & $\begin{array}{l}\text { SMD } 0.06 \text { lower } \\
\text { ( } 0.3 \text { lower to } 0.17 \\
\text { higher) }\end{array}$ & - & $\begin{array}{l}382 \\
\text { (8 studies) }\end{array}$ & $\begin{array}{l}\oplus \oplus \ominus \ominus \\
\text { LOW } 123\end{array}$ & $\begin{array}{l}\text { This translates to no clear difference in PFWD } \\
\text { at the end of training when comparing alter- } \\
\text { native modes of exercise with walking exer- } \\
\text { cise. }\end{array}$ \\
\hline $\begin{array}{l}\text { Health-related QoL } \\
\text { (at end of training, rang- } \\
\text { ing from } 12 \text { to } 24 \text { weeks) }\end{array}$ & - & - & - & - & - & $\begin{array}{l}\text { Four studies reported HR-QoL using different } \\
\text { outcome measurements so meaningful com- } \\
\text { parison was not possible. }\end{array}$ \\
\hline
\end{tabular}


Self-reported function-

al impairment (WIQ)

(at end of training, ranging from 12 to 24 weeks)
This translates to little or no important difference in the WIQ score when comparing alternative modes of exercise with walking exercise.

${ }^{*}$ The risk in the intervention group (and its 95\% confidence interval) is based on the assumed risk in the comparison group and the relative effect of the intervention (and its $95 \% \mathrm{Cl})$.

CI: confidence interval; IC: intermittent claudication; HR-QoL; health related quality of life; MD: mean difference; MWD: maximum walking distance; PFWD: pain-free walking distance; QoL: quality of life; SMD: standardised mean difference; WIQ: Walking Impairment Questionnaire

\section{GRADE Working Group grades of evidence}

High certainty: We are very confident that the true effect lies close to that of the estimate of the effect

Moderate certainty: We are moderately confident in the effect estimate: The true effect is likely to be close to the estimate of the effect, but there is a possibility that it is substantially different

Low certainty: Our confidence in the effect estimate is limited: The true effect may be substantially different from the estimate of the effect

Very low certainty: We have very little confidence in the effect estimate: The true effect is likely to be substantially different from the estimate of effect

1 The certainty of evidence was downgraded one level, because of evidence of clinical inconsistency, as studies used different alternative modes of exercise in the control groups.

2 The certainty of evidence was downgraded one level, because this analysis included 3 studies with risk of bias concerns.

3 The possibility of publication bias could not be ruled out, yet we did not consider it sufficient to downgrade the certainty of the evidence.

4 The certainty of evidence was downgraded one level, because results were based on a relatively small sample size. 


\section{B A C K G R O U N D}

This review includes a glossary of abbreviations and definitions (Table 1).

\section{Description of the condition}

Peripheral arterial disease (PAD) is a chronic arterial occlusive disease caused by progressive atherosclerosis. Several arterial segments can be affected, such as the aorta and iliac, femoral, popliteal, and tibial arteries in the limbs. Approximately 202 million people are affected with PAD of the lower extremities, defined as an ankle-brachial index below 0.90 in either leg (Fowkes 2013). The incidence of PAD increases with age, in particular after the age of 40 years. In high-income countries, PAD affects $5.41 \%$ of men and $5.28 \%$ of women at the age of 45 to 49 years. This prevalence rises to $18.83 \%$ in men and $18.38 \%$ in women at the age of 85 to 89 years (Fowkes 2013). The most common symptom is intermittent claudication (IC), defined as a cramping pain in the muscles of the leg(s) that occurs during exercise and is relieved by a short period of rest. Because of this symptom, patients have a reduced painfree and maximum walking capacity, which restricts the patients' activity and mobility, leading to diminished health-related quality of life (Dumville 2004; McDermott 2001).

Moreover, given that PAD is a systemic disease which is characterised by generalised atherosclerosis, individuals with IC have an increased total risk of cardiovascular events beyond the claudication symptoms. Patients with IC have a five-year all-cause mortality rate of $10 \%$ to $15 \%$ and a $20 \%$ chance of a non-fatal cardiovascular event (Aboyans 2018). When IC progresses to critical limb ischaemia, an even higher mortality rate of $25 \%$ after one year is found (Conte 2015).

\section{Description of the intervention}

All patients with IC should receive a multicomponent therapy consisting of cardiovascular risk management, lifestyle counselling, and exercise therapy to reduce the associated serious health risks (Aboyans 2018; Gerhard-Herman 2017). Several randomised controlled trials and systematic reviews have compared walking exercise supervised by a physical or exercise therapist to non-supervised exercise, usual care, placebo, single walking advice, endovascular interventions, or bypass surgery (Fakhry 2018; Hageman 2018; Lane 2017; Parmenter 2015). The current evidence supports supervised exercise therapy as the primary treatment to improve walking capacity and health-related quality of life in patients with IC. Furthermore, community-based supervised exercise appears to be at least as efficacious as programmes provided in a hospital setting (Bendermacher 2007; Kruidenier 2009; Nicolaï 2010). Less attention has been paid to the mode of (supervised) exercise. Besides traditional walking, alternative modes of supervised exercise training, such as cycling, upper-extremity cycle ergometer exercise, Nordic walking, and strength training exist and are associated with a significantly improved walking capacity (Golledge 2018; Parmenter 2011; Tompra 2015). Notably, this update includes Nordic walking as an alternative exercise mode, in contrast to the original review in which Nordic walking was considered a different walking protocol (Lauret 2014). Recent research has provided new insights on the potential benefits of Nordic walking. This core-focused walking technique substantially differs from traditional walking, as it engages the muscles of the arms and trunk to reduce the load on the legs during walking (Golledge 2018).

Exercise training often provokes the claudication symptoms, depending on the protocol used (pain-free walking or walking until maximum pain). This can be considered as an adverse event, which is particularly relevant to patients in the context of expectation management. It generally takes several weeks for the patient to experience improvement and this type of treatment requires perseverance from the patient. Research has demonstrated that supervised exercise therapy is safe and has an exceedingly low allcause complication rate (Gommans 2015).

\section{How the intervention might work}

Physical activity, which includes exercise, is associated with many health benefits (Piercy 2018). In patients with IC, exercise therapy significantly reduces symptoms and improves healthrelated quality of life. The exact mechanism for these benefits remains unclear and is probably multifactorial. A number of potential mechanisms have been suggested, such as induction of vascular angiogenesis, metabolic adaptations within skeletal muscle, improved endothelial flow-mediated dilatation, reduced inflammatory activation, reduced endothelial and mitochondrial dysfunction, improved walking efficiency, and increased pain tolerance (Conte 2015; Haas 2012; Harwood 2016). Additionally, supervised exercise therapy potentially reduces cardiovascular risk (Jansen 2019).

If walking ability is severely compromised by IC symptoms, traditional walking exercise may not provide sufficient stimulus to improve aerobic capacity. In those patients, alternative modes of aerobic exercise might be more beneficial than traditional walking. An example is Nordic walking, which is a core-focused walking technique which reduces the load on the legs during walking (Golledge 2018). Cycling is also a non-weight-bearing mode of exercise; and muscle strength seems to be associated with improved walking ability, which might explain the potential benefits of progressive resistance training of the lower limbs (Parmenter 2013b).

\section{Why it is important to do this review}

In most studies, supervised exercise programmes involve treadmill or track walking that is of sufficient intensity to provoke claudication symptoms. Walking exercise is alternated with rest over the course of a 30- to 60-minute session. Unfortunately, not all patients with IC are able to complete the exercise protocol because of concomitant comorbidity, such as arthrosis, chronic obstructive pulmonary disease, stroke, or cardiac complaints. For these patients, an adjusted protocol or alternative exercise regimen may be proposed. Being able to offer several modes of exercise might improve therapy adherence, as this enables better alignment with personal preferences. Combinations of aerobic and musclestrengthening activities might be preferable, as these provide the most extensive health benefits according to the Physical Activity Guidelines (Piercy 2018).

This systematic review aims to determine the effect of alternative exercise modes on walking distance and health-related quality of life in patients with IC, compared to traditional walking exercise. Other Cochrane systematic reviews have demonstrated favourable results for supervised exercise programmes compared to usual care 
and non-supervised programmes (Hageman 2018; Lane 2017). We solely compared different exercise modalities between supervised programmes.

This is the first update of the original review published in 2014 (Lauret 2014). The original review concluded that there was no clear difference between supervised walking exercise and alternative exercise modes in improving the maximum and pain-free walking distance, but also highlighted the need for more studies with larger sample sizes. The international guidelines for the management of IC recommend considering the use of alternative exercise modes (such as cycling, upper-arm ergometry and strength training) to improve walking ability and functional status when walking is not an option for patients (Aboyans 2018; Gerhard-Herman 2017). In this update, we have presented all the currently available evidence on alternative exercise modes to help patients and healthcare providers determine which may offer the most benefit to them.

\section{O B J E C T I VES}

To assess the effects of alternative modes of supervised exercise therapy compared to traditional walking exercise in patients with intermittent claudication.

\section{METHOD S}

\section{Criteria for considering studies for this review}

\section{Types of studies}

We included parallel-group randomised controlled trials (RCTs) comparing (combinations of) alternative modes of exercise training (for example, ergometry, strength training, aerobic exercise, Nordic walking, etc.) with traditional walking exercise in patients with intermittent claudication (IC). Quasi-randomised trials were also included, but were distinguished from properly randomised trials in 'Risk of bias' assessment. We excluded cross-over, factorial, or cluster-RCTs.

\section{Types of participants}

We included studies where the study participants consisted of adults (18 years and older) with clinically determined IC (Fontaine II or Rutherford 1 to 3 (Aboyans 2018)), who were considered for conservative treatment. We excluded studies of participants with asymptomatic lower-limb atherosclerosis identified by testing. When studies described a mixture of asymptomatic and symptomatic participants, we contacted the authors to ask if a subanalysis was available. If not, we excluded these studies.

\section{Types of interventions}

We included all RCTs comparing alternative modes of exercise training (e.g. arm ergometry, strength training, cycling, Nordic walking, etc.) or combinations of exercise modes with a control group of traditional walking exercise. All exercise programmes had to be supervised at least twice a week during six consecutive weeks of training. We excluded studies reporting an exercise programme with a duration of less than six weeks of training or with less than two supervised sessions a week.

We excluded all types of mechanical intermittent compression treatments as we did not consider them to be exercise training. We excluded studies comparing different settings of walking exercise (supervised versus unsupervised, community versus hospital-based) or comparisons of different walking protocols (lowversus high-frequency training, low- versus high-intensity training, different treadmill exercise protocols).

\section{Types of outcome measures}

Studies were included only if reported outcome measures were available at baseline and after at least six weeks of follow-up.

\section{Primary outcomes}

- Maximal treadmill walking distance or time (MWD/T)

\section{Secondary outcomes}

- Pain-free treadmill walking distance or time (PFWD/T)

- Health-related quality of life scores (HR-QoL)

- Self-reported functional impairment (Walking Impairment Questionnaire)

\section{Search methods for identification of studies}

\section{Electronic searches}

The Cochrane Vascular Information Specialist conducted systematic searches of the following databases for randomised controlled trials and controlled clinical trials without language, publication year or publication status restrictions:

- Cochrane Vascular Specialised Register via the Cochrane Register of Studies (CRS-Web searched on 4 March 2019);

- Cochrane Central Register of Controlled Trials (CENTRAL) Cochrane Register of Studies Online (CRSO 2019, issue 2);

- MEDLINE (Ovid MEDLINE ${ }^{\circledR}$ Epub Ahead of Print, In-Process \& Other Non-Indexed Citations, Ovid MEDLINE ${ }^{\circledR}$ Daily and Ovid MEDLINE ${ }^{\circledR}$ ) (searched from 1 January 2013 to 4 March 2019);

- Embase Ovid (searched from 1 January 2013 to 4 March 2019);

- CINAHL Ebsco (searched from 1 January 2017 to 4 March 2019);

- AMED Ovid (searched from 1 January 2017 to 4 March 2019).

The Information Specialist modelled search strategies for other databases on the search strategy designed for CENTRAL. Where appropriate, they were combined with adaptations of the highly sensitive search strategy designed by the Cochrane Collaboration for identifying randomised controlled trials and controlled clinical trials (as described in the Cochrane Handbook for Systematic Reviews of Interventions Chapter 6, Lefebvre 2011). Search strategies for major databases are provided in Appendix 1.

The Information Specialist searched the following trials registries on 4 March 2019:

- World Health Organization International Clinical Trials Registry Platform (who.int/trialsearch);

- ClinicalTrials.gov (clinicaltrials.gov).

\section{Searching other resources}

We searched the reference lists of relevant studies identified by the above search strategies to identify other relevant citations. 


\section{Data collection and analysis}

\section{Selection of studies}

Two review authors (SJ and UA) independently selected studies for this review. Three review authors (GJ, HF, and JT) confirmed the suitability of selected studies for inclusion. Any disagreements regarding inclusion/exclusion of selected studies were solved through discussion.

\section{Data extraction and management}

Two review authors (SJ and UA) independently extracted data using a standard data collection form and entered data into Review Manager (Review Manager 2020). When necessary, additional information from included studies was sought by contacting study authors. The extracted study data consisted of the following:

- study characteristics, including study design, method of randomisation, exclusions post-randomisation, publication year, country, and study period;

- baseline characteristics, including number of participants, losses to follow-up, mean age, gender distribution, and inclusion and exclusion criteria;

- type of interventions, including mode(s) of exercise, duration of programme, number of sessions, number of supervised sessions, and exercise protocol; and

- mean maximum walking distance or time, mean pain-free walking distance or time, mean quality of life scores at baseline and follow-up periods, and functional impairment information.

\section{Assessment of risk of bias in included studies}

Two review authors (SJ and UA) assessed the risk of bias for each study according to the checklist of design components, which comprised sequence generation, allocation concealment, blinding of personnel and participants, blinding of outcome assessments, incomplete outcome data, selective reporting, and other forms of bias. Another review author (GJ) confirmed the methodological quality of studies, primarily for adequacy of allocation concealment and follow-up. Due to the intervention (exercise), blinding of participants and personnel was not possible. Although this could introduce bias, we decided to consider the risk of bias to be low, since all studies experienced the same limitation. Consensus was achieved through informal discussion. The adequacy of each category was summarised as having 'low', 'unclear', or 'high' risk, according to criteria provided in the Cochrane Handbook for Systematic Reviews of Interventions (Higgins 2019).

\section{Measures of treatment effect}

We assessed treatment effects on the MWD and PFWD after 12 weeks follow-up and at the end of training. As studies with different treadmill test protocols and different measuring units (metres, minutes, or seconds) were included, the standardised mean difference (SMD) with 95\% confidence intervals $(\mathrm{CI})$ approach was used for summary statistics of MWD and PFWD. The SMDs were interpreted by using rules of thumb for effect sizes, in which a SMD of 0.2 represents a small effect, 0.5 a moderate effect, and 0.8 a large effect (Cohen 1988). For HR-QoL and functional impairment scores, data were only pooled if more than one study used the same questionnaire. Therefore, the summary statistic was expressed as mean difference (MD) with $95 \% \mathrm{Cl}$.

\section{Unit of analysis issues}

We used the individual participant as the unit of analysis. Studies using cross-over design were not included in this review.

\section{Dealing with missing data}

Where applicable, missing data were requested from the authors. We expected that most studies reported baseline and final values with the corresponding standard deviations (SD). Where only change scores were provided, final value means were calculated using change score means and baseline data. Standard deviations were imputed using a conservative correlation coefficient of 0.5 for within-patient correlation from baseline to follow-up according to instructions in the Cochrane Handbook for Systematic Reviews of Interventions (Higgins 2019).

\section{Assessment of heterogeneity}

Statistical heterogeneity was assessed by the $\mathrm{Chi}^{2}$-test $(\mathrm{P}<0.10$ considered as heterogeneous) and the $\mathrm{I}^{2}$ statistic $\left(\mathrm{I}^{2}>50 \%\right.$ considered as moderate to substantial risk of heterogeneity), in order to assess whether observed variation in trial results was compatible with the variation expected by chance alone (Higgins 2019). A rough guide to help interpretation of the $I^{2}$ statistic is as follows: $0 \%$ to $40 \%$ : might not be important; $30 \%$ to $60 \%$ : may represent moderate heterogeneity; $50 \%$ to $90 \%$ : may represent substantial heterogeneity; and $75 \%$ to $100 \%$ : considerable heterogeneity.

\section{Assessment of reporting biases}

No language restrictions were applied, to prevent language bias. In case of sufficient studies ( $\geq 10$ studies), we planned to assess publication bias with a funnel plot (Higgins 2019). If bias was present (demonstrated by an asymmetrical appearance of the funnel plot), the effect calculated by the meta-analysis would tend to overestimate the intervention effect.

\section{Data synthesis}

Data were analysed using Review Manager software (Review Manager 2020). We used final values, SDs, and number of participants to enable calculation of the SMD. The SDs were used to standardise the mean differences to a single scale and to compute study weights. It was assumed that between-study variation in SDs reflected only differences in measurement scales and not differences in the reliability of outcome measures or variability among study populations. As the alternative modes of exercise included in the current review consisted of several different types of exercise, we could not assume that intervention effects across studies were identical. Therefore, the DerSimonian and Laird random-effects model was used to analyse treatment effect, to account for between-study variance (DerSimonian 1986). The data of each study were summarised in forest plots and summary estimates with a $95 \% \mathrm{Cl}$ were calculated. A two-sided $\mathrm{P}$ (with a value $\leq 0.05$ ) was considered statistically significant.

\section{Subgroup analysis and investigation of heterogeneity}

Treatment effects were based on the outcomes after 12 weeks follow-up and at the end of training, in order to deal with heterogeneity in follow-up duration and because international guidelines recommend a programme duration of 12 weeks. Furthermore, we performed subgroup analyses of each type of alternative exercise mode and combinations of exercise modes, 
if more than one trial comparing the specific exercise mode or combinations of exercise to traditional walking was available.

\section{Sensitivity analysis}

We examined individual study effects by removing each study one at a time to check whether excluding a particular study significantly changed the results. In addition, we planned to perform sensitivity analyses on the methodological quality of the studies. Studies with apparent risk of bias were removed to examine whether excluding these studies significantly changed the results. Studies with more than one domain at high risk or more than three domains at unclear risk were considered to be at high risk of bias.

\section{Summary of findings and the assessment of certainty of the evidence}

We created a 'Summary of findings' table using GRADE-proGDT software (GRADEproGDT 2015) to present the main review findings for 'Alternative modes of exercise compared to walking exercise in people with intermittent claudication' (Summary of findings 1). We included the outcomes listed in Types of outcome measures. These were MWD, PFWD, HRQoL and functional impairment. The system developed by the Grades of Recommendation, Assessment, Development and Evaluation Working Group (GRADE working group) was used for grading the certainty of the evidence as high, moderate, low and very low, based on within-study risk of bias, directness of evidence, heterogeneity, precision of effects estimates, and risk of publication bias (Atkins 2004).

\section{RESULTS}

\section{Description of studies}

See: Characteristics of included studies; Characteristics of excluded studies; Characteristics of ongoing studies.

\section{Results of the search}

See Figure 1. 


\section{Figure 1. Study flow diagram}

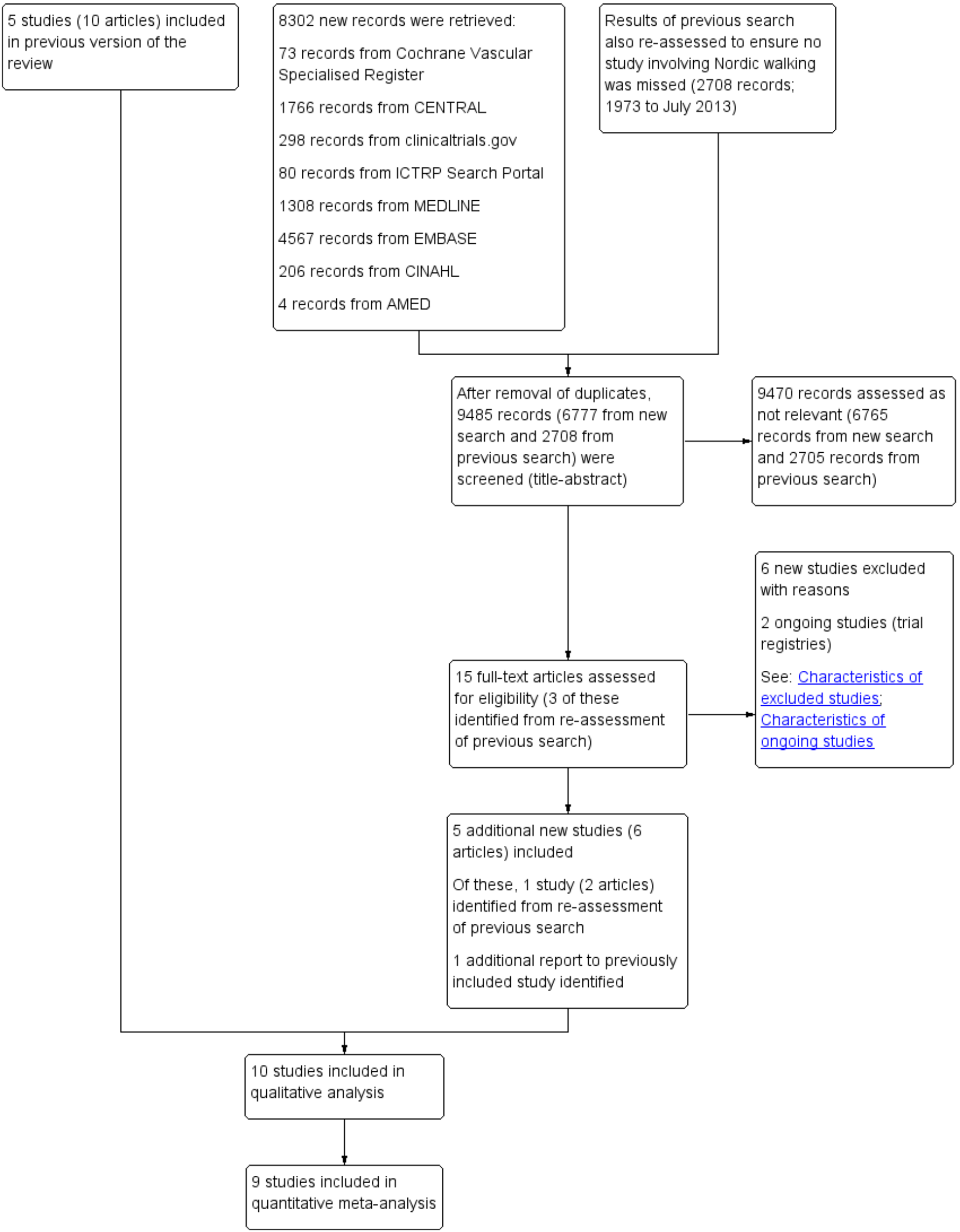

For this update, the updated electronic searches identified 6777

studies were included in the review (Bulinska 2016; Delaney 2015; new records (after removal of duplicates), of which four new Kropielnicka 2018; Szymczak 2016). We also re-evaluated the 2708 
records identified in the first review published in 2014, according to the updated inclusion criteria (inclusion of Nordic walking as an alternative mode of exercise). This resulted in the inclusion of one additional study (Collins 2012). Two new ongoing studies were identified (ACTRN12616000243415; NCT03837639); and six new studies were excluded (Delaney 2014; EXERT Study 2018; Kao 2012; Oakley 2008; Parmenter 2013; Van Schaardenburgh 2017).

\section{Included studies}

For this update, five additional studies were included (Bulinska 2016; Collins 2012; Delaney 2015; Kropielnicka 2018; Szymczak 2016), making a total of 10 included studies (Bulinska 2016; Collins 2012; Delaney 2015; Kropielnicka 2018; McDermott 2009; Regensteiner 1996; Ritta-Dias 2010; Sanderson 2006; Szymczak 2016; Treat-Jacobson 2009). A summary of included studies is provided in the Characteristics of included studies tables. In these 10 studies, a total of 527 participants with intermittent claudication (IC) were randomised, of which 488 participants were randomised to the treatment arms that were relevant to this review. One study was relatively small involving fewer than 30 participants (Regensteiner 1996), six studies included more than 30 but fewer than 70 participants (Delaney 2015; McDermott 2009; Ritta-Dias 2010; Sanderson 2006; Szymczak 2016; Treat-Jacobson 2009); and three studies included 70 or more participants (Bulinska 2016; Collins 2012; Kropielnicka 2018). The mean age of the participants in the included studies varied between 62.0 and 73.4 years. All studies included both men and women, with the percentages of female participants ranging from $7 \%$ to $54 \%$. The studies were conducted in Australia (2), Brazil (1), Poland (3) and the United States (4). Nine studies compared supervised walking exercise to a single alternative mode of exercise, which was lower-extremity resistance training in four studies (McDermott 2009; Regensteiner 1996; Ritta-Dias 2010; Szymczak 2016), Nordic walking in three studies (Bulinska 2016; Collins 2012; Kropielnicka 2018), cycling (Sanderson 2006) and arm ergometry (Treat-Jacobson 2009). Four studies compared walking exercise to combination treatment, consisting of walking and lower-extremity resistance training (Delaney 2015; Regensteiner 1996), walking and arm ergometry (Treat-Jacobson 2009) and Nordic walking and lower extremity resistance training (Kropielnicka 2018).

Enrolment criteria were relatively homogeneous. In all studies, participants were included if a decrease in ankle brachial index (ABI) was present together with limiting or disabling symptoms of IC. Two studies (Collins 2012; McDermott 2009) assessed claudication symptoms by a questionnaire (Edinburgh Claudication Questionnaire and San Diego Claudication Questionnaire, respectively). McDermott 2009 included both symptomatic and asymptomatic patients with PAD, however only the data of participants with IC were included in this review. Delaney 2015 only included participants with radiographic evidence of infra-inguinal disease in the absence of aorta-iliac disease. In all studies, the presence of critical limb ischaemia was an exclusion criterion. Participants were also excluded if the exercise capacity was limited by another factor than IC (e.g. angina, chronic obstructive pulmonary disease, arthrosis) or if they were unable to perform the exercise programme (e.g. unable to walk on a treadmill or with Nordic poles). Szymczak 2016 excluded patients with diabetes and Kropielnicka 2018 excluded participants with "generally poor health". In four studies, claudication symptoms needed to be stable for three months (Kropielnicka 2018; Regensteiner 1996), six months (Ritta-Dias 2010), or more than 12 months (Sanderson 2006). Four studies excluded participants if a revascularisation procedure was performed in the previous year (Delaney 2015; Regensteiner 1996; Ritta-Dias 2010; Szymczak 2016). Szymczak 2016 excluded participants that suffered from stroke in the prior six months or had cardiac surgery in the prior 12 months. Three studies excluded participants if a coronary or lower-extremity revascularisation procedure was performed within the prior three months (Bulinska 2016; Kropielnicka 2018; Treat-Jacobson 2009). Two studies excluded participants in case of a cardiovascular event in the prior three months (Bulinska 2016); or 12 months (Kropielnicka 2018). One study excluded patients that participated in another exercise programme in the prior three weeks (Collins 2012). The two remaining studies excluded participants if they recently underwent surgery or a cardiovascular event (McDermott 2009; Sanderson 2006). Treatment duration varied between studies ranging from six weeks training (Sanderson 2006), to 12week training (Bulinska 2016; Delaney 2015; Kropielnicka 2018; Regensteiner 1996; Ritta-Dias 2010; Szymczak 2016; Treat-Jacobson 2009) and 24-week training (Collins 2012; McDermott 2009).

\section{Excluded studies}

For this update, six additional studies (six publications) were excluded based on full-text assessment (Delaney 2014; EXERT Study 2018; Kao 2012; Oakley 2008; Parmenter 2013; Van Schaardenburgh 2017).

Overall, 23 studies were excluded based on full-text assessment. A summary of excluded studies is available in the Characteristics of excluded studies table. Three studies were excluded because they were not randomised (or quasi-randomised) controlled trials (Gardner 2011; Kim 2006; Roitman 2010). Five studies were excluded because they were meeting posters with a limited description of the methods and results and no related articles were published or available after contact with the authors (Dedes 2010; Kao 2012; Kuwabara 2010; Ornelas 2011; Treat-Jacobson 2012). Twelve studies were excluded because they did not assess adequately supervised exercise therapy, according to the inclusion criteria of this review (Nawaz 2001; Oakley 2008; Parmenter 2013; Parr 2009; Saxton 2008; Saxton 2011; Van Schaardenburgh 2017; Tebbutt 2011; Treat-Jacobson 2012; Walker 2000; Wang 2008; Zwierska 2005). Six studies did not report the primary and secondary outcome measures of this review (Delaney 2014; Nawaz 2001; Saxton 2008; Saxton 2011; Treat-Jacobson 2011; Walker 2000). One study was excluded because the outcome measures were not clearly described and we did not receive additional information upon request (Jones 1996). The previous version of this review identified the EXERT study as an ongoing study (EXERT Study 2018). Although this study was completed, the original results have not been published. Only one publication was available comparing long-term follow-up (one to four years) to end of study results (24 weeks). Baseline data were not available from the authors, so we have now excluded this study.

\section{Ongoing studies}

Two ongoing studies were identified (ACTRN12616000243415; NCT03837639), for which a summary of study protocols is available in the Characteristics of ongoing studies table. One study (ACTRN12616000243415) has been completed, but the results have not yet been published or available from the authors (status: preparing the manuscript for submission to a peer-reviewed journal). 


\section{Risk of bias in included studies}

See Figure 2 and Figure 3.

Figure 2. Risk of bias graph: review authors' judgements about each risk of bias item presented as percentages across all included studies.

Random sequence generation (selection bias)

Allocation concealment (selection bias)

Blinding of participants and personnel (performance bias): All outcomes

Blinding of outcome assessment (detection bias): All outcomes Incomplete outcome data (attrition bias): All outcomes

Selective reporting (reporting bias)

Other bias
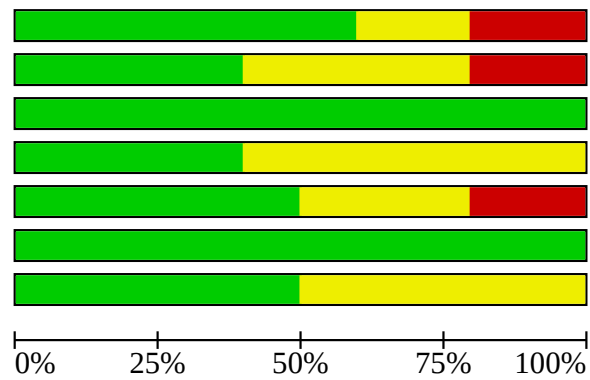
Figure 3. 'Risk of bias' summary: review authors' judgements about each 'Risk of bias' item for each included study

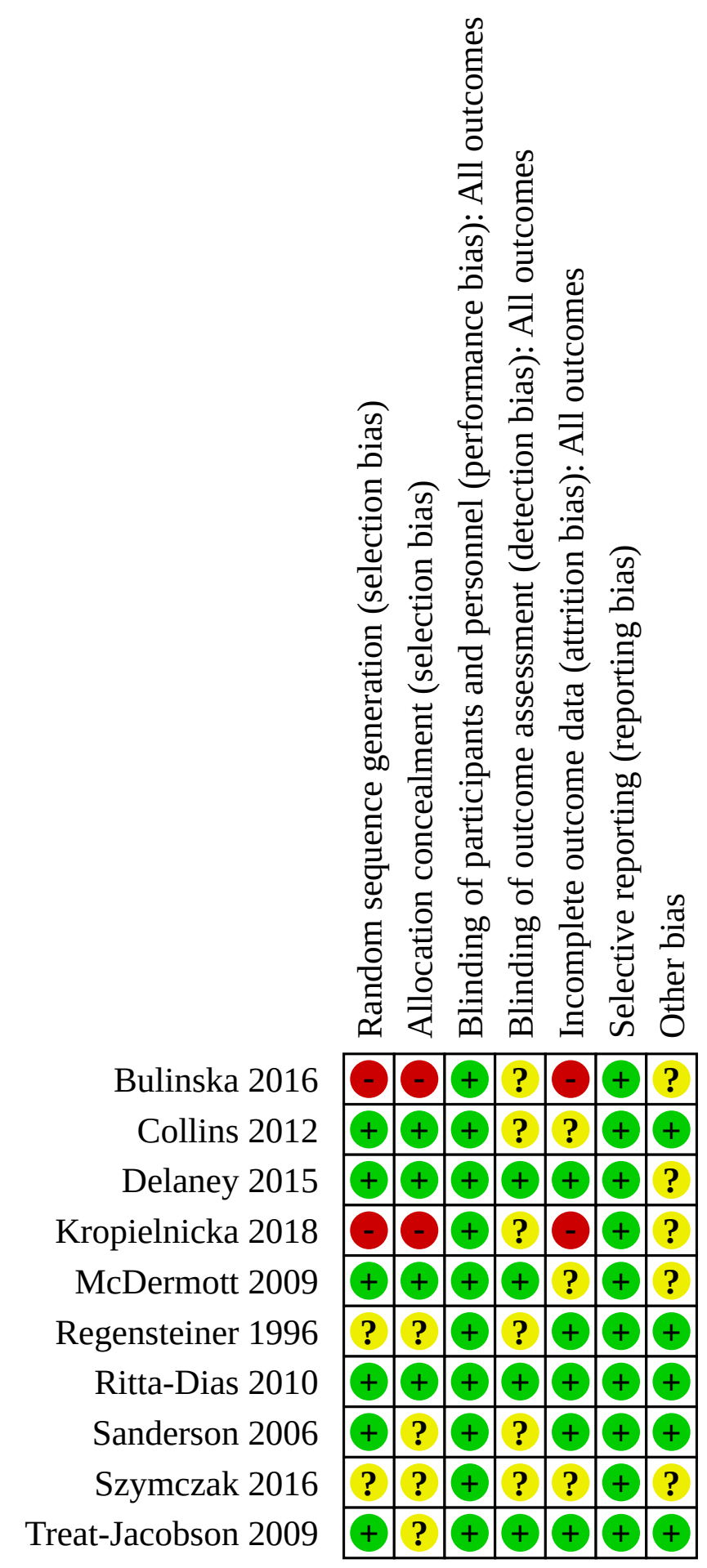




\section{Allocation}

Four studies described adequate sequence generation and allocation concealment by means of computer randomisation and so were at low risk of selection bias (Collins 2012; Delaney 2015; McDermott 2009; Ritta-Dias 2010). Two studies were judged to be at low risk for randomisation sequence bias but at unclear risk for allocation concealment as they described an adequate sequence generation, but did not describe the allocation concealment (Sanderson 2006; Treat-Jacobson 2009). Two studies were judged to have high risk of bias because they used a pseudorandomisation method in which participants were allocated by the investigators using a fixed block size (Bulinska 2016; Kropielnicka 2018). The two remaining studies did not describe the randomisation process and so were at an unclear risk of selection bias (Regensteiner 1996; Szymczak 2016).

\section{Blinding}

In all of the included studies, participants and personnel could not be blinded to the intervention (exercise). For this reason, bias could be introduced. However, since all studies experienced the same limitation, we considered the risk of bias to be low on this domain for all studies. Detection bias can be avoided by blinding the outcome assessors, which was achieved by four studies who were judged to be at low risk of bias (Delaney 2015; McDermott 2009; Ritta-Dias 2010; Treat-Jacobson 2009). The remaining studies did not provide information on blinding of outcome assessors and so were at unclear risk of detection bias (Bulinska 2016; Collins 2012; Kropielnicka 2018; Regensteiner 1996; Sanderson 2006; Szymczak 2016).

\section{Incomplete outcome data}

Five studies provided well-described reasons for missing data, which we considered to be plausible and well distributed among the groups and were at low risk of attrition bias (Delaney 2015; Regensteiner 1996; Ritta-Dias 2010; Sanderson 2006; TreatJacobson 2009). McDermott 2009 included both symptomatic and asymptomatic participants with PAD. We received the data for participants with IC upon request. Although the article described the missing data, it was unclear to what extent they were related to the group of symptomatic participants. Therefore, we considered the risk of attrition bias to be unclear. Two studies were judged to have high risk of attrition bias because missing data were not balanced across groups and no intention-to-treat analysis was performed (Bulinska 2016; Kropielnicka 2018). Bulinska 2016 did not provide reasons for drop-outs, while in the other study the majority of reasons was directly related to one of the interventions (Kropielnicka 2018). In Collins 2012, the risk of attrition bias was considered to be unclear, as the number of drop-outs was high and not evenly distributed among groups (18 versus 13). Szymczak 2016 did not provide information on incomplete outcome data, and so was also considered to be at an unclear risk of bias.

\section{Selective reporting}

We judged all studies to have low risk of reporting bias because published reports included all expected outcomes or because we obtained missing outcomes by contacting the authors (Bulinska 2016; Collins 2012; Delaney 2015; Kropielnicka 2018; McDermott 2009; Regensteiner 1996; Ritta-Dias 2010; Sanderson 2006; Szymczak 2016; Treat-Jacobson 2009).

\section{Other potential sources of bias}

Since we included only nine studies in the quantitative analysis, we could not detect publication bias by using a funnel plot. We considered five studies to potentially have other sources of bias and so were judged as 'unclear' (Bulinska 2016; Delaney 2015; Kropielnicka 2018; McDermott 2009; Szymczak 2016). Bulinska 2016 reported significant differences in relevant baseline characteristics (hypertension and degenerative changes of spine and peripheral joints) which might have affected outcomes. Delaney 2015 excluded patients with radiographic aortic-iliac disease, but there is no scientific evidence that confirms a difference in treatment effects of exercise related to the level of disease. Therefore, this was also considered as a potential source of bias. McDermott 2009 included both asymptomatic and symptomatic participants with PAD. Although we only included data of symptomatic participants in this review, the article provided baseline characteristics for the total study population (including asymptomatic participants), which introduces a potential source of bias. In two other studies, baseline characteristics were either not clearly presented (Szymczak 2016) or very limited (Kropielnicka 2018). We identified no other potential sources of bias in the included studies.

\section{Effects of interventions}

See: Summary of findings 1 Alternative modes of exercise compared to walking exercise for people with intermittent claudication

\section{Alternative modes of exercise training compared to traditional walking exercise after 12 weeks of training}

\section{Maximum walking distance (MWD)}

Six studies reported the MWD after 12 weeks of training (Bulinska 2016; Kropielnicka 2018; Regensteiner 1996; Ritta-Dias 2010; Szymczak 2016; Treat-Jacobson 2009), with a total sample size of 274 participants. Overall, there was no clear difference detected between alternative modes of exercise compared to traditional walking (standardised mean difference (SMD) $-0.01,95 \% \mathrm{Cl}-0.29$ to $0.27 ; P=0.95$; low-certainty evidence; see Analysis 1.1). Heterogeneity was considered low $\left(P=0.28, I^{2}=18 \%\right)$. See Summary of findings 1 . Sensitivity analysis was carried out by removing studies with high risk of bias, as defined in the Sensitivity analysis section (Bulinska 2016; Kropielnicka 2018; Szymczak 2016), and this had no effect on the SMD.

We investigated different modes of exercise by subgroup analysis (see Analysis 1.1). These are summarised below. No differences were detected by the test for subgroup differences $(P=0.16)$.

\section{Lower extremity resistance training versus walking exercise}

Three studies reported the MWD after 12 weeks of training (Regensteiner 1996; Ritta-Dias 2010; Szymczak 2016), with a sample size of 94 participants. No difference was detected between the resistance and walking exercise groups (SMD $-0.02,95 \% \mathrm{Cl}-0.59$ to $0.55 ; \mathrm{P}=0.94 ;$ Analysis 1.1$)$. Heterogeneity was considered low $\left(\mathrm{I}^{2}=\right.$ $40 \% ; P=0.19)$ and sensitivity analysis had no significant effect on the SMD.

\section{Nordic walking versus walking exercise}

Two studies compared Nordic walking with walking and reported MWD after 12 weeks of training, with a sample size of 88 participants (Bulinska 2016; Kropielnicka 2018). The SMD of 0.31 represented 
little or no difference $(95 \% \mathrm{Cl}-0.12$ to $0.74 ; \mathrm{P}=0.15$; Analysis 1.1$)$. Heterogeneity was low $\left(\mathrm{I}^{2}=0 \%\right)$.

\section{Combination of exercise modes versus walking exercise}

Three studies with a sample size of 74 participants compared a combination of exercise modes with walking and reported MWD after 12 weeks of training (Kropielnicka 2018; Regensteiner 1996; Treat-Jacobson 2009). We found no clear difference for MWD (SMD $-0.19,95 \% \mathrm{Cl}-0.66$ to $0.29 ; \mathrm{P}=0.44$; Analysis 1.1 ). Heterogeneity was low $\left(I^{2}=0 \%\right)$.

\section{Arm ergometry versus walking exercise}

Only one small study investigated arm ergometry compared to walking exercise and no clear differences were detected in MWD between the groups (SMD $-0.84,95 \% \mathrm{Cl}-1.87$ to $0.19 ; 18$ participants; Analysis 1.1) (Treat-Jacobson 2009).

\section{Pain-free walking distance (PFWD)}

Five studies reported the PFWD after 12 weeks of training (Bulinska 2016; Kropielnicka 2018; Ritta-Dias 2010; Szymczak 2016; TreatJacobson 2009), with a sample size of 249 participants. Pooling did not detect a difference in PFWD between alternative modes and walking exercise (SMD $-0.01,95 \% \mathrm{Cl}-0.26$ to $0.25 ; \mathrm{P}=0.97$; lowcertainty evidence; see Analysis 1.2$)$. Heterogeneity was low $\left(I^{2}=\right.$ $0 \%)$. We carried out sensitivity analysis by removing studies with a high risk of bias, as defined in the Sensitivity analysis section (Bulinska 2016; Kropielnicka 2018; Szymczak 2016), and this had no effect on the SMD.

We investigated different modes of exercise by subgroup analysis (see Analysis 1.2). These are summarised below. No differences were detected by the test for subgroup differences $(P=0.39)$.

\section{Lower extremity resistance training versus walking exercise}

Two studies reported the PFWD after 12 weeks of training, with a sample size of 80 participants (Ritta-Dias 2010; Szymczak 2016). There was no clear difference between groups for the pooled PFWD (SMD 0.11, 95\% Cl-0.32 to $0.55 ; \mathrm{P}=0.61 ;$ Analysis 1.2 ). Heterogeneity was low $\left(I^{2}=0 \%\right)$.

\section{Walking versus Nordic walking versus walking exercise}

Two studies reported PFWD after 12 weeks of training, with a sample size of 88 participants (Bulinska 2016; Kropielnicka 2018). No clear difference was detected between groups (SMD 0.14, 95\% $\mathrm{Cl}-0.28$ to $0.57 ; \mathrm{P}=0.51 ;$ Analysis 1.2 ). Studies were considered homogeneous $\left(I^{2}=0 \%\right)$.

\section{Combination of exercise modes versus walking exercise}

Two studies reported PFWD after 12 weeks of training, with a sample size of 63 participants (Kropielnicka 2018; Treat-Jacobson 2009). Little to no difference was found between groups (SMD -0.22, $95 \% \mathrm{Cl}-0.74$ to $0.30 ; \mathrm{P}=0.40$; Analysis 1.2 ). Included studies were considered homogeneous $\left(I^{2}=0 \%\right)$.

\section{Arm ergometry versus walking exercise}

Only one small study investigated arm ergometry compared to walking exercise and no clear differences were detected in PFWD between the groups (SMD $-0.65,95 \% \mathrm{Cl}-1.66$ to $0.36 ; 18$ participants; Analysis 1.2) (Treat-Jacobson 2009).

\section{Alternative modes of exercise training compared to traditional walking exercise at end of training}

\section{Maximum walking distance (MWD)}

Nine studies reported the MWD at the end of training with a total sample size of 412 participants (Bulinska 2016; Collins 2012; Kropielnicka 2018; McDermott 2009; Regensteiner 1996; Ritta-Dias 2010; Sanderson 2006; Szymczak 2016; Treat-Jacobson 2009). The duration of exercise programmes varied from 6 to 24 weeks. Pooling detected no clear difference between groups (SMD $-0.11,95 \% \mathrm{Cl}$ -0.33 to $0.11 ; \mathrm{P}=0.32$; low-certainty evidence, see Analysis 2.1). The impact of heterogeneity was considered to be low $\left(P=0.30 ; I^{2}=\right.$ $15 \%)$. Sensitivity analysis was carried out by removing studies at risk of bias (Bulinska 2016; Kropielnicka 2018; Szymczak 2016), and resulted in a small to moderate effect on MWD in favour of walking exercise, with a SMD of $-0.36\left(95 \% \mathrm{Cl}-0.63\right.$ to $-0.10 ; \mathrm{P}=0.008 ; \mathrm{I}^{2}=$ 0\%) (Figure 4). 
Figure 4. Alternative modes of exercise training compared to traditional walking exercise at end of training: maximum walking distance (MWD). Sensitivity analysis: excluding studies at risk of bias (Bulinska 2016; Kropielnicka 2018; Szymczak 2016)

\begin{tabular}{|c|c|c|c|c|c|c|c|c|c|c|c|}
\hline \multirow[b]{2}{*}{ Study or Subgroup } & \multicolumn{3}{|c|}{ Alternative exercise mode } & \multicolumn{3}{|c|}{ Walking exercise } & \multicolumn{3}{|c|}{ Std. Mean Difference } & \multirow{2}{*}{$\begin{array}{l}\text { Std. Mean Difference } \\
\text { IV, Random, } 95 \% \mathrm{Cl}\end{array}$} & Risk of Bias \\
\hline & Mean & SD & Total & Mean & SD & Total & Weight & IV, Random, $95 \% \mathrm{Cl}$ & & & A B C DEFG \\
\hline \multicolumn{12}{|c|}{ 2.1.1 Lower extremity resistance training } \\
\hline McDermott 2009 & 9.45 & 3.66 & 16 & 10.62 & 4.85 & 17 & $15.0 \%$ & $-0.26[-0.95,0.42]$ & & 千 & \multirow{5}{*}{ 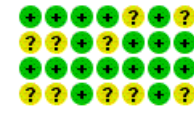 } \\
\hline Regensteiner 1996 & 8.5 & 5.2 & 9 & 14.7 & 7.3 & 5 & $5.1 \%$ & $-0.97[-2.14,0.20]$ & & & \\
\hline Ritta-Dias 2010 & 775 & 334 & 15 & 721 & 289 & 15 & $13.7 \%$ & $0.17[-0.55,0.89]$ & & & \\
\hline Szymczak 2016 & 402.7 & 501.6 & 26 & 318.3 & 230.8 & 24 & $0.0 \%$ & $0.21[-0.35,0.77]$ & & & \\
\hline Subtotal $(95 \% \mathrm{Cl})$ & & & 40 & & & 37 & $33.9 \%$ & $-0.22[-0.77,0.32]$ & & & \\
\hline \multicolumn{12}{|c|}{$\begin{array}{l}\text { Heterogeneity: } \text { Tau }^{2}=0.06 ; \mathrm{Chi}^{2}=2.70, \mathrm{df}=2(\mathrm{P}=0.26) ; \mathrm{I}^{2}=26 \% \\
\text { Test for overall effect: } Z=0.80(\mathrm{P}=0.42)\end{array}$} \\
\hline \multicolumn{12}{|l|}{ 2.1.2 Nordic walking } \\
\hline Bulinska 2016 & 363.67 & 225.19 & 21 & 290.232 & 222.28 & 31 & $0.0 \%$ & $0.32[-0.23,0.88]$ & & & \multirow{4}{*}{ 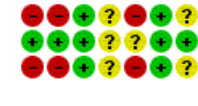 } \\
\hline Collins 2012 & 15.02 & 12.32 & 34 & 21.1 & 17.07 & 43 & $34.2 \%$ & $-0.40[-0.85,0.06]$ & & & \\
\hline Kropielnicka 2018 & 372.7 & 231.64 & 21 & 303.092 & 228.71 & 15 & $0.0 \%$ & $0.30[-0.37,0.96]$ & & & \\
\hline Subtotal $(95 \% \mathrm{Cl})$ & & & 34 & & & 43 & $34.2 \%$ & $-0.40[-0.85,0.06]$ & & & \\
\hline \multirow{2}{*}{\multicolumn{12}{|c|}{$\begin{array}{l}\text { Heterogeneity: Not applicable } \\
\text { Test for overall effect: } Z=1.71(P=0.09)\end{array}$}} \\
\hline & & & & & & & & & & & \\
\hline \multicolumn{12}{|c|}{ 2.1.3 Combined exercise modes } \\
\hline Kropielnicka 2018 & 309.7 & 223.09 & 28 & 303.092 & 228.71 & 16 & $0.0 \%$ & $0.03[-0.59,0.64]$ & & & \multirow{4}{*}{ 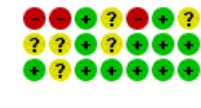 } \\
\hline Regensteiner 1996 & 11.8 & 6 & 6 & 14.7 & 7.3 & 5 & $4.9 \%$ & $-0.40[-1.61,0.80]$ & & & \\
\hline Treat-Jacobson 2009 & 658.5 & 160.6 & 12 & 778 & 252.6 & 7 & $7.8 \%$ & $-0.58[-1.53,0.38]$ & & & \\
\hline Subtotal $(95 \% \mathrm{Cl})$ & & & 18 & & & 12 & $12.6 \%$ & $-0.51[-1.26,0.24]$ & & & \\
\hline \multicolumn{12}{|c|}{$\begin{array}{l}\text { Heterogeneity: } \text { Tau }^{2}=0.00 ; C h i^{2}=0.05, d f=1(P=0.82) ; I^{2}=0 \% \\
\text { Test for overall effect: } Z=1.33(P=0.18)\end{array}$} \\
\hline \multicolumn{12}{|l|}{ 2.1.4 Arm ergometry } \\
\hline $\begin{array}{l}\text { Treat-Jacobson } 2009 \\
\text { Subtotal }(95 \% \mathrm{Cl})\end{array}$ & 603.7 & 166.6 & $\begin{array}{l}12 \\
12\end{array}$ & 778 & 252.6 & $\begin{array}{l}6 \\
6\end{array}$ & $\begin{array}{l}6.7 \% \\
6.7 \%\end{array}$ & $\begin{array}{l}-0.84[-1.87,0.19] \\
-0.84[-1.87,0.19]\end{array}$ & & & $\odot ? \odot \odot \odot \odot ૯$ \\
\hline \multirow{2}{*}{\multicolumn{12}{|c|}{$\begin{array}{l}\text { Heterogeneity: Not applicable } \\
\text { Test for overall effect: } Z=1.60(P=0.11)\end{array}$}} \\
\hline & & & & & & & & & & & \\
\hline \multicolumn{12}{|l|}{ 2.1.5 Cycling } \\
\hline $\begin{array}{l}\text { Sanderson } 2006 \\
\text { Subtotal }(\mathbf{9 5 \%} \mathrm{Cl})\end{array}$ & 1,089 & 578 & $\begin{array}{l}15 \\
15\end{array}$ & 1,254 & 414 & $\begin{array}{l}13 \\
13\end{array}$ & $\begin{array}{l}12.6 \% \\
12.6 \%\end{array}$ & $\begin{array}{l}-0.31[-1.06,0.43] \\
-0.31[-1.06,0.43]\end{array}$ & & & \multirow[t]{3}{*}{$๑ ? \odot ? \odot \odot \odot$} \\
\hline \multirow{2}{*}{\multicolumn{11}{|c|}{$\begin{array}{l}\text { Heterogeneity: Not applicable } \\
\text { Test for overall effect: } Z=0.82(P=0.41)\end{array}$}} & \\
\hline & & & & & & & & & & & \\
\hline Total $(95 \% \mathrm{Cl})$ & & & 119 & & & 111 & $100.0 \%$ & $-0.36[-0.63,-0.10]$ & & 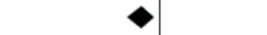 & \\
\hline \multirow{3}{*}{\multicolumn{9}{|c|}{$\begin{array}{l}\text { Heterogeneity: } \text { Tau }^{2}=0.00 ; \mathrm{Ch}^{2}=4.28, \mathrm{df}=7(\mathrm{P}=0.75) ; \mathrm{I}^{2}=0 \% \\
\text { Test for overall effect: } \mathrm{Z}=2.67(P=0.008) \\
\text { Test for subgroup differences: } \mathrm{Chi}^{2}=1.23, \mathrm{df}=4(\mathrm{P}=0.87), \mathrm{I}^{2}=0 \%\end{array}$}} & -4 & $\begin{array}{ccc}1 & 1 & 1 \\
-2 & 0 & 2\end{array}$ & + \\
\hline & & & & & & & & & -4 & Favours walking Favours alt & odes \\
\hline & & & & & & & & & & & \\
\hline Risk of bias legend & & & & & & & & & & & \\
\hline (A) Random sequence & eneration (s & election & & & & & & & & & \\
\hline (B) Allocation concealn & nt (selectio & bias) & & & & & & & & & \\
\hline (C) Blinding of particip & is and pers & nnel (per & nance $b$ & ias) & & & & & & & \\
\hline (D) Blinding of outcom & issessmen & (detectio & & & & & & & & & \\
\hline (E) Incomplete outcom & data (attritio & bias) & & & & & & & & & \\
\hline (F) Selective reporting & porting bias & & & & & & & & & & \\
\hline (G) Other bias & & & & & & & & & & & \\
\hline
\end{tabular}

We investigated different modes of exercise by subgroup analysis (see Analysis 2.1). These are summarised below. No clear differences were detected by the test for subgroup differences $(P=$ 0.62).

\section{Lower extremity resistance training versus walking exercise}

Four studies reported the MWD at the end of training with a sample size of 127 participants (McDermott 2009; Regensteiner 1996; Ritta-Dias 2010; Szymczak 2016). The duration of exercise programmes varied from 12 to 24 weeks. There was no clear difference in MWD (SMD - $0.06,95 \% \mathrm{Cl}-0.48$ to $0.35 ; \mathrm{P}=0.77$; Analysis 2.1). Heterogeneity was considered low $\left(P=0.27 ; I^{2}=24 \%\right)$ and sensitivity analysis had no significant effect on the SMD.

\section{Nordic walking versus walking exercise}

Three studies reported MWD at the end of training, with a sample size of 165 participants and programme duration varying from 12 to 24 weeks (Bulinska 2016; Collins 2012; Kropielnicka 2018). No clear difference was found (SMD $0.04,95 \% \mathrm{Cl}-0.47$ to $0.54 ; \mathrm{P}=$ 0.88 ; Analysis 2.1). The moderate heterogeneity $\left(P=0.08, I^{2}=60 \%\right)$ seemed largely due to one study (Collins 2012). Sensitivity analysis to exclude this trial did result in statistical homogeneity, but did not significantly alter the SMD.

\section{Combination of exercise modes versus walking exercise}

Three studies compared combination of exercise modes with walking exercise (Kropielnicka 2018; Regensteiner 1996; TreatJacobson 2009). As all three studies had a training duration of 12 weeks, results are reported above (Analysis 1.1).

\section{Arm ergometry versus walking exercise}

Only Treat-Jacobson 2009 compared arm ergometry with walking exercise. As the training duration was 12 weeks, results are reported above (Analysis 1.1).

\section{Cycling versus walking exercise}

Only one small study with 28 participants compared cycling to walking exercise and no differences were detected in MWD between the groups (SMD $-0.31,95 \% \mathrm{Cl}-1.06$ to $0.43 ; \mathrm{P}=0.41$; Analysis 2.1 ) (Sanderson 2006). 


\section{Pain-free walking distance (SMDs)}

Eight studies reported the PFWD at the end of training with a sample size of 382 participants (Bulinska 2016; Collins 2012; Kropielnicka 2018; McDermott 2009; Ritta-Dias 2010; Sanderson 2006; Szymczak 2016; Treat-Jacobson 2009). The duration of exercise programmes varied from 6 to 24 weeks. There was no clear difference between groups with a small SMD of $-0.06(95 \% \mathrm{Cl}$ -0.30 to $0.17 ; P=0.59$; low-certainty evidence, see Analysis 2.2). The heterogeneity of included studies was considered low $\left(P=0.24, I^{2}\right.$ $=22 \%$ ). Sensitivity analysis by removing studies with a risk of bias did not alter the SMD (Bulinska 2016; Kropielnicka 2018; Szymczak 2016).

We investigated different modes of exercise by subgroup analysis (see Analysis 2.2). These are summarised below. The test for subgroup differences detected a difference $\left(P=0.04, \mathrm{I}^{2}=60.4 \%\right)$, which seemed to be caused by the cycling subgroup that included only one study (Sanderson 2006). After removing this study, no subgroup differences were detected $\left(P=0.27, I^{2}=23.5 \%\right)$.

\section{Lower extremity resistance training versus walking exercise}

Three studies reported PFWD at the end of training, with a sample size of 108 participants (McDermott 2009; Ritta-Dias 2010; Szymczak 2016). The duration of exercise programmes varied from 12 to 24 weeks. There was no clear difference between groups (SMD $0.01 ; 95 \% \mathrm{Cl}-0.37$ to $0.38 ; \mathrm{P}=0.98$; Analysis 2.2). The included studies were considered homogeneous $\left(\mathrm{I}^{2}=0 \%\right)$ and sensitivity analyses had no important effect on the SMD.

\section{Nordic walking versus walking exercise}

Three studies reported PFWD at the end of training, with a sample size of 165 participants and programme duration varying from 12 to 24 weeks (Bulinska 2016; Collins 2012; Kropielnicka 2018). The SMD of 0.21 represented little to no difference between groups $(95 \% \mathrm{Cl}$ -0.10 to $0.52 ; \mathrm{P}=0.19)$. Studies were considered homogeneous $\left(\mathrm{I}^{2}\right.$ $=0 \%)$.

\section{Combination of exercise modes versus walking exercise}

Two studies compared combination of exercise modes with walking exercise (Kropielnicka 2018; Treat-Jacobson 2009). As these had a training duration of 12 weeks, results are reported above (Analysis 1.2).

\section{Arm ergometry versus walking exercise}

Only Treat-Jacobson 2009 compared arm ergometry with walking exercise. As the training duration was 12 weeks, results are reported above (Analysis 1.2).

\section{Cycling versus walking exercise}

Only one small study with 28 participants investigated cycling compared to walking exercise and a possible benefit from walking exercise may be seen in PFWD between the groups (SMD -1.01, 95\% $\mathrm{Cl}-1.81$ to $-0.22 ; \mathrm{P}=0.01$; Analysis 2.2) (Sanderson 2006).

\section{Health-related quality of life (HR-QOL)}

Four studies described HR-QoL (Collins 2012; Delaney 2015; McDermott 2009; Regensteiner 1996). Two studies reported the physical functioning score of the SF-36 (Collins 2012; McDermott 2009). Because of the skewed data of one of the studies (McDermott 2009), with relatively small sample size, we did not perform a meta-analysis. Both studies found an improvement in both exercise groups. In McDermott 2009, the physical functioning score improved to a median score of 50.0 (interquartile range 40.0 to 60.0 ) after 24 weeks of treadmill walking $(n=17)$ and to a median score of 60.0 (interquartile range 35.0 to 70.0 ) after strength training ( $n=$ $14, P=0.811$ ). In Collins 2012, the mean score was 60.42 (SD 21.75) after 24 weeks of treadmill walking $(n=43)$ and 55.51 (SD 21.27) after Nordic walking $(n=34, P=0.22)$.

Regensteiner 1996, with a sample size of 25 participants, used the Medical Outcomes Study (MOS) SF-20, which consists of five domain scores: physical functioning score, social functioning score, role functioning score, overall health score, and well-being score. After 12 weeks of training, the physical functioning scores improved by $24 \%$ for the walking group ( $95 \% \mathrm{Cl} 9$ to 39), and the well-being scores increased by $9 \%(95 \% \mathrm{Cl} 2$ to 16$)$ for the lower-extremity resistance training group. No improvement in the other MOS domains was detected. In the combined group, no improvement in MOS scores was seen.

Delaney 2015 used the Australian Vascular Quality of Life Index, in which a lower score represents higher quality of life. It found an improved HR-QoL in both the treadmill walking group $(n=15)$ and the combination exercise group $(n=12)$, with a mean decrease of 1.6 points (SD 2.4) and 3.3 points (SD 3.9), respectively $(P=0.18)$.

\section{Self-reported functional impairment}

Three studies used the WIQ to measure functional impairment (Collins 2012; McDermott 2009; Regensteiner 1996). All three studies reported the WIQ distance score and two studies also reported the speed and stair-climbing scores (McDermott 2009; Regensteiner 1996). One study had relatively small sample size and a non-normal distribution of outcomes (McDermott 2009). Therefore, it was considered inappropriate to transform these skewed data to enable pooling. Meta-analysis of the two remaining studies, with a sample size of 96 participants, showed little or no difference between the study arms, with a mean difference of -5.52 (95\% $\mathrm{Cl}-17.41$ to $6.36, \mathrm{P}=0.36$; low-certainty evidence; see Analysis 2.3). The included studies were considered homogeneous $\left(I^{2}=0 \%\right)$.

In McDermott 2009, the WIQ distance score improved in both the strength $(n=15)$ and treadmill walking group $(n=15)$, with a median of, respectively, 14.0 points (interquartile range $=1.56$ to 26.6 ) and 7.46 points (interquartile range $=-0.36$ to $25.0 ; \mathrm{P}=$ $0.431)$. WIQ speed score improved in both the strength $(n=15)$ and treadmill walking group $(n=16)$, with a median of, respectively, 3.26 points (interquartile range $=-7.61$ to 26.1 ) and 1.63 points (interquartile range $=-3.80$ to $28.8 ; \mathrm{P}=0.736$ ). WIQ stair-climbing score improved in the strength training group $(n=15)$, with a median of, respectively, 12.5 points (interquartile range $=4.17$ to 25.0), while no improvement was seen in the median score in the treadmill walking group $(n=16$, median score of 0.00 points, interquartile range $=0.00$ to $14.6 ; \mathrm{P}=0.136$ ). Finally, the remaining study (Regensteiner 1996), showed little or no difference in the WIQ speed score with an effect size of $-4.50 \%(95 \% \mathrm{Cl}-27.34$ to 18.34 ; $\mathrm{P}=0.70)$ and a decreased WIQ stair-climbing score with an effect size of $-29.50 \%(95 \% \mathrm{Cl}-51.65$ to $-7.35, \mathrm{P}=0.009)$, both in favour of alternative exercise. 


\section{DISCUSSION}

\section{Summary of main results}

See Summary of findings 1.

In this update, five additional studies were included, making a total of 10 studies that randomised a total of 527 participants. The alternative modes of exercise therapy included cycling, lower-extremity resistance training, upper-arm ergometry, Nordic walking, and combinations of exercise modes. Besides randomised controlled trials, two quasi-randomised trials were included. Our assessment of the overall risk of bias of included studies varied from high to low risk of bias. Using the GRADE criteria, the certainty of evidence was judged to be low due to the relatively small sample sizes, clinical inconsistency, and inclusion of three studies with risk of bias concerns.

Overall, no clear differences were detected between alternative exercise modes and walking exercise for mean walking distance (MWD) at 12 weeks (standardised mean difference (SMD) - $0.01,95 \%$ $\mathrm{Cl}-0.29$ to $0.27 ; \mathrm{P}=0.95 ; 6$ studies; 274 participants; low-certainty evidence); or at the end of training (SMD $-0.11,95 \% \mathrm{Cl}-0.33$ to $0.11 ; \mathrm{P}=0.32$; 9 studies; 412 participants; low-certainty evidence). Similarily, no clear differences were detected for PFWD at 12 weeks (SMD $-0.01,95 \% \mathrm{Cl}-0.26$ to $0.25 ; \mathrm{P}=0.97 ; 5$ studies; 249 participants; low-certainty evidence) or at the end of training (SMD -0.06, 95\% $\mathrm{Cl}-0.30$ to $0.17 ; \mathrm{P}=0.59 ; 8$ studies, 382 participants; low-certainty evidence).

Four studies reported on HR-QoL and three studies reported on functional impairment. However, meta-analysis was only possible for the WIQ distance score, which demonstrated little or no important difference between study groups (MD $-5.52,95 \% \mathrm{Cl}$ -17.41 to $6.36 ; \mathrm{P}=0.36 ; 2$ studies; 96 participants; low-certainty evidence).

We carried out subgroup analyses by type of alternative exercise mode (cycling, lower-extremity resistance training, upper-arm ergometry, Nordic walking, and combinations of exercise modes) for the main outcomes of MWD and PFWD at 12 weeks and end of training. No differences were detected by the test for subgroup differences in MWD or PFWD at 12 weeks $(P=0.16$; $P=0.39$; respectively). At the end of training, no difference was detected between the subgroups for MWD $(P=0.62)$; but a difference was detected in PFWD $(P=0.04)$, which seemed to be caused by the cycling subgroup that included only one study with 28 participants (Sanderson 2006). After removing this study, no subgroup differences were detected $\left(P=0.27, I^{2}=23.5 \%\right)$.

Sensitivity analysis did not significantly alter the results, except for the primary comparison of MWD at the end of training. In this comparison, excluding studies with apparent risk of bias resulted in a small to moderate effect on MWD in favour of walking exercise (SMD - $0.36,95 \% \mathrm{Cl}-0.63$ to $-0.10 ; \mathrm{P}=0.0008 ; 5$ studies; 230 participants; low-certainty evidence). This might suggest that, in the absence of the influence of bias, walking exercise interventions provide more benefit for MWD at the end of intervention compared to alternative modes of exercise. The use of SMDs makes it difficult to determine whether the difference was clinically relevant. Interpretation is further complicated by the fact that the alternative exercise group includes different types of exercises. Moreover, our level of certainty regarding this evidence is low considering it was from a small number of studies with relatively small sample size. Future research is likely to have a relevant impact on our confidence in the estimate of effect.

\section{Overall completeness and applicability of evidence}

Although the subject of this review is increasing in interest, only five new studies could be included since the previous search of July 2013. In addition to this, we have identified some possible factors which may limit the completeness and applicability of the evidence presented:

\section{Participants}

The enrolment criteria were relatively homogeneous among included studies. All studies excluded participants if the exercise capacity was limited by comorbidity. However, comorbidity is common among patients with IC, as they are mostly elderly. Therefore, excluding participants with comorbidity probably affects the generalisability of the observed effects.

\section{Interventions}

The vast majority of studies met the guidelines' recommendations for a minimum programme duration of 12 weeks, with durations ranging from six weeks (Sanderson 2006), to 12 weeks (Bulinska 2016; Delaney 2015; Kropielnicka 2018; Regensteiner 1996; RittaDias 2010; Szymczak 2016; Treat-Jacobson 2009), and 24 weeks (Collins 2012, McDermott 2009). The included studies reported outcomes on five alternative modes of exercise, namely cycling (Sanderson 2006), lower-extremity resistance training (McDermott 2009; Regensteiner 1996; Ritta-Dias 2010; Szymczak 2016), upperarm ergometry (Treat-Jacobson 2009), Nordic walking (Bulinska 2016; Collins 2012; Kropielnicka 2018), and combinations of exercise modes (Kropielnicka 2018; Regensteiner 1996; TreatJacobson 2009). Subgroup analysis was carried out with the available data but each subgroup included a small number of studies. Overall, more studies are needed to make meaningful comparisons between each alternative exercise mode and the current standard of walking exercise.

\section{Outcomes}

Only a few studies reported HR-QoL (Collins 2012; Delaney 2015; McDermott 2009; Regensteiner 1996), using different measuring instruments, and self-reported functional impairment (Collins 2012; McDermott 2009; Regensteiner 1996). Meta-analysis was only possible for one of the WIQ subscores. Therefore, more studies are needed to make meaningful comparisons for these outcomes.

\section{Applicability}

For the overall meta-analysis, the sample size seemed sufficient, but the results should be interpreted with caution because of the risk of bias ranging from high to low and heterogeneity due to the different types of alternative interventions included and the different units of outcomes across studies. Participant numbers for the subgroup analyses were limited. The SMDs were not back-transformed to metres or seconds, because this could be misleading and there is no consensus in the literature on a minimum clinically relevant difference in metres. Using the rules of thumb for effect sizes might simplify interpretation of the results (SMD of 0.2 represents a small effect, 0.5 a moderate effect, and 0.8 a large effect). 
The approach chosen in this review has two main limitations that need to be considered. Different types of interventions were lumped together given that our primary aim was to compare alternative modes of exercise to traditional treadmill walking, and the small number of studies looking at different modes of exercises complicated subanalysis. Furthermore, a non-inferiority approach would have been ideal, but this was not feasible due to the mixed alternative modes of exercise group and the impossibility of predetermining a substantiated non-inferiority margin. Despite these limitations, this updated review provides valuable information.

This review focused on treadmill walking distances. However treadmill walking does not necessarily correlate to walking ability in daily life (Gommans 2016), nor does an increased treadmill walking distance always lead to more walking (Fokkenrood 2015). Additionally, a possible training effect of treadmill walking might affect treadmill testing, which probably causes an underestimation of the effect of alternative exercise modes. Because of these aspects, focusing on treadmill walking capacity alone probably has limited value in optimising the treatment of IC. Moreover, improving physical fitness and reducing cardiovascular risk, e.g. by increasing physical activity, are important treatment goals in IC. Therefore, objective measurements of functional impairment, physical activity, and physical condition might be interesting, provided that they are measured with validated measuring instruments. Unfortunately, the current lack of consensus and availability of reliable instruments leads to a high heterogeneity with regard to the use of measuring instruments and outcomes.

\section{Quality of the evidence}

The risk of bias of included studies varied from high to low and three studies were considered to have risk of bias concerns (Bulinska 2016; Kropielnicka 2018; Szymczak 2016) (see Figure 2 and Figure 3). This review demonstrates that alternative modes of exercise therapy seem to yield similar results to walking therapy and may be considered useful when supervised walking exercise is not an option for the patient. The certainty of the evidence according to the GRADE criteria was low for the overall comparison of alternative exercise modes versus walking exercise (Summary of findings 1). The certainty was downgraded due to the relatively small sample sizes, clinical inconsistency, and concerns over risk of bias. Furthermore, we could not investigate possible publication bias, because the limited number of studies did not allow for assessment of asymmetry in funnel plots.

\section{Potential biases in the review process}

We used the SMD as a summary statistic to reduce potential heterogeneity due to the use of different treadmill protocols between studies. Furthermore, we performed subgroup analyses if data were available. It was not possible to conduct a formal analysis of possible publication bias by using a funnel plot owing to the limited number of studies included in the meta-analysis. Several studies were excluded, solely because they did not report the correct outcome measures. Although we carefully ascertained that relevant outcomes were not available because they were not measured rather than not reported, this could introduce bias in the review process. In future updates, we will pay further attention to this potential source of bias.
Many studies were excluded in the title-abstract screening, because they were not RCTs, examined nonsupervised programmes or compared alternative modes of exercise to a non-exercise control group. Furthermore, this review only included supervised exercise programmes, thus excluding home-based or partially supervised programmes comparing walking exercise to alternative modes of exercise. However, considering the findings of other studies, this did not substantially alter results (see Agreements and disagreements with other studies or reviews).

\section{Agreements and disagreements with other studies or reviews}

The findings of this update are in line with the findings of the previous version of this review (Lauret 2014), as well as findings of several other systematic reviews. One previously published systematic review (Parmenter 2011), which included unsupervised exercise programmes and RCTs with a non-exercise control group, found no clear difference between alternative aerobic exercise modes and walking exercise for IC. The data on resistance training were considered insufficient to make clinical recommendations and further research was needed. A systematic review and metaanalysis on Nordic walking (Golledge 2018) suggested that Nordic walking might be more effective in improving cardiovascular fitness than standard walking. However, no benefit of Nordic walking was found compared to standard walking, including unsupervised and supervised settings. A subgroup analysis of completely supervised programmes also demonstrated similar improvements in MWD (SMD - $0.79 ; 95 \% \mathrm{Cl}-2.81$ to $1.24 ; \mathrm{P}=0.446$ ). Furthermore, a recent statement from the American Heart Association (Treat-Jacobson 2019), was based on a systematic review, which included the comparison of treatment modalities. Evidence for each of the alternative exercise modes was summarised separately, and the authors concluded that modalities other than supervised treadmill exercise, including arm ergometry, cycling, and possibly resistance training, can also improve relevant outcomes. In summary, our findings agree with currently available evidence that alternative exercise modes are as effective as standard walking, however, more evidence is needed.

\section{AUTHORS' CONCLUSIONS}

\section{Implications for practice}

Overall, this review demonstrates that there is no clear difference between alternative modes of exercise and supervised walking exercise regarding maximum and pain-free walking distance in patients with intermittent claudication, which means that both interventions yield similar improvements. The certainty of this evidence was judged to be low, mainly due to the small sample size and risk of bias concerns. The findings of this review indicate that alternative exercise modes may be useful when supervised walking exercise is not an option. This is consistent with current international guidelines (Aboyans 2018; Gerhard-Herman 2017).

\section{Implications for research}

Although this update included five additional studies, the overall sample size was relatively small. More RCTs with adequate methodological quality and sufficient power are needed to provide more robust evidence for comparisons between each alternative exercise mode and the current standard of supervised treadmill walking. Those RCTs should preferably investigate 
exercise programmes with a minimum of three sessions a week for a consecutive 12 weeks, as this is recommended based on currently available evidence (Treat-Jacobson 2019). Walking capacity should not solely be measured with treadmill tests, as this might result in an underestimation of the effect of alternative exercise modes and probably does not represent 'daily life' walking. Future studies should investigate functional outcome measures on walking behaviour, physical activity, cardiovascular risk, and HR-QoL, using standardised testing methods and reporting of outcomes to allow meaningful comparison across studies. Furthermore, studies should include patients with comorbidity in order to be more representative of the PAD population. Finally, research is needed to explore possibilities to optimise exercise programmes, taking into account the personal preferences, therapy compliance, and long-term effects. It is thought that more varied and personalised programmes will possibly improve therapy adherence. Furthermore, this might lead to better compliance with the recommendations for physical activity, because combinations of aerobic and muscle-strengthening activities are preferable, according to the Physical Activity Guidelines (Piercy 2018).

\section{ACKNOWLEDGEMENTS}

We acknowledge the support provided by Dr Marlene Stewart, Managing Editor of Cochrane Vascular, Dr Cathryn Broderick, Assistant Managing Editor of Cochrane Vascular, and Ms Candida Fenton, Cochrane Vascular Information Specialist, in updating this review. We would also like to thank the previous authors for their contributions to the previous version of this review: Professor Hunink and Dr Spronk. The review authors, and the Cochrane Vascular editorial base, wish to thank the following peer reviewers for their input as well as the reviewer who opted to remain anonymous: Dr Ralph G DePalma, Uniformed Services University of the Health Sciences, Washington and Department of Veteran Affairs, Washington, US; Associate Professor Anthony Leicht, James Cook University, Australia; Dr Jonathan Moran, Trinity College Dublin, Ireland; LeAnne Lovett-Floom, DNP, MSN, RN, PHN-BC, US. 


\section{R E F E R E N C E S}

\section{References to studies included in this review}

Bulinska 2016 \{published data only\}

Bulinska K, Kropielnicka K, Jasinski T, Wojcieszczyk-Latos J, Pilch U, Dabrowska G, et al. Nordic pole walking improves walking capacity in patients with intermittent claudication: a randomized controlled trial. Disability and Rehabilitation 2016;38(13):1318-24. [PMID: 26305413]

Collins 2012 \{published data only\}

Collins EG, McBurney C, Butler J, Jelinek C, O'Connell S, Fritschi $C$, et al. The effects of walking or walking-with-poles training on tissue oxygenation in patients with peripheral arterial disease. International Journal of Vascular Medicine 2012;2012:985025. [PMID: 23050152]

* Collins EG, O'Connell S, McBurney C, Jelinek C, Butler J, Reda $\mathrm{D}$, et al. Comparison of walking with poles and traditional walking for peripheral arterial disease rehabilitation. Journal of Cardiopulmonary Rehabilitation and Prevention 2012;32(4):210-8. [PMID: 22595894]

\section{Delaney 2015 \{published data only\}}

Delaney CL, Miller MD, Allan RB, Spark JI. The impact of different supervised exercise regimens on endothelial function in patients with intermittent claudication. Vascular 2015;23(6):561-9. [PMID: 25406267]

\section{Kropielnicka 2018 \{published data only\}}

Kropielnicka K, Dziubek W, Bulinska K, Stefanska M, Wojcieszczyk-Latos J, Jasinski R, et al. Influence of the physical training on muscle function and walking distance in symptomatic peripheral arterial disease in elderly. BioMed Research International 2018;2018:1937527. [PMID: 30345295]

\section{McDermott 2009 \{published data only\}}

* McDermott MM, Ades P, Guralnik JM, Dyer A, Ferrucci L, Liu K, et al. Treadmill exercise and resistance training in patients with peripheral arterial disease with and without intermittent claudication: a randomized controlled trial. Journal of the American Medical Association 2009;301(2):165-74. [PMID: 19141764]

McDermott MM, Kibbe MR, Guralnik JM, Ferrucci L, Criqui MH, Domanchuk K, et al. Durability of benefits from supervised treadmill exercise in people with peripheral artery disease. Journal of the American Heart Association 2019;8(1):e009380. [PMID: 30587066]

\section{Regensteiner 1996 \{published data only\}}

Hiatt WR, Regensteiner JG, Wolfel EE, Carry MR, Brass EP. Effect of exercise training on skeletal muscle histology and metabolism in peripheral arterial disease. Journal of Applied Physiology 1996;81(2):780-8. [PMID: 8872646]

Hiatt WR, Wolfel EE, Meier RH, Regensteiner JG. Superiority of treadmill walking exercise versus strength training for patients with peripheral arterial disease. Implications for the mechanism of the training response. Circulation 1994;90(4):1866-74. [PMID: 7923674]
* Regensteiner JG, Steiner JF, Hiatt WR. Exercise training improves functional status in patients with peripheral arterial disease. Journal of Vascular Surgery 1996;23(1):104-15. [PMID: 8558725]

Ritta-Dias 2010 \{published data only\}

Grizzo Cucato G, De Moraes Forjaz CL, Kanegusuku H, Da Rocha Chechuen M, Riani Costa LA, Wolosker N, et al. Effects of walking and strength training on resting and exercise cardiovascular responses in patients with intermittent claudication. Vasa 2011;40(5):390-7. [PMID: 21948782]

Menêses AL, De Lima GH, Forjaz CL, Lima AH, Silva GQ, Cucato $\mathrm{GG}$, et al. Impact of a supervised strength training or walking training over a subsequent unsupervised therapy period on walking capacity in patients with claudication. Journal of Vascular Nursing 2011;29(2):81-6. [PMID: 21558030]

* Ritti-Dias RM, Wolosker N, De Moraes Forjaz CL, Carvalho CR, Cucato GG, Leão PP, et al. Strength training increases walking tolerance in intermittent claudication patients: randomized trial. Journal of Vascular Surgery 2010;51(1):89-95. [PMID: 19837534]

\section{Sanderson 2006 \{published data only\}}

Sanderson B, Askew C, Stewart I, Walker P, Gibbs H, Green S. Short-term effects of cycle and treadmill training on exercise tolerance in peripheral arterial disease. Journal of Vascular Surgery 2006;44(1):119-27. [PMID: 16828435]

\section{Szymczak 2016 \{published data only\}}

Szymczak M, Oszkinis G, Majchrzycki M. The impact of walking exercises and resistance training upon the walking distance in patients with chronic lower limb ischaemia. BioMed Research International 2016;2016:7515238. [PMID: 27833919]

\section{Treat-Jacobson 2009 \{published data only\}}

Bronas UG, Treat-Jacobson D, Leon AS. Comparison of the effect of upper body ergometry aerobic training vs treadmill training on central cardiorespiratory improvement and walking distance in patients with claudication. Journal of Vascular Surgery 2011;53(6):1557-64. [PMID: 21515017]

* Treat-Jacobson D, Bronas UG, Leon AS. Efficacy of armergometry versus treadmill exercise training to improve walking distance in patients with claudication. Vascular Medicine 2009;14(3):203-13. [PMID: 19651669]

\section{References to studies excluded from this review}

Dedes 2010 \{published data only\}

Dedes H, Figoni SF, Kalioundji G, Kunkel C, Peter A, Phillips A, et al. Prospective trial of calf ergometry training on walking ability in peripheral arterial disease. $P M \& R$ : Journal of Injury, Function, and Rehabilitation 2010;2(9 Suppl 1):S26.

Delaney 2014 \{published data only\}

* Delaney CL, Miller MD, Chataway TK, Spark JI. A randomised controlled trial of supervised exercise regimens and their 
impact on walking performance, skeletal muscle mass and calpain activity in patients with intermittent claudication. European Journal of Vascular and Endovascular Surgery 2014;47(3):304-10. [PMID: 24445084]

Delaney CL, Spark JI. A randomised controlled trial of two supervised exercise regimens and their impact on inflammatory burden in patients with intermittent claudication. Vascular 2016;24(3):264-72. [PMID: 26567275]

\section{EXERT Study 2018 \{published data only\}}

Kirk LN, Brown R, Treat-Jacobson D. Long-term outcomes of supervised exercise in peripheral artery disease: impact of differing modes of exercise 1-4 years after intervention. Journal of Vascular Nursing 2018;36(3):121-8. [PMID: 30139449]

* NCT00895635. Evaluating two exercise training programs to reduce leg pain in people with peripheral arterial disease (the EXERT study). clinicaltrials.gov/ct2/show/NCT00895635 (first received 8 May 2009).

\section{Gardner 2011 \{published data only\}}

Gardner AW. Supervised exercise therapy provided by local physiotherapists improves walking distance in patients with claudication. Evidence-based Medicine 2011;16(2):43-4. [PMID: 21427053]

\section{Jones 1996 \{published data only\}}

Jones PP, Skinner JS, Smith LK, John FM, Bryant CX. Functional improvements following Stairmaster versus treadmill exercise training for patients with intermittent claudication. Journal of Cardiopulmonary Rehabilitation 1996;16(1):47-55. [PMID: 8907442]

\section{Kao 2012 \{published data only\}}

Kao K, Choi S, Etnyre G, Figoni SF, Kunkel CF, Ornelas CC, et al. Comparison of calf exercise and treadmill training in peripheral arterial disease. $P M \& R$ : Journal of Injury, Function, and Rehabilitation 2012;4(10):S346.

Kim 2006 \{published data only\}

Kim DH. Exercise and peripheral arterial disease. Annals of Internal Medicine 2006;144(9):author reply 699-700. [PMID: 16670144]

\section{Kuwabara 2010 \{published data only\}}

Kuwabara M, Anzai H, Nishi Y, Hayashida N, Hisatome I. Treadmill and ergometer exercise once a week equally improve not only exercise-tolerance but also cardio-renal function in peripheral arterial disease (PAD) patients with claudication. Journal of the American College of Cardiology 2010;55(10s1):E1479-A158. [DOI: 10.1016/ S0735-1097(10)61480-5]

\section{Nawaz 2001 \{published data only\}}

Nawaz S, Walker RD, Wilkinson CH, Saxton JM, Pockley AG, Wood RF. The inflammatory response to upper and lower limb exercise and the effects of exercise training in patients with claudication. Journal of Vascular Surgery 2001;33(2):392-9. [PMID: 11174795]

\section{Oakley 2008 \{published data only\}}

Oakley C, Zwierska I, Tew G, Beard JD, Saxton JM. Nordic poles immediately improve walking distance in patients with intermittent claudication. European Journal of Vascular and Endovascular Surgery 2008;36(6):689-94; discussion 695-6. [PMID: 18835794]

\section{Ornelas 2011 \{published data only\}}

Ornelas CC, Dhingsa K, Etnyre G, Figoni SF, Fung DA, Kunkel C, et al. Comparison of calf ergometer and treadmill exercise training interventions for participants with intermittent claudication due to peripheral arterial disease. $P M \& R$ : Journal of Injury, Function, and Rehabilitation 2011;3(10 Suppl 1):S266-7. [DOI: 10.1016/j.pmrj.2011.08.302]

\section{Parmenter 2013 \{published data only\}}

Parmenter BJ, Raymond J, Dinnen P, Lusby RJ, Fiatarone Singh MA. High-intensity progressive resistance training improves flat-ground walking in older adults with symptomatic peripheral arterial disease. Journal of the American Geriatrics Society 2013;61(11):1964-70.

Parr 2009 \{published data only\}

Parr BM, Noakes TD, Derman EW. Peripheral arterial disease and intermittent claudication: efficacy of short-term upper body strength training, dynamic exercise training, and advice to exercise at home. South African Medical Journal 2009;99(11):800-4. [PMID: 20218480]

\section{Roitman 2010 \{published data only\}}

Roitman JL. Treadmill exercise and resistance training in patients with peripheral arterial disease with and without intermittent claudication: a randomized controlled trial. Journal of Cardiopulmonary Rehabilitation and Prevention 2010;30(1):62.

\section{Saxton 2008 \{published data only\}}

Saxton JM, Zwierska I, Hopkinson K, Espigares E, Choksy S, Nawaz S, et al. Effect of upper- and lower-limb exercise training on circulating soluble adhesion molecules, hs-CRP and stress proteins in patients with intermittent claudication. European Journal of Vascular and Endovascular Surgery 2008;35(5):607-13. [PMID: 18226561]

\section{Saxton 2011 \{published data only\}}

Saxton JM, Zwierska I, Blagojevic M, Choksy SA, Nawaz S, Pockley AG. Upper- versus lower-limb aerobic exercise training on health-related quality of life in patients with symptomatic peripheral arterial disease. Journal of Vascular Surgery 2011;53(5):1265-73. [PMID: 21215558]

Tebbutt 2011 \{published data only\}

Tebbutt N, Robinson L, Todhunter J, Jonker L. A plantar flexion device exercise programme for patients with peripheral arterial disease: a randomised prospective feasibility study. Physiotherapy 2011;97(3):244-9. [PMID: 21820543]

Treat-Jacobson 2011 \{published data only\}

Treat-Jacobson D, Henly SJ, Bronas UG, Leon AS, Henly GA. The pain trajectory during treadmill testing in peripheral artery 
disease. Nursing Research 2011;60(3 Suppl):S38-49. [PMID: 21543960]

Treat-Jacobson 2012 \{published data only\}

Treat-Jacobson D, Bronas UG, Krause BJ, Robinson CA, Santilli SM, Leon AS. Aerobic arm exercise training to improve outcomes for patients with severe claudication and ischemic rest pain. Vascular Medicine 2012;17(3):204.

\section{Van Schaardenburgh 2017 \{published data only\}}

Van Schaardenburgh M, Wohlwend M, Rognmo O, Mattsson EJR. Exercise in claudicants increase or decrease walking ability and the response relates to mitochondrial function. Journal of Translational Medicine 2017;15(1):130. [PMID: 28592294]

\section{Walker 2000 \{published data only\}}

Walker RD, Nawaz S, Wilkinson CH, Saxton JM, Pockley AG, Wood RF. Influence of upper- and lower-limb exercise training on cardiovascular function and walking distances in patients with intermittent claudication. Journal of Vascular Surgery 2000;31(4):662-9. [PMID: 10753273]

\section{Wang 2008 \{published data only\}}

Wang E, Hoff J, Loe H, Kaehler N, Helgerud J. Plantar flexion: an effective training for peripheral arterial disease. European Journal of Applied Physiology 2008;104(4):749-56. [PMID: 18726111]

\section{Zwierska 2005 \{published data only\}}

Zwierska I, Walker RD, Choksy SA, Male JS, Pockley AG, Saxton JM. Upper- vs lower-limb aerobic exercise rehabilitation in patients with symptomatic peripheral arterial disease: a randomized controlled trial. Journal of Vascular Surgery 2005;42(6):1122-30. [PMID: 16376202]

\section{References to ongoing studies}

\section{ACTRN12616000243415 \{published data only\}}

ACTRN12616000243415. Comparison of the effects of supervised treadmill walking training and supervised walking with poles on functional capabilities in patients with intermittent claudication. anzctr.org.au/Trial/Registration/ TrialReview.aspx?id=369663 (first received 23 November 2015).

\section{NCT03837639 \{published data only\}}

NCT03837639. Arm-crank exercise training on cardiovascular function of patients with peripheral artery disease. clinicaltrials.gov/ct2/show/NCT03837639 (first received 12 February 2019).

\section{Additional references}

\section{Aboyans 2018 \\ Aboyans V, Ricco JB, Bartelink MEL, Bjorck M, Brodmann M, Cohnert T, et al. Editor's Choice - 2017 ESC Guidelines on the diagnosis and treatment of peripheral arterial diseases, in collaboration with the European Society for Vascular Surgery (ESVS). European Journal of Vascular and Endovascular Surgery 2018;55(3):305-68. [PMID: 28851596]}

\section{Atkins 2004}

Atkins D, Best D, Briss PA, Eccles M, Falck-Ytter Y, Flottorp S, et al. Grading quality of evidence and strength of recommendations. British Medical Journal 2004;328(7454):1490-4.

\section{Bendermacher 2007}

Bendermacher BL, Willigendael EM, Nicolaï SP, Kruidenier LM, Welten RJ, Hendriks E, et al. Supervised exercise therapy for intermittent claudication in a community-based setting is as effective as clinic-based. Journal of Vascular Surgery 2007;45(6):1192-6. [PMID: 17543684]

\section{Cohen 1988}

Cohen J. Statistical Power Analysis in the Behavioral Sciences. 2nd edition. Hillsdale (NJ): Lawrence Erlbaum Associates, Inc, 1988.

\section{Conte 2015}

Conte MS, Pomposelli FB, Clair DG, Geraghty PJ, McKinsey JF, Mills JL, et al. Society for Vascular Surgery practice guidelines for atherosclerotic occlusive disease of the lower extremities: management of asymptomatic disease and claudication. Journal of Vascular Surgery 2015;61(3 Suppl):2S-41S. [PMID: 25638515]

\section{DerSimonian 1986}

DerSimonian R, Laird N. Meta-analysis in clinical trials. Controlled Clinical Trials 1986;7(3):177-88. [PMID: 3802833]

\section{Dumville 2004}

Dumville JC, Lee AJ, Smith FB, Fowkes FG. The health-related quality of life of people with peripheral arterial disease in the community: the Edinburgh Artery Study. British Journal of General Practice 2004;54(508):826-31. [PMID: 15527608]

\section{Fakhry 2018}

Fakhry F, Fokkenrood HJ, Spronk S, Teijink JA, Rouwet EV, Hunink MGM. Endovascular revascularisation versus conservative management for intermittent claudication. Cochrane Database of Systematic Reviews 2018, Issue 3. Art. No: CD010512. [DOI: 10.1002/14651858.CD010512.pub2]

\section{Fokkenrood 2015}

Fokkenrood HJ, Lauret GJ, Verhofstad N, Bendermacher BL, Scheltinga MR, Teijink JA. The effect of supervised exercise therapy on physical activity and ambulatory activities in patients with intermittent claudication. European Journal of Vascular and Endovascular Surgery 2015;49(2):184-91. [PMID: 25496986]

\section{Fowkes 2013}

Fowkes FG, Rudan D, Rudan I, Aboyans V, Denenberg JO, McDermott MM, et al. Comparison of global estimates of prevalence and risk factors for peripheral artery disease in 2000 and 2010: a systematic review and analysis. Lancet (London, England) 2013;382(9901):1329-40. [PMID: 23915883]

\section{Gerhard-Herman 2017}

Gerhard-Herman MD, Gornik HL, Barrett C, Barshes NR, Corriere MA, Drachman DE, et al. 2016 AHA/ACC Guideline on the management of patients with lower extremity peripheral 
artery disease: executive summary: a report of the American College of Cardiology/American Heart Association Task Force on Clinical Practice Guidelines. Circulation 2017;135(12):e686-725. [PMID: 27840332]

\section{Golledge 2018}

Golledge J, Maarij K, Moxon JV, Beard JD, Girold S, Wrang H, et al. Systematic review and meta-analysis of clinical trials examining the benefit of exercise programmes using Nordic walking in patients with peripheral artery disease. European Journal of Vascular Endovascular Surgery 2018;56(4):534-43.

\section{Gommans 2015}

Gommans LN, Fokkenrood HJ, Van Dalen HC, Scheltinga MR, Teijink JA, Peters RJ. Safety of supervised exercise therapy in patients with intermittent claudication. Journal of Vascular Surgery 2015;61(2):512-8.e2. [PMID: 25441008]

\section{Gommans 2016}

Gommans LN, Hageman D, Jansen I, De Gee R, Van Lummel RC, Verhofstad N, et al. Minimal correlation between physical exercise capacity and daily activity in patients with intermittent claudication. Journal of Vascular Surgery 2016;63(4):983-9. [PMID: 26806522]

\section{GRADEproGDT 2015 [Computer program]}

McMaster University (developed by Evidence Prime) GRADEproGDT. Version version accessed 15 November 2019. Hamilton (ON): McMaster University (developed by Evidence Prime), 2015. Available from www.gradepro.org.

\section{Haas 2012}

Haas TL, Lloyd PG, Yang HT, Terjung RL. Exercise training and peripheral arterial disease. Comprehensive Physiology 2012;2(4):2933-3017. [PMID: 23720270]

\section{Hageman 2018}

Hageman D, Fokkenrood HJ, Gommans LN, Van den Houten MM, Teijink JA. Supervised exercise therapy versus home-based exercise therapy versus walking advice for intermittent claudication. Cochrane Database of Systematic Reviews 2018, Issue 4. Art. No: CD005263. [DOI: 10.1002/14651858.CD005263.pub4]

\section{Harwood 2016}

Harwood AE, Cayton T, Sarvanandan R, Lane R, Chetter I. A review of the potential local mechanisms by which exercise improves functional outcomes in intermittent claudication. Annals of Vascular Surgery 2016;30:312-20. [PMID: 26362620]

\section{Higgins 2019}

Higgins JP, Thomas J, Chandler J, Cumpston M, Li T, Page MJ, Welch VA (editors). Cochrane Handbook for Systematic Reviews of Interventions Version 6.0 (updated July 2019). Cochrane, 2019. Available from www.training.cochrane.org/handbook.

\section{Jansen 2019}

Jansen SCP, Hoorweg BBN, Hoeks SE, Van den Houten MML, Scheltinga MRM, Teijink JAW, et al. A systematic review and meta-analysis of the effects of supervised exercise therapy on modifiable cardiovascular risk factors in intermittent claudication. Journal of Vascular Surgery 2019;69(4):1293-1308.e2. [PMID: 30777692]

\section{Kruidenier 2009}

Kruidenier LM, Nicolai SP, Hendriks EJ, Bollen EC, Prins MH, Teijink JA. Supervised exercise therapy for intermittent claudication in daily practice. Journal of Vascular Surgery 2009;49(2):363-70. [PMID: 19028059]

\section{Lane 2017}

Lane R, Harwood A, Watson L, Leng GC. Exercise for intermittent claudication. Cochrane Database of Systematic Reviews 2017, Issue 12. Art. No: CD000990. [DOI: 10.1002/14651858.CD000990.pub4]

\section{Lefebvre 2011}

Lefebvre C, Manheimer E, Glanville J. Chapter 6: Searching for studies. In: Higgins JP, Green S editor(s). Cochrane Handbook for Systematic Reviews of Interventions Version 5.1.0 (updated March 2011). The Cochrane Collaboration, 2011. Available from handbook.cochrane.org.

\section{McDermott 2001}

McDermott MM, Greenland P, Liu K, Guralnik JM, Criqui MH, Dolan NC, et al. Leg symptoms in peripheral arterial disease: associated clinical characteristics and functional impairment. Journal of the American Medical Association 2001;286(13):1599-606. [PMID: 11585483]

\section{Nicolaï 2010}

Nicolaï SP, Teijink JA, Prins MH, Exercise Therapy in Peripheral Arterial Disease Study Group. Multicenter randomized clinical trial of supervised exercise therapy with or without feedback versus walking advice for intermittent claudication. Journal of Vascular Surgery 2010;52(2):348-55. [PMID: 20478681]

\section{Parmenter 2011}

Parmenter BJ, Raymond J, Dinnen P, Singh MA. A systematic review of randomized controlled trials: walking versus alternative exercise prescription as treatment for intermittent claudication. Atherosclerosis 2011;218(1):1-12. [PMID: 21601857]

\section{Parmenter 2013b}

Parmenter BJ, Raymond J, Fiatarone Singh MA. The effect of exercise on fitness and performance-based tests of function in intermittent claudication: a systematic review. Sports Medicine (Auckland, NZ) 2013;43(6):513-24. [PMID: 23539309]

\section{Parmenter 2015}

Parmenter BJ. Exercise training for management of peripheral arterial disease: a systematic review and meta-analysis. Sports Medicine 2015;45(2):231-44.

\section{Piercy 2018}

Piercy KL, Troiano RP, Ballard RM, Carlson SA, Fulton JE, Galuska DA, et al. The Physical Activity Guidelines for Americans. JAMA 2018;320(19):2020-8. [PMID: 30418471]

\section{Review Manager 2020 [Computer program]}

The Cochrane Collaboration Review Manager 5 (RevMan 5). Version 5.4. Copenhagen: The Cochrane Collaboration, 2020. 
Tompra 2015

Tompra N, Foster C, Sanchis-Gomar F, De Koning JJ, Lucia A, Emanuele E. Upper versus lower limb exercise training in patients with intermittent claudication: a systematic review. Atherosclerosis 2015;239(2):599-606.

\section{Treat-Jacobson 2019}

Treat-Jacobson D, McDermott MM, Bronas UG, Campia U, Collins TC, Criqui MH, et al. Optimal exercise programs for patients with peripheral artery disease: a scientific statement from the American Heart Association. Circulation 2019;139(4):e10-33. [PMID: 30586765]

CHARACTERISTICS OF STUDIES

Characteristics of included studies [ordered by study ID]

Bulinska 2016

\section{References to other published versions of this review}

\section{Lauret 2012}

Lauret GJ, Fakhry F, Fokkenrood HJP, Hunink MG, Teijink JAW, Spronk S. Modes of exercise training for intermittent claudication. Cochrane Database of Systematic Reviews 2012, Issue 2. Art. No: CD009638. [DOI: 10.1002/14651858.CD009638]

\section{Lauret 2014}

Lauret GJ, Fakhry F, Fokkenrood HJP, Hunink MGM, Teijink JAW, Spronk S. Modes of exercise training for intermittent claudication. Cochrane Database of Systematic Reviews 2014, Issue 7. Art. No: CD009638. [DOI: 10.1002/14651858.CD009638.pub2]

* Indicates the major publication for the study

\section{Study characteristics}

\begin{tabular}{ll}
\hline Methods & RCT \\
\hline Participants & $\begin{array}{l}\text { The number of eligible patients was not described, } 70 \text { participants were randomised and 52 partici- } \\
\text { pants completed follow-up (4 drop-outs in group 1 and 14 in group 2) }\end{array}$ \\
\hline Interventions & Group 1: 12 weeks of supervised treadmill exercise \\
& Group 2: 12 weeks of supervised Nordic walking \\
\hline Outcomes & $\begin{array}{l}\text { Claudication distance, MWD, 6-minute walking test, heart rate, blood pressure, and rating of perceived } \\
\text { exertion }\end{array}$ \\
\hline Notes & -
\end{tabular}

\section{Risk of bias}

\begin{tabular}{|c|c|c|}
\hline Bias & Authors' judgement & Support for judgement \\
\hline $\begin{array}{l}\text { Random sequence genera- } \\
\text { tion (selection bias) }\end{array}$ & High risk & $\begin{array}{l}\text { Pseudorandomisation method was used in which recruited participants were } \\
\text { allocated by the investigators using a fixed block size. }\end{array}$ \\
\hline $\begin{array}{l}\text { Allocation concealment } \\
\text { (selection bias) }\end{array}$ & High risk & $\begin{array}{l}\text { Pseudorandomisation method was used in which recruited participants were } \\
\text { allocated by the investigators using a fixed block size. }\end{array}$ \\
\hline $\begin{array}{l}\text { Blinding of participants } \\
\text { and personnel (perfor- } \\
\text { mance bias) } \\
\text { All outcomes }\end{array}$ & Low risk & $\begin{array}{l}\text { In all of the included studies, participants and direct personnel could not be } \\
\text { blinded to the intervention (exercise). For this reason, bias could be intro- } \\
\text { duced. However, since all studies experienced the same limitation, we consid- } \\
\text { ered the risk of bias to be low for all studies. }\end{array}$ \\
\hline $\begin{array}{l}\text { Blinding of outcome as- } \\
\text { sessment (detection bias) } \\
\text { All outcomes }\end{array}$ & Unclear risk & No information provided \\
\hline $\begin{array}{l}\text { Incomplete outcome data } \\
\text { (attrition bias) }\end{array}$ & High risk & $\begin{array}{l}\text { The authors reported } 18 \text { drop-outs ( } 4 \text { in group } 1 \text { and } 14 \text { in group } 2 \text { ), without } \\
\text { providing clear reasons ("The main reasons for dropouts from the training pro- }\end{array}$ \\
\hline
\end{tabular}


Bulinska 2016 (Continued)

All outcomes grammes were personal problems and health disturbances"). The risk of bias was considered high as the number of drop-outs was high and not evenly distributed, and no intention-to-treat analysis was performed.

\begin{tabular}{lll}
\hline $\begin{array}{l}\text { Selective reporting (re- } \\
\text { porting bias) }\end{array}$ & Low risk & All relevant outcomes were described in the study results. \\
\hline Other bias & Unclear risk & $\begin{array}{l}\text { Significant differences in baseline characteristics were reported for hyperten- } \\
\text { sion and degenerative changes of spine and peripheral joints. These character- } \\
\text { istics might affect outcomes. We identified no other forms of bias. }\end{array}$
\end{tabular}

Collins 2012

\section{Study characteristics}

\begin{tabular}{|c|c|c|}
\hline Methods & \multicolumn{2}{|l|}{$\mathrm{RCT}$} \\
\hline Participants & \multicolumn{2}{|c|}{$\begin{array}{l}2296 \text { potential participants were screened for eligibility, } 146 \text { were enrolled and } 103 \text { were randomised. } \\
\text { The authors reported } 18 \text { drop-outs in group } 1 \text { and } 13 \text { in group } 2 \text {. }\end{array}$} \\
\hline Interventions & \multicolumn{2}{|c|}{ Group 1: 24 weeks of supervised treadmill exercise } \\
\hline & \multicolumn{2}{|c|}{ Group 2: 24 weeks of supervised Nordic walking } \\
\hline Outcomes & \multicolumn{2}{|c|}{$\begin{array}{l}\text { Onset of claudication time, maximum walking time, SF-36 (physical function subscale), WIQ (distance } \\
\text { subscale) and tissue oxygenation measured using near-infrared spectroscopy }\end{array}$} \\
\hline Notes & \multicolumn{2}{|l|}{-} \\
\hline \multicolumn{3}{|l|}{ Risk of bias } \\
\hline Bias & Authors' judgement & Support for judgement \\
\hline $\begin{array}{l}\text { Random sequence genera- } \\
\text { tion (selection bias) }\end{array}$ & Low risk & Randomisation was performed with computer-generated permuted blocks. \\
\hline $\begin{array}{l}\text { Allocation concealment } \\
\text { (selection bias) }\end{array}$ & Low risk & Randomisation was performed with computer-generated permuted blocks. \\
\hline $\begin{array}{l}\text { Blinding of participants } \\
\text { and personnel (perfor- } \\
\text { mance bias) } \\
\text { All outcomes }\end{array}$ & Low risk & $\begin{array}{l}\text { In all of the included studies, participants and direct personnel could not be } \\
\text { blinded to the intervention (exercise). For this reason, bias could be intro- } \\
\text { duced. However, since all studies experienced the same limitation, we consid- } \\
\text { ered the risk of bias to be low for all studies. }\end{array}$ \\
\hline $\begin{array}{l}\text { Blinding of outcome as- } \\
\text { sessment (detection bias) } \\
\text { All outcomes }\end{array}$ & Unclear risk & No information provided \\
\hline $\begin{array}{l}\text { Incomplete outcome data } \\
\text { (attrition bias) } \\
\text { All outcomes }\end{array}$ & Unclear risk & $\begin{array}{l}\text { The authors reported } 18 \text { drop-outs in group } 1 \text { and } 13 \text { drop-outs in group } 2 . \\
\text { The reasons were compliance (10), cardiac (9), peripheral vascular surgery ( } 3 \text { ), } \\
\text { death (1), other medical ( } 7) \text {, and moved (1). Although plausible reasons were } \\
\text { provided and intention-to-treat analysis was performed, the risk of bias was } \\
\text { considered unclear as the number of drop-outs was high and not evenly dis- } \\
\text { tributed among groups. }\end{array}$ \\
\hline
\end{tabular}


Collins 2012 (Continued)
Selective reporting (re-
Low risk
All relevant outcomes were described in the study results. porting bias)

Other bias

Low risk

No significant differences in baseline characteristics were found. We identified no other forms of bias.

Delaney 2015

\section{Study characteristics}

\begin{tabular}{ll}
\hline Methods & RCT \\
\hline Participants & $\begin{array}{l}111 \text { potential participants assessed for eligibility, } 35 \text { participants were randomised (18 in group } 1 \text { and } \\
17 \text { in group 2). The authors reported } 3 \text { drop-outs in group } 1 \text { and } 5 \text { in group } 2 .\end{array}$ \\
\hline Interventions & Group 1: 12 weeks of supervised treadmill exercise \\
& Group 2: 12 weeks of combination training (supervised treadmill exercise and resistance training) \\
\hline Outcomes & Australian Vascular QoLIndex, 6-minute walking test, and endothelial function \\
\hline Notes & -
\end{tabular}

\section{Risk of bias}

\begin{tabular}{|c|c|c|}
\hline Bias & Authors' judgement & Support for judgement \\
\hline $\begin{array}{l}\text { Random sequence genera- } \\
\text { tion (selection bias) }\end{array}$ & Low risk & $\begin{array}{l}\text { Randomisation was performed by computer-based random number genera- } \\
\text { tion using a 1:1 allocation ratio for block sizes which represented the number } \\
\text { of participants recruited within each 3-month interval. }\end{array}$ \\
\hline $\begin{array}{l}\text { Allocation concealment } \\
\text { (selection bias) }\end{array}$ & Low risk & $\begin{array}{l}\text { Randomisation was performed by computer-based random number genera- } \\
\text { tion. }\end{array}$ \\
\hline $\begin{array}{l}\text { Blinding of participants } \\
\text { and personnel (perfor- } \\
\text { mance bias) } \\
\text { All outcomes }\end{array}$ & Low risk & $\begin{array}{l}\text { In all of the included studies, participants and direct personnel could not be } \\
\text { blinded to the intervention (exercise). For this reason, bias could be intro- } \\
\text { duced. However, since all studies experienced the same limitation, we consid- } \\
\text { ered the risk of bias to be low for all studies. }\end{array}$ \\
\hline
\end{tabular}

Blinding of outcome as- Low risk Outcome assessors were blinded to the allocated intervention.

sessment (detection bias)

All outcomes

\begin{tabular}{ll}
\hline $\begin{array}{l}\text { Incomplete outcome data } \\
\text { (attrition bias) }\end{array}$ & Low risk \\
$\begin{array}{ll}\text { All outcomes } & \text { The authors reported } 8 \text { drop-outs: } 3 \text { in group } 1 \text { due to MI (1), sepsis (1), and lost } \\
& \text { of interest (1); and } 5 \text { in group } 2 \text { due to transient ischaemic attack (2), disc pro- } \\
& \text { lapse (1), diabetic foot sepsis (1), and lost of interest (1). ITT analysis and per- } \\
\text { protocol analysis were performed. }\end{array}$ \\
\hline
\end{tabular}

Selective reporting (re- Low risk All relevant outcomes were described in the study results.
porting bias)

Other bias Unclear risk
Participants with radiographic aortic-iliac disease were excluded from the
study, but there is no scientific evidence that confirms a difference in treat-
ment effects of exercise related to the level of disease. No significant differ- 


\section{Study characteristics}

\begin{tabular}{ll}
\hline Methods & RCT \\
\hline Participants & $\begin{array}{l}\text { 219 potentially eligible patients, } 144 \text { qualified according to criteria, } 95 \text { participants were randomised. } \\
\text { The authors reported } 15 \text { drop-outs (1 in group 1, } 11 \text { in group 2, 3 in group 3), which were excluded from } \\
\text { analysis. }\end{array}$
\end{tabular}

Interventions

Group 1: 12 weeks of supervised treadmill exercise

Group 2: 12 weeks of supervised Nordic walking

Group 3: 12 weeks of supervised combination training (resistance training and Nordic walking)

\begin{tabular}{ll}
\hline Outcomes & Initial claudication distance, maximum claudication distance, 6-minute walking test, force-velocity pa- \\
rameters of flexor and extensor muscles in the knee and ankle joints
\end{tabular}

$\begin{array}{ll}\text { Notes } & \begin{array}{l}\text { We contacted the authors and received relevant outcome data, which were not clearly described in the } \\ \text { paper. }\end{array}\end{array}$

\section{Risk of bias}

\begin{tabular}{|c|c|c|}
\hline Bias & Authors' judgement & Support for judgement \\
\hline $\begin{array}{l}\text { Random sequence genera- } \\
\text { tion (selection bias) }\end{array}$ & High risk & $\begin{array}{l}\text { Pseudorandomisation method was used in which recruited participants were } \\
\text { allocated by the investigators using a fixed block size. }\end{array}$ \\
\hline $\begin{array}{l}\text { Allocation concealment } \\
\text { (selection bias) }\end{array}$ & High risk & $\begin{array}{l}\text { Pseudorandomisation method was used in which recruited participants were } \\
\text { allocated by the investigators using a fixed block size. }\end{array}$ \\
\hline $\begin{array}{l}\text { Blinding of participants } \\
\text { and personnel (perfor- } \\
\text { mance bias) } \\
\text { All outcomes }\end{array}$ & Low risk & $\begin{array}{l}\text { In all of the included studies, participants and direct personnel could not be } \\
\text { blinded to the intervention (exercise). For this reason, bias could be intro- } \\
\text { duced. However, since all studies experienced the same limitation, we consid- } \\
\text { ered the risk of bias to be low for all studies. }\end{array}$ \\
\hline $\begin{array}{l}\text { Blinding of outcome as- } \\
\text { sessment (detection bias) } \\
\text { All outcomes }\end{array}$ & Unclear risk & No information provided \\
\hline $\begin{array}{l}\text { Incomplete outcome data } \\
\text { (attrition bias) } \\
\text { All outcomes }\end{array}$ & High risk & $\begin{array}{l}18 \text { participants dropped out after randomisation: } 1 \text { in the treadmill group } \\
\text { due to deterioration of health and } 11 \text { in the Nordic walking group due to dis- } \\
\text { tance between place of residence and place of training (6), health concerns for } \\
\text { undertaking outdoor training (4), and malaise (1); and } 3 \text { in the combination } \\
\text { group due to insufficient participation in exercise training (2) and unwilling- } \\
\text { ness to participate in final tests (1). Drop-outs were not evenly distributed and } \\
\text { for } 10 \text { participants in group } 2 \text { the reasons were related to the intervention it- } \\
\text { self. All drop-outs were excluded from analysis; no intention-to-treat analysis } \\
\text { was performed. }\end{array}$ \\
\hline
\end{tabular}


Kropielnicka 2018 (Continued)

\begin{tabular}{lll}
$\begin{array}{l}\text { Selective reporting (re- } \\
\text { porting bias) }\end{array}$ & Low risk & $\begin{array}{l}\text { Relevant outcome data for this review (initial claudication distance and maxi- } \\
\text { mal walking distance) were only presented in a figure; no numerical data were } \\
\text { given. However, after contacting the authors, we collected these data. }\end{array}$ \\
\hline Other bias & Unclear risk & $\begin{array}{l}\text { The presented baseline characteristics were very limited. We identified no oth- } \\
\text { er forms of bias. }\end{array}$
\end{tabular}
er forms of bias.

McDermott 2009

\section{Study characteristics}

\begin{tabular}{ll}
\hline Methods & RCT \\
\hline Participants & $\begin{array}{l}1009 \text { participants with asymptomatic and symptomatic PAD were assessed for eligibility; } 156 \text { partici- } \\
\text { pants were randomised; after contacting authors, } 33 \text { randomised participants were affected by IC. }\end{array}$
\end{tabular}

Interventions Group 1: 24 weeks of supervised treadmill walking

Group 2: 24 weeks of supervised lower-extremity resistance training

Group 3 (control group): 11 nutritional information sessions over 6 months

\begin{tabular}{ll}
\hline Outcomes & $\begin{array}{l}\text { 6-minute walk test, short physical performance battery, brachial artery flow-mediated dilation, physi- } \\
\text { cal activity (accelerometry), maximum treadmill walking time, treadmill time to onset of leg symptoms, } \\
\text { SF-36 physical functioning score, WIQ, knee extension isometric strength/power, plantar flexion iso- } \\
\text { metric strength }\end{array}$ \\
\hline Notes & $\begin{array}{l}\text { We contacted the authors for more information regarding study results for the subgroup of participants } \\
\text { with intermittent claudication. }\end{array}$
\end{tabular}

\section{Risk of bias}

\begin{tabular}{|c|c|c|}
\hline Bias & Authors' judgement & Support for judgement \\
\hline $\begin{array}{l}\text { Random sequence genera- } \\
\text { tion (selection bias) }\end{array}$ & Low risk & $\begin{array}{l}\text { Participants were randomised by computer using a randomly permuted block } \\
\text { method. Randomisation was stratified by the presence versus absence of in- } \\
\text { termittent claudication. }\end{array}$ \\
\hline $\begin{array}{l}\text { Allocation concealment } \\
\text { (selection bias) }\end{array}$ & Low risk & $\begin{array}{l}\text { Participants were randomised by computer using a randomly permuted block } \\
\text { method. }\end{array}$ \\
\hline $\begin{array}{l}\text { Blinding of participants } \\
\text { and personnel (perfor- } \\
\text { mance bias) } \\
\text { All outcomes }\end{array}$ & Low risk & $\begin{array}{l}\text { In all of the included studies, participants and direct personnel could not be } \\
\text { blinded to the intervention (exercise). For this reason, bias could be intro- } \\
\text { duced. However, since all studies experienced the same limitation, we consid- } \\
\text { ered the risk of bias to be low for all studies. }\end{array}$ \\
\hline
\end{tabular}

Blinding of outcome as- Low risk Examiners were blinded to participant group assignment.
sessment (detection bias)

All outcomes

Incomplete outcome data Unclear risk (attrition bias)

All outcomes
ITT analyses were performed for drop-outs. Analyses were repeated using multiple imputation for persons who died or dropped out before completing 6-month follow-up testing. However, because of the study setting, it was not clear which participants with IC (instead of asymptomatic PAD) dropped out. The paper stated that missing data at follow-up were more common in more frail participants. On the other hand, the authors performed a sensitivity 
McDermott 2009 (Continued)

analysis and showed that the missing data were not likely to have significantly altered the findings.

\begin{tabular}{lll}
\hline $\begin{array}{l}\text { Selective reporting (re- } \\
\text { porting bias) }\end{array}$ & Low risk & $\begin{array}{l}\text { All relevant outcomes were described. Although not all secondary outcomes } \\
\text { were mentioned in the trial registration, all outcomes mentioned in the study } \\
\text { protocol were reported in the final draft of the paper. }\end{array}$ \\
\hline Other bias & Unclear risk & $\begin{array}{l}\text { Because of the study setting (the study included participants with asympto- } \\
\text { matic or symptomatic PAD), the baseline characteristics of the subgroup of } \\
\text { participants with IC were not described. We identified no other forms of bias. }\end{array}$ \\
\hline
\end{tabular}

Regensteiner 1996

\section{Study characteristics}

\begin{tabular}{ll}
\hline Methods & RCT \\
\hline Participants & $\begin{array}{l}44 \text { participants evaluated: } 15 \text { were excluded before randomisation; } 29 \text { participants were enrolled and } \\
\text { randomised. }\end{array}$ \\
\hline Interventions & $\begin{array}{l}\text { Group 1: } 12 \text { weeks of supervised walking exercise. Secondly, } 12 \text { weeks of additional supervised walking } \\
\text { exercise }\end{array}$ \\
& Group 2: 12 weeks of strength training. Secondly, 12 weeks of additional supervised walking exercise \\
& $\begin{array}{l}\text { Group 3 (control group): no treatment for } 12 \text { weeks. Secondly, } 12 \text { weeks of a combination of supervised } \\
\text { walking exercise and strength training }\end{array}$ \\
\hline Outcomes & Peak treadmill walking time, ABI (in rest and after exercise), WIQ score, Physical Activity Recall score, \\
Medical Outcomes Study Questionnaire score, Vitalog activity monitor
\end{tabular}

\section{Risk of bias}

\begin{tabular}{|c|c|c|}
\hline Bias & Authors' judgement & Support for judgement \\
\hline $\begin{array}{l}\text { Random sequence genera- } \\
\text { tion (selection bias) }\end{array}$ & Unclear risk & No information provided \\
\hline $\begin{array}{l}\text { Allocation concealment } \\
\text { (selection bias) }\end{array}$ & Unclear risk & No information provided \\
\hline $\begin{array}{l}\text { Blinding of participants } \\
\text { and personnel (perfor- } \\
\text { mance bias) } \\
\text { All outcomes }\end{array}$ & Low risk & $\begin{array}{l}\text { In all of the included studies, participants and direct personnel could not be } \\
\text { blinded to the intervention (exercise). For this reason, bias could be intro- } \\
\text { duced. However, since all studies experienced the same limitation, we consid- } \\
\text { ered the risk of bias to be low for all studies. }\end{array}$ \\
\hline \multirow[t]{2}{*}{$\begin{array}{l}\text { Blinding of outcome as- } \\
\text { sessment (detection bias) } \\
\text { All outcomes }\end{array}$} & Unclear risk & $\begin{array}{l}\text { To minimise the potential for bias in the self-evaluation of walking ability and } \\
\text { functional status, questionnaires were administered before the treadmill } \\
\text { test. Thus, participants' questionnaire responses were not influenced by their } \\
\text { treadmill exercise performance. In addition, the interviewer and participant } \\
\text { were blinded to previous questionnaire scores. }\end{array}$ \\
\hline & & $\begin{array}{l}\text { The paper did not describe whether examiners were blinded to participant } \\
\text { group assignment. }\end{array}$ \\
\hline
\end{tabular}


Regensteiner 1996 (Continued)

Incomplete outcome data Low risk Two participants in the control group were not available for follow-up at the (attrition bias)

12 -week evaluation. They were excluded from further analysis. In the super-

All outcomes

vised walking and strength training group, no missing outcome data were described.

Selective reporting (re- Low risk All relevant outcomes were described in the study results.
porting bias)

$\begin{array}{ll}\text { Other bias } \quad \text { Low risk } & \begin{array}{l}\text { No significant differences in baseline characteristics were found. We identified } \\ \text { no other forms of bias. }\end{array}\end{array}$

Ritta-Dias 2010

\section{Study characteristics}

\begin{tabular}{ll}
\hline Methods & RCT \\
\hline Participants & $\begin{array}{l}\text { 34 participants were randomised; } 4 \text { participants did not complete training; 30 participants completed } \\
\text { the study protocol (15 per group). }\end{array}$ \\
\hline Interventions & Group 1: 12 weeks of supervised treadmill exercise \\
& Group 2: 12 weeks of strength training \\
\hline Outcomes & $\begin{array}{l}\text { Initial claudication distance, total walking distance, peak } \mathrm{VO}_{2}, \mathrm{VO}_{2} \text { at the first stage of treadmill test, is- } \\
\text { chaemic window, leg strength with lower ABI, leg strength with higher ABI }\end{array}$ \\
\hline Notes & No ITT analysis
\end{tabular}

\section{Risk of bias}

\begin{tabular}{|c|c|c|}
\hline Bias & Authors' judgement & Support for judgement \\
\hline $\begin{array}{l}\text { Random sequence genera- } \\
\text { tion (selection bias) }\end{array}$ & Low risk & Randomisation was performed by computer random number generation. \\
\hline $\begin{array}{l}\text { Allocation concealment } \\
\text { (selection bias) }\end{array}$ & Low risk & Randomisation was performed by computer random number generation. \\
\hline $\begin{array}{l}\text { Blinding of participants } \\
\text { and personnel (perfor- } \\
\text { mance bias) } \\
\text { All outcomes }\end{array}$ & Low risk & $\begin{array}{l}\text { In all of the included studies, participants and direct personnel could not be } \\
\text { blinded to the intervention (exercise). For this reason, bias could be intro- } \\
\text { duced. However, since all studies experienced the same limitation, we consid- } \\
\text { ered the risk of bias to be low for all studies. }\end{array}$ \\
\hline $\begin{array}{l}\text { Blinding of outcome as- } \\
\text { sessment (detection bias) } \\
\text { All outcomes }\end{array}$ & Low risk & $\begin{array}{l}\text { Participants were evaluated at baseline (pre-training) and after } 12 \text { weeks of ex- } \\
\text { ercise training (post-training) by a physician who was blinded to the exercise } \\
\text { programme performed by participants. }\end{array}$ \\
\hline $\begin{array}{l}\text { Incomplete outcome data } \\
\text { (attrition bias) } \\
\text { All outcomes }\end{array}$ & Low risk & $\begin{array}{l}4 \text { participants ( } 2 \text { in the strength training groups and } 2 \text { in the walking exercise } \\
\text { groups) did not complete the training programmes for the following reasons: } \\
\text { inguinal hernia }(n=1) \text {, gastrointestinal infection }(n=1) \text {, ongoing treatment for } \\
\text { lung cancer }(n=1) \text {, and diagnosis of abdominal aneurysm }(n=1) \text {. } \\
\text { Although no ITT analysis was performed, reasons for missing data were plausi- } \\
\text { ble and well distributed among intervention groups. }\end{array}$ \\
\hline
\end{tabular}


Ritta-Dias 2010 (Continued)

Selective reporting (re- Low risk All relevant outcomes were described in the study results. porting bias)

Other bias Low risk

No significant differences in baseline characteristics were found. We identified no other forms of bias.

Sanderson 2006

\section{Study characteristics}

\begin{tabular}{ll}
\hline Methods & RCT \\
\hline Participants & 694 participants were assessed for eligibility; 43 participants were randomised. \\
\hline Interventions & Group 1: 6 weeks of supervised treadmill exercise \\
& Group 2: 6 weeks of supervised cycling \\
& Group 3 (control group): cardiovascular risk management and exercise advice \\
\hline Outcomes & Maximum walking time, pain-free walking time, maximum cycling time, pain-free cycling time, submax- \\
& imal and peak heart rate/VO ${ }_{2} /$ respiratory exchange ratio/minute ventilation \\
\hline Notes & $\begin{array}{l}\text { We contacted the authors and received relevant outcome data, which were not clearly described in the } \\
\text { paper. }\end{array}$ \\
\hline
\end{tabular}

\section{Risk of bias}

\begin{tabular}{|c|c|c|}
\hline Bias & Authors' judgement & Support for judgement \\
\hline $\begin{array}{l}\text { Random sequence genera- } \\
\text { tion (selection bias) }\end{array}$ & Low risk & $\begin{array}{l}\text { A closed-envelope system was used to randomise participants from the strat- } \\
\text { ified groups to a control group, a cycle-training group, or a treadmill training } \\
\text { group. }\end{array}$ \\
\hline $\begin{array}{l}\text { Allocation concealment } \\
\text { (selection bias) }\end{array}$ & Unclear risk & No information provided \\
\hline $\begin{array}{l}\text { Blinding of participants } \\
\text { and personnel (perfor- } \\
\text { mance bias) } \\
\text { All outcomes }\end{array}$ & Low risk & $\begin{array}{l}\text { In all of the included studies, participants and direct personnel could not be } \\
\text { blinded to the intervention (exercise). For this reason, bias could be intro- } \\
\text { duced. However, since all studies experienced the same limitation, we consid- } \\
\text { ered the risk of bias to be low for all studies. }\end{array}$ \\
\hline
\end{tabular}

Blinding of outcome as- Unclear risk No blinding of outcome assessment was described.
sessment (detection bias)

All outcomes

$\begin{array}{ll}\text { Incomplete outcome data Low risk } & \text { One participant in the treadmill training group withdrew after } 1 \text { week of train } \\ \text { (attrition bias) } & \text { ing. The baseline data have been omitted. }\end{array}$

All outcomes ing. The baseline data have been omitted.

\begin{tabular}{ll}
\hline $\begin{array}{l}\text { Selective reporting (re- } \\
\text { porting bias) }\end{array}$ & Low risk \\
& $\begin{array}{l}\text { Relevant outcome data for this review (maximum and pain-free walking time) } \\
\text { were only presented in a figure; no numerical data were given. However, after } \\
\text { contacting the authors, we collected these data. }\end{array}$
\end{tabular}

Other bias Low risk
No significant differences in baseline characteristics were found. We identified no other forms of bias. 
Szymczak 2016

\section{Study characteristics}

\begin{tabular}{ll}
\hline Methods & RCT \\
\hline Participants & $\begin{array}{l}50 \text { participants were randomised; the number of eligible patients and the number of participants that } \\
\text { completed follow-up were not provided. }\end{array}$ \\
\hline Interventions & Group 1: 12 weeks of supervised treadmill exercise \\
& Group 2: 12 weeks of lower limbs resistance training \\
\hline Outcomes & Initial claudication distance, absolute claudication distance, 6-minute walking test, ABI
\end{tabular}

\section{Risk of bias}

\begin{tabular}{|c|c|c|}
\hline Bias & Authors' judgement & Support for judgement \\
\hline $\begin{array}{l}\text { Random sequence genera- } \\
\text { tion (selection bias) }\end{array}$ & Unclear risk & "Patients were randomly assigned". No further information provided \\
\hline $\begin{array}{l}\text { Allocation concealment } \\
\text { (selection bias) }\end{array}$ & Unclear risk & "Patients were randomly assigned". No further information provided \\
\hline $\begin{array}{l}\text { Blinding of participants } \\
\text { and personnel (perfor- } \\
\text { mance bias) } \\
\text { All outcomes }\end{array}$ & Low risk & $\begin{array}{l}\text { In all of the included studies, participants and direct personnel could not be } \\
\text { blinded to the intervention (exercise). For this reason, bias could be intro- } \\
\text { duced. However, since all studies experienced the same limitation, we consid- } \\
\text { ered the risk of bias to be low for all studies. }\end{array}$ \\
\hline $\begin{array}{l}\text { Blinding of outcome as- } \\
\text { sessment (detection bias) } \\
\text { All outcomes }\end{array}$ & Unclear risk & No information provided \\
\hline $\begin{array}{l}\text { Incomplete outcome data } \\
\text { (attrition bias) } \\
\text { All outcomes }\end{array}$ & Unclear risk & $\begin{array}{l}\text { The text did not specify the number of eligible participants or the number of } \\
\text { participants that completed follow-up. There was no information about drop- } \\
\text { outs or types of analysis (ITT or per-protocol). }\end{array}$ \\
\hline $\begin{array}{l}\text { Selective reporting (re- } \\
\text { porting bias) }\end{array}$ & Low risk & All relevant outcomes were described in the study results. \\
\hline Other bias & Unclear risk & $\begin{array}{l}\text { The baseline characteristics were not clearly presented. According to the text } \\
\text { there was a significant difference for baseline ABI between groups. We identi- } \\
\text { fied no other forms of bias. }\end{array}$ \\
\hline
\end{tabular}

\section{Treat-Jacobson 2009}

\section{Study characteristics}

\begin{tabular}{ll}
\hline Methods & RCT \\
\hline Participants & 102 participants were assessed for eligibility; 45 participants were randomised. \\
\hline Interventions & Group 1: 12 weeks of arm ergometry \\
\hline
\end{tabular}


Treat-Jacobson 2009 (Continued)

Group 2: 12 weeks of supervised treadmill walking

Group 3: 12 weeks of a combination of arm ergometry and supervised treadmill walking

Group 4 (control group): usual care (cardiovascular management and exercise advice)

\begin{tabular}{ll}
\hline Outcomes & MWD, pain-free walking distance, resting ABI/heart rate/blood pressure, functional capacity $\left(\right.$ peak VO $\left.{ }_{2}\right)$ \\
\hline Notes & $\begin{array}{l}\text { The study paper mentioned only the change in walking distances. We were not able to retrieve the ab- } \\
\text { solute values at follow-up for the walking distances through contact with the authors. }\end{array}$
\end{tabular}

\section{Risk of bias}

\begin{tabular}{|c|c|c|}
\hline Bias & Authors' judgement & Support for judgement \\
\hline $\begin{array}{l}\text { Random sequence genera- } \\
\text { tion (selection bias) }\end{array}$ & Low risk & $\begin{array}{l}\text { Eligible participants were randomised by simple randomisation tables to } 1 \text { of } \\
\text { the } 4 \text { study groups. }\end{array}$ \\
\hline $\begin{array}{l}\text { Allocation concealment } \\
\text { (selection bias) }\end{array}$ & Unclear risk & No information provided \\
\hline $\begin{array}{l}\text { Blinding of participants } \\
\text { and personnel (perfor- } \\
\text { mance bias) } \\
\text { All outcomes }\end{array}$ & Low risk & $\begin{array}{l}\text { In all of the included studies, participants and direct personnel could not be } \\
\text { blinded to the intervention (exercise). For this reason, bias could be intro- } \\
\text { duced. However, since all studies experienced the same limitation, we consid- } \\
\text { ered the risk of bias to be low for all studies. }\end{array}$ \\
\hline $\begin{array}{l}\text { Blinding of outcome as- } \\
\text { sessment (detection bias) } \\
\text { All outcomes }\end{array}$ & Low risk & $\begin{array}{l}\text { The physician supervising the treadmill tests was blinded to treatment group } \\
\text { assignment. However, other staff assisting with testing were not blinded. To } \\
\text { mitigate for this limitation, care was taken to ensure standardisation of exer- } \\
\text { cise-testing protocols. }\end{array}$ \\
\hline $\begin{array}{l}\text { Incomplete outcome data } \\
\text { (attrition bias) } \\
\text { All outcomes }\end{array}$ & Low risk & $\begin{array}{l}\text { Incomplete outcome data are well described and equally distributed among } \\
\text { intervention groups. } 4 \text { of the } 45 \text { participants withdrew from the study before } \\
\text { completing exercise training ( } 2 \text { participants in the arm-ergometry group and } \\
2 \text { participants in the treadmill walking group). Therefore, only } 41 \text { participants } \\
\text { completed the } 12 \text {-week follow-up. } 31 \text { participants completed the } 24 \text {-week fol- } \\
\text { low-up. }\end{array}$ \\
\hline $\begin{array}{l}\text { Selective reporting (re- } \\
\text { porting bias) }\end{array}$ & Low risk & All relevant outcomes were described in the study results. \\
\hline Other bias & Low risk & $\begin{array}{l}\text { No significant differences in baseline characteristics were found. We identified } \\
\text { no other forms of bias. }\end{array}$ \\
\hline
\end{tabular}

ABI: ankle brachial index

IC: intermittent claudication

ITT: intention-to-treat

MI: myocardial infarction

MWD: maximal walking distance

PAD: peripheral arterial disease

PFWD: pain-free walking distance

QoL: quality of life

RCT: randomised controlled trial

SET: supervised exercise therapy

SF-36: 36-item Short Form Health Survey

SMM: skeletal muscle mass

$\mathrm{VO}_{2}$ : pulmonary oxygen uptake

WIQ: Walking Impairment Questionnaire 
Characteristics of excluded studies [ordered by study ID]

\begin{tabular}{|c|c|}
\hline Study & Reason for exclusion \\
\hline Dedes 2010 & Meeting poster; no journal article available \\
\hline Delaney 2014 & No correct outcome measures \\
\hline EXERT Study 2018 & $\begin{array}{l}\text { The original results of the EXERT study are not published. Only one publication is available com- } \\
\text { paring long-term follow-up ( } 1 \text { to } 4 \text { years) to end of study results ( } 24 \text { weeks). Baseline data were not } \\
\text { available from the authors. }\end{array}$ \\
\hline Gardner 2011 & Commentary on other journal article; not an RCT \\
\hline Jones 1996 & Outcome measures unclearly described; no information from authors \\
\hline Kao 2012 & Meeting poster; no article available (authors contacted) \\
\hline Kim 2006 & Commentary on other journal article; not an RCT \\
\hline Kuwabara 2010 & Meeting poster; no article available \\
\hline Nawaz 2001 & No intervention group with adequate supervised walking therapy; no correct outcome measures \\
\hline Oakley 2008 & No intervention group with adequate supervised walking therapy \\
\hline Ornelas 2011 & Meeting poster; no article available \\
\hline Parmenter 2013 & No control group with SET \\
\hline Parr 2009 & No intervention group with adequate supervised walking therapy \\
\hline Roitman 2010 & Editorial; not an RCT \\
\hline Saxton 2008 & No control group with adequate SET; no correct outcome measures \\
\hline Saxton 2011 & $\begin{array}{l}\text { No control group with adequate SET; no correct outcome measures (MWD assessed by shuttle-walk } \\
\text { test instead of protocolised treadmill test) }\end{array}$ \\
\hline Tebbutt 2011 & No control group with adequate SET \\
\hline Treat-Jacobson 2011 & No relevant outcome measures for this review assessed and reported \\
\hline Treat-Jacobson 2012 & Meeting poster; no journal article available; no control group with adequate SET \\
\hline Van Schaardenburgh 2017 & No control group with adequate SET \\
\hline Walker 2000 & No control group with adequate SET; no correct outcome measures (no treadmill test) \\
\hline Wang 2008 & No control group with SET \\
\hline Zwierska 2005 & No control group with adequate SET \\
\hline
\end{tabular}

MWD: maximum walking distance

$\mathrm{RCT}$ : randomised controlled trial

SET: supervised exercise therapy 
Characteristics of ongoing studies [ordered by study ID]

\section{ACTRN12616000243415}

Study name
Comparison of the effects of supervised treadmill walking training and supervised walking with poles on the functional capabilities, the function of endothelium and the metabolic cost of walking in patients with IC

\section{Methods}

$$
\text { Study type: interventional }
$$

Study design: RCT

Masking: open (no masking used)

Primary purpose: treatment

\begin{tabular}{|c|c|}
\hline Participants & $\begin{array}{l}\text { Recruitment status: completed } \\
\text { Number of participants: } 90 \\
\text { Inclusion criteria: } \\
\text { - Age: older than } 50 \text { years; } \\
\text { - Patients with atherosclerosis of lower extremities evaluated according to the Fontaine's classifi- } \\
\text { cation as degree IIA and IIB; } \\
\text { - ABI<0.9; } \\
\text { - No systemic contraindications to undertake the proposed forms of exercise; } \\
\text { - Written consent to participate in a clinical trial. } \\
\text { Exclusion criteria: } \\
\text { - Inability to walk on a treadmill at a speed of } 2 \text { mph; } \\
\text { - Recently completed vascular treatments (less than } 6 \text { months); } \\
\text { - Changes in pharmacological treatment (less than } 6 \text { months); } \\
\text { - Symptomatic coronary artery disease, exertional dyspnoea, resting blood pressure higher than } \\
160 / 100 \text { mmHg, resting tachycardia higher than } 100 / \text { min, thrombophlebitis, arterial embolism, } \\
\text { active cancer, exercise-induced asthma, cardiorespiratory failure (NYHA III) }\end{array}$ \\
\hline
\end{tabular}

- 12 weeks of supervised treadmill walking three times a week

- 12 weeks of supervised walking with poles three times a week

- A control group that will be instructed according to standard preventive recommendation and will not undergo walking training

\section{Outcomes}

All outcomes will be measured at baseline and after 12 weeks

Primary outcome measures:

- MWD (treadmill test, Gardner protocol)

- Vascular endothelial function (flow mediated dilatation)

- Metabolic cost of walking determined using oxygen consumption measure (graded treadmill walking test with simultaneous breath-by-breath $\mathrm{VO}_{2}$ measurements)

Secondary outcomes measures:

- PFWD (treadmill test, Gardner protocol)

- Functional walking ability (WIQ) 
ACTRN12616000243415 (Continued)

Date of last participant enrolment: March 2018

Date of last data collection: June 2018

\begin{tabular}{ll}
\hline Contact information & Miss Ewelina Rosloniec \\
& $\begin{array}{l}\text { Akademia Wychowania Fizycznego w Krakowie } \\
\text { Zawodzie } 1 \mathrm{a} / 18,31-232 \text { Krakow, Poland }\end{array}$ \\
\hline Notes & $\begin{array}{l}\text { We contacted the study authors: the study is completed, but results are not yet published or avail- } \\
\text { able. }\end{array}$ \\
\hline
\end{tabular}

\section{NCT03837639}

\begin{tabular}{ll}
\hline Study name & Effects of arm-crank exercise training on cardiovascular function of patients with PAD: an RCT \\
\hline Methods & Study type: interventional \\
Study design: RCT; parallel assignment & Masking: double (investigator, outcome assessor) \\
& Primary purpose: treatment \\
\hline Estimated enrolment: 45 participants \\
Inclusion criteria: \\
- Age 45 to 85 years \\
- PAD stage II \\
- ABI < 0.90 in one or both lower limbs \\
- Women in postmenopause phase without hormone replacement therapy \\
- Able to perform exercise training \\
Exclusion criteria: \\
- PAD stage I, III and IV \\
Presence of diabetic neuropathy \\
\hline
\end{tabular}

Interventions

There are three study arms:

- 12 weeks of supervised arm-crank exercise twice a week

- 12 weeks of supervised treadmill walking twice a week

- 12 weeks of active control sessions twice a week (patients will perform manual tasks without exercise component)

Primary outcome measure:

- Ambulatory blood pressure (systolic, diastolic and mean blood pressure)

Secondary outcome measures:

- Clinical blood pressure (systolic and diastolic blood pressure)

- Cardiac autonomic modulation (heart rate monitor)

- Arterial stiffness (pulse wave velocity) 
NCT03837639 (Continued)

- Vasodilatory capacity (flow mediated dilation)

Other measures (additional information on request, not described in trial registry):

- 6-minute walking test

- Functional capacity ( 2 questionnaires: Walking Estimated-Limitation Calculated by History (WELCH) and WIQ)

\begin{tabular}{ll}
\hline Starting date & Estimated starting date: April 2019 \\
\hline Contact information & Gabriel Cucato, PhD \\
& Hospital Israelita Albert Einstein, São Paulo, Brazil, 05652-900 \\
\hline Notes & We contacted Dr Cucato to confirm that functional tests will be performed. \\
\hline
\end{tabular}

$A B I$ : ankle brachial index

IC: intermittent claudication

mph: miles per hour

MWD: maximal walking distance

PAD: peripheral arterial disease

PFWD: pain-free walking distance

$\mathrm{RCT}$ : randomised controlled trial

WELCH: walking estimated-limitation calculated by history

WIQ: walking impairment questionnaire

\section{DATA AND ANALYSES}

\section{Comparison 1. Alternative modes of exercise versus walking exercise at 12 weeks}

\begin{tabular}{|c|c|c|c|c|}
\hline $\begin{array}{l}\text { Outcome or subgroup ti- } \\
\text { tle }\end{array}$ & No. of studies & $\begin{array}{l}\text { No. of partici- } \\
\text { pants }\end{array}$ & Statistical method & Effect size \\
\hline $\begin{array}{l}1.1 \text { Maximum walking dis- } \\
\text { tance }\end{array}$ & 6 & 274 & $\begin{array}{l}\text { Std. Mean Difference (IV, Random, 95\% } \\
\mathrm{Cl} \text { ) }\end{array}$ & $-0.01[-0.29,0.27]$ \\
\hline $\begin{array}{l}\text { 1.1.1 Lower-extremity re- } \\
\text { sistance training }\end{array}$ & 3 & 94 & $\begin{array}{l}\text { Std. Mean Difference (IV, Random, 95\% } \\
\mathrm{Cl} \text { ) }\end{array}$ & $-0.02[-0.59,0.55]$ \\
\hline 1.1.2 Nordic walking & 2 & 88 & $\begin{array}{l}\text { Std. Mean Difference (IV, Random, 95\% } \\
\mathrm{CI} \text { ) }\end{array}$ & $0.31[-0.12,0.74]$ \\
\hline $\begin{array}{l}\text { 1.1.3 Combined exercise } \\
\text { modes }\end{array}$ & 3 & 74 & $\begin{array}{l}\text { Std. Mean Difference (IV, Random, 95\% } \\
\mathrm{Cl} \text { ) }\end{array}$ & $-0.19[-0.66,0.29]$ \\
\hline 1.1.4 Arm ergometry & 1 & 18 & $\begin{array}{l}\text { Std. Mean Difference (IV, Random, 95\% } \\
\mathrm{Cl} \text { ) }\end{array}$ & $-0.84[-1.87,0.19]$ \\
\hline $\begin{array}{l}\text { 1.2 Pain-free walking dis- } \\
\text { tance }\end{array}$ & 5 & 249 & $\begin{array}{l}\text { Std. Mean Difference (IV, Random, 95\% } \\
\mathrm{Cl} \text { ) }\end{array}$ & $-0.01[-0.26,0.25]$ \\
\hline $\begin{array}{l}\text { 1.2.1 Lower-extremity re- } \\
\text { sistance training }\end{array}$ & 2 & 80 & $\begin{array}{l}\text { Std. Mean Difference (IV, Random, 95\% } \\
\mathrm{Cl} \text { ) }\end{array}$ & $0.11[-0.32,0.55]$ \\
\hline
\end{tabular}




\begin{tabular}{|c|c|c|c|c|}
\hline $\begin{array}{l}\text { Outcome or subgroup ti- } \\
\text { tle }\end{array}$ & No. of studies & $\begin{array}{l}\text { No. of partici- } \\
\text { pants }\end{array}$ & Statistical method & Effect size \\
\hline 1.2.2 Nordic walking & 2 & 88 & $\begin{array}{l}\text { Std. Mean Difference (IV, Random, 95\% } \\
\text { Cl) }\end{array}$ & $0.14[-0.28,0.57]$ \\
\hline $\begin{array}{l}\text { 1.2.3 Combined exercise } \\
\text { modes }\end{array}$ & 2 & 63 & $\begin{array}{l}\text { Std. Mean Difference (IV, Random, 95\% } \\
\mathrm{CI} \text { ) }\end{array}$ & $-0.22[-0.74,0.30]$ \\
\hline 1.2.4 Arm ergometry & 1 & 18 & $\begin{array}{l}\text { Std. Mean Difference (IV, Random, 95\% } \\
\mathrm{CI} \text { ) }\end{array}$ & $-0.65[-1.66,0.36]$ \\
\hline
\end{tabular}

\section{Analysis 1.1. Comparison 1: Alternative modes of exercise versus walking exercise at 12 weeks, Outcome 1: Maximum walking distance}

\begin{tabular}{|c|c|c|c|c|c|c|c|c|c|}
\hline \multirow[b]{2}{*}{ Study or Subgroup } & \multicolumn{3}{|c|}{ Alternative exercise mode } & \multicolumn{3}{|c|}{ Walking exercise } & \multirow[b]{2}{*}{ Weight } & \multirow{2}{*}{$\begin{array}{l}\text { Std. Mean Difference } \\
\text { IV, Random, } 95 \% \text { CI }\end{array}$} & \multirow{2}{*}{$\begin{array}{l}\text { Std. Mean Difference } \\
\text { IV, Random, } 95 \% \text { CI }\end{array}$} \\
\hline & Mean & SD & Total & Mean & SD & Total & & & \\
\hline \multicolumn{10}{|c|}{ 1.1.1 Lower-extremity resistance training } \\
\hline Regensteiner 1996 & 8.5 & 5.2 & 9 & 14.7 & 7.3 & 5 & $5.1 \%$ & $-0.97[-2.14,0.20]$ & \\
\hline Ritta-Dias 2010 & 775 & 334 & 15 & 721 & 289 & 15 & $12.0 \%$ & $0.17[-0.55,0.89]$ & - \\
\hline Szymczak 2016 & 402.7 & 501.6 & 26 & 318.3 & 230.8 & 24 & $17.7 \%$ & $0.21[-0.35,0.77]$ & \\
\hline Subtotal (95\% CI) & & & 50 & & & 44 & $34.8 \%$ & $-0.02[-0.59,0.55]$ & \\
\hline \multicolumn{10}{|c|}{ Heterogeneity: $\mathrm{Tau}^{2}=0.10 ; \mathrm{Chi}^{2}=3.33, \mathrm{df}=2(\mathrm{P}=0.19) ; \mathrm{I}^{2}=40 \%$} \\
\hline \multicolumn{10}{|c|}{ Test for overall effect: $\mathrm{Z}=0.07(\mathrm{P}=0.94)$} \\
\hline \multicolumn{10}{|l|}{ 1.1.2 Nordic walking } \\
\hline Bulinska 2016 & 363.67 & 225.19 & 21 & 290.23 & 222.28 & 31 & $17.6 \%$ & $0.32[-0.23,0.88]$ & - \\
\hline Kropielnicka 2018 & 372.7 & 231.64 & 21 & 303.09 & 228.71 & 15 & $13.5 \%$ & $0.30[-0.37,0.96]$ & \\
\hline Subtotal (95\% CI) & & & 42 & & & 46 & $31.1 \%$ & $0.31[-0.12,0.74]$ & \\
\hline \multicolumn{10}{|c|}{ Heterogeneity: $\mathrm{Tau}^{2}=0.00 ; \mathrm{Chi}^{2}=0.00, \mathrm{df}=1(\mathrm{P}=0.95) ; \mathrm{I}^{2}=0 \%$} \\
\hline \multicolumn{10}{|c|}{ Test for overall effect: $\mathrm{Z}=1.43(\mathrm{P}=0.15)$} \\
\hline \multicolumn{10}{|c|}{ 1.1.3 Combined exercise modes } \\
\hline Kropielnicka 2018 & 309.7 & 223.09 & 28 & 303.09 & 228.71 & 16 & $15.3 \%$ & $0.03[-0.59,0.64]$ & - \\
\hline Regensteiner 1996 & 11.8 & 6 & 6 & 14.7 & 7.3 & 5 & $4.9 \%$ & $-0.40[-1.61,0.80]$ & \\
\hline Treat-Jacobson 2009 & 658.5 & 160.6 & 12 & 778 & 252.6 & 7 & $7.4 \%$ & $-0.58[-1.53,0.38]$ & \\
\hline Subtotal $(95 \% \mathrm{CI})$ & & & 46 & & & 28 & $27.6 \%$ & $-0.19[-0.66,0.29]$ & \\
\hline \multicolumn{10}{|c|}{ Heterogeneity: $\mathrm{Tau}^{2}=0.00 ; \mathrm{Chi}^{2}=1.24, \mathrm{df}=2(\mathrm{P}=0.54) ; \mathrm{I}^{2}=0 \%$} \\
\hline \multicolumn{10}{|c|}{ Test for overall effect: $\mathrm{Z}=0.77(\mathrm{P}=0.44)$} \\
\hline \multicolumn{10}{|l|}{ 1.1.4 Arm ergometry } \\
\hline Treat-Jacobson 2009 & 603.7 & 166.6 & 12 & 778 & 252.6 & 6 & $6.5 \%$ & $-0.84[-1.87,0.19]$ & \\
\hline Subtotal (95\% CI) & & & 12 & & & 6 & $6.5 \%$ & $-0.84[-1.87,0.19]$ & \\
\hline \multicolumn{10}{|c|}{ Heterogeneity: Not applicable } \\
\hline \multicolumn{10}{|c|}{ Test for overall effect: $\mathrm{Z}=1.60(\mathrm{P}=0.11)$} \\
\hline Total $(95 \% \mathrm{CI})$ & & & 150 & & & 124 & $100.0 \%$ & $-0.01[-0.29,0.27]$ & \\
\hline \multicolumn{10}{|c|}{ Heterogeneity: $\mathrm{Tau}^{2}=0.03 ; \mathrm{Chi}^{2}=9.81, \mathrm{df}=8(\mathrm{P}=0.28) ; \mathrm{I}^{2}=18 \%$} \\
\hline Test for overall effect & $0.06(P=0$. & & & & & & & & $\begin{array}{cc}-1 & -1 \\
-2 & -1\end{array}$ \\
\hline Test for subgroup diff & es: $\mathrm{Chi}^{2}=5$ & $2, \mathrm{df}=3$ & $=0.16), I^{2}$ & $=42.5 \%$ & & & & & walking \\
\hline
\end{tabular}


Analysis 1.2. Comparison 1: Alternative modes of exercise versus walking exercise at 12 weeks, Outcome 2: Pain-free walking distance

\begin{tabular}{|c|c|c|c|c|c|c|c|c|c|}
\hline \multirow[b]{2}{*}{ Study or Subgroup } & \multicolumn{3}{|c|}{ Alternative exercise mode } & \multicolumn{3}{|c|}{ Walking exercise } & \multirow[b]{2}{*}{ Weight } & \multirow{2}{*}{$\begin{array}{l}\text { Std. Mean Difference } \\
\text { IV, Random, } 95 \% \text { CI }\end{array}$} & \multirow{2}{*}{$\begin{array}{l}\text { Std. Mean Difference } \\
\text { IV, Random, } 95 \% \text { CI }\end{array}$} \\
\hline & Mean & SD & Total & Mean & SD & Total & & & \\
\hline \multicolumn{10}{|c|}{ 1.2.1 Lower-extremity resistance training } \\
\hline Ritta-Dias 2010 & 504 & 276 & 15 & 469 & 237 & 15 & $12.6 \%$ & $0.13[-0.58,0.85]$ & 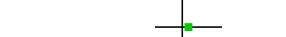 \\
\hline Szymczak 2016 & 186.7 & 211.9 & 26 & 168.5 & 113.2 & 24 & $21.0 \%$ & $0.10[-0.45,0.66]$ & \\
\hline Subtotal (95\% CI) & & & 41 & & & 39 & $33.6 \%$ & $0.11[-0.32,0.55]$ & \\
\hline \multicolumn{10}{|c|}{ Heterogeneity: $\mathrm{Tau}^{2}=0.00 ; \mathrm{Chi}^{2}=0.00, \mathrm{df}=1(\mathrm{P}=0.95) ; \mathrm{I}^{2}=0 \%$} \\
\hline \multicolumn{10}{|c|}{ Test for overall effect: $\mathrm{Z}=0.51(\mathrm{P}=0.61)$} \\
\hline \multicolumn{10}{|l|}{ 1.2.2 Nordic walking } \\
\hline Bulinska 2016 & 166.05 & 97.53 & 21 & 151.38 & 95.3 & 31 & $21.0 \%$ & $0.15[-0.40,0.70]$ & \\
\hline Kropielnicka 2018 & 169.21 & 98.63 & 21 & 155.96 & 96.83 & 15 & $14.7 \%$ & $0.13[-0.53,0.80]$ & \\
\hline Subtotal (95\% CI) & & & 42 & & & 46 & $35.7 \%$ & $0.14[-0.28,0.57]$ & \\
\hline \multicolumn{10}{|c|}{ Heterogeneity: $\mathrm{Tau}^{2}=0.00 ; \mathrm{Chi}^{2}=0.00, \mathrm{df}=1(\mathrm{P}=0.97) ; \mathrm{I}^{2}=0 \%$} \\
\hline \multicolumn{10}{|c|}{ Test for overall effect: $\mathrm{Z}=0.66(\mathrm{P}=0.51)$} \\
\hline \multicolumn{10}{|c|}{ 1.2.3 Combined exercise modes } \\
\hline Kropielnicka 2018 & 143.02 & 101.38 & 28 & 155.96 & 96.83 & 16 & $17.1 \%$ & $-0.13[-0.74,0.49]$ & \\
\hline Treat-Jacobson 2009 & 235.54 & 105.5 & 12 & 292 & 149.9 & 7 & $7.2 \%$ & $-0.44[-1.38,0.51]$ & \\
\hline Subtotal (95\% CI) & & & 40 & & & 23 & $24.3 \%$ & $-0.22[-0.74,0.30]$ & \\
\hline \multicolumn{10}{|c|}{ Heterogeneity: $\mathrm{Tau}^{2}=0.00 ; \mathrm{Chi}^{2}=0.29, \mathrm{df}=1(\mathrm{P}=0.59) ; \mathrm{I}^{2}=0 \%$} \\
\hline \multicolumn{10}{|c|}{ Test for overall effect: $\mathrm{Z}=0.84(\mathrm{P}=0.40)$} \\
\hline \multicolumn{10}{|l|}{ 1.2.4 Arm ergometry } \\
\hline Treat-Jacobson 2009 & 222.7 & 69.6 & 12 & 292 & 149.9 & 6 & $6.4 \%$ & $-0.65[-1.66,0.36]$ & \\
\hline Subtotal (95\% CI) & & & 12 & & & 6 & $6.4 \%$ & $-0.65[-1.66,0.36]$ & \\
\hline \multicolumn{10}{|c|}{ Heterogeneity: Not applicable } \\
\hline \multicolumn{10}{|c|}{ Test for overall effect: $\mathrm{Z}=1.26(\mathrm{P}=0.21)$} \\
\hline Total $(95 \%$ CI $)$ & & & 135 & & & 114 & $100.0 \%$ & $-0.01[-0.26,0.25]$ & \\
\hline \multicolumn{10}{|c|}{ Heterogeneity: $\mathrm{Tau}^{2}=0.00 ; \mathrm{Chi}^{2}=3.28, \mathrm{df}=6(\mathrm{P}=0.77) ; \mathrm{I}^{2}=0 \%$} \\
\hline Test for overall effect: & $0.04(\mathrm{P}=0$ & & & & & & & & $\begin{array}{ll}1 & 1 \\
-2 & -1\end{array}$ \\
\hline Test for subgroup diffe & es: $\mathrm{Chi}^{2}=2$ & $8, \mathrm{df}=3($ & $=0.39), \mathrm{I}^{2}$ & $=0 \%$ & & & & & Favours walking \\
\hline
\end{tabular}

Comparison 2. Alternative modes of exercise versus walking exercise at the end of training

\begin{tabular}{|c|c|c|c|c|}
\hline $\begin{array}{l}\text { Outcome or subgroup ti- } \\
\text { tle }\end{array}$ & No. of studies & $\begin{array}{l}\text { No. of partici- } \\
\text { pants }\end{array}$ & Statistical method & Effect size \\
\hline $\begin{array}{l}2.1 \text { Maximum walking dis- } \\
\text { tance }\end{array}$ & 9 & 412 & $\begin{array}{l}\text { Std. Mean Difference (IV, Random, } \\
95 \% \mathrm{CI} \text { ) }\end{array}$ & $-0.11[-0.33,0.11]$ \\
\hline $\begin{array}{l}\text { 2.1.1 Lower-extremity re- } \\
\text { sistance training }\end{array}$ & 4 & 127 & $\begin{array}{l}\text { Std. Mean Difference (IV, Random, } \\
95 \% \mathrm{CI} \text { ) }\end{array}$ & $-0.06[-0.48,0.35]$ \\
\hline 2.1.2 Nordic walking & 3 & 165 & $\begin{array}{l}\text { Std. Mean Difference (IV, Random, } \\
95 \% \mathrm{Cl} \text { ) }\end{array}$ & $0.04[-0.47,0.54]$ \\
\hline $\begin{array}{l}\text { 2.1.3 Combined exercise } \\
\text { modes }\end{array}$ & 3 & 74 & $\begin{array}{l}\text { Std. Mean Difference (IV, Random, } \\
95 \% \mathrm{CI})\end{array}$ & $-0.19[-0.66,0.29]$ \\
\hline 2.1.4 Arm ergometry & 1 & 18 & $\begin{array}{l}\text { Std. Mean Difference (IV, Random, } \\
95 \% \mathrm{CI})\end{array}$ & $-0.84[-1.87,0.19]$ \\
\hline 2.1.5 Cycling & 1 & 28 & $\begin{array}{l}\text { Std. Mean Difference (IV, Random, } \\
95 \% \mathrm{CI} \text { ) }\end{array}$ & $-0.31[-1.06,0.43]$ \\
\hline $\begin{array}{l}\text { 2.2 Pain-free walking dis- } \\
\text { tance }\end{array}$ & 8 & 382 & $\begin{array}{l}\text { Std. Mean Difference (IV, Random, } \\
95 \% \mathrm{Cl} \text { ) }\end{array}$ & $-0.06[-0.30,0.17]$ \\
\hline
\end{tabular}




\begin{tabular}{|c|c|c|c|c|}
\hline $\begin{array}{l}\text { Outcome or subgroup ti- } \\
\text { tle }\end{array}$ & No. of studies & $\begin{array}{l}\text { No. of partici- } \\
\text { pants }\end{array}$ & Statistical method & Effect size \\
\hline $\begin{array}{l}\text { 2.2.1 Lower-extremity re- } \\
\text { sistance training }\end{array}$ & 3 & 108 & $\begin{array}{l}\text { Std. Mean Difference (IV, Random, } \\
95 \% \mathrm{Cl})\end{array}$ & $0.01[-0.37,0.38]$ \\
\hline 2.2.2 Nordic walking & 3 & 165 & $\begin{array}{l}\text { Std. Mean Difference (IV, Random, } \\
95 \% \mathrm{CI})\end{array}$ & $0.21[-0.10,0.52]$ \\
\hline $\begin{array}{l}\text { 2.2.3 Combined exercise } \\
\text { modes }\end{array}$ & 2 & 63 & $\begin{array}{l}\text { Std. Mean Difference (IV, Random, } \\
95 \% \mathrm{CI} \text { ) }\end{array}$ & $-0.22[-0.74,0.30]$ \\
\hline 2.2.4 Arm ergometry & 1 & 18 & $\begin{array}{l}\text { Std. Mean Difference (IV, Random, } \\
95 \% \mathrm{CI} \text { ) }\end{array}$ & $-0.65[-1.66,0.36]$ \\
\hline 2.2.5 Cycling & 1 & 28 & $\begin{array}{l}\text { Std. Mean Difference (IV, Random, } \\
95 \% \mathrm{CI} \text { ) }\end{array}$ & $-1.01[-1.81,-0.22]$ \\
\hline $\begin{array}{l}\text { 2.3 Functional impairment } \\
\text { (WIQ distance score) }\end{array}$ & 2 & 96 & Mean Difference (IV, Random, 95\% CI) & $-5.52[-17.41,6.36]$ \\
\hline $\begin{array}{l}\text { 2.3.1 Lower-extremity re- } \\
\text { sistance training }\end{array}$ & 1 & 19 & Mean Difference (IV, Random, 95\% CI) & $-14.00[-36.64,8.64]$ \\
\hline 2.3.2 Nordic walking & 1 & 77 & Mean Difference (IV, Random, 95\% CI) & $-2.30[-16.26,11.66]$ \\
\hline
\end{tabular}




\section{Analysis 2.1. Comparison 2: Alternative modes of exercise versus walking} exercise at the end of training, Outcome 1: Maximum walking distance

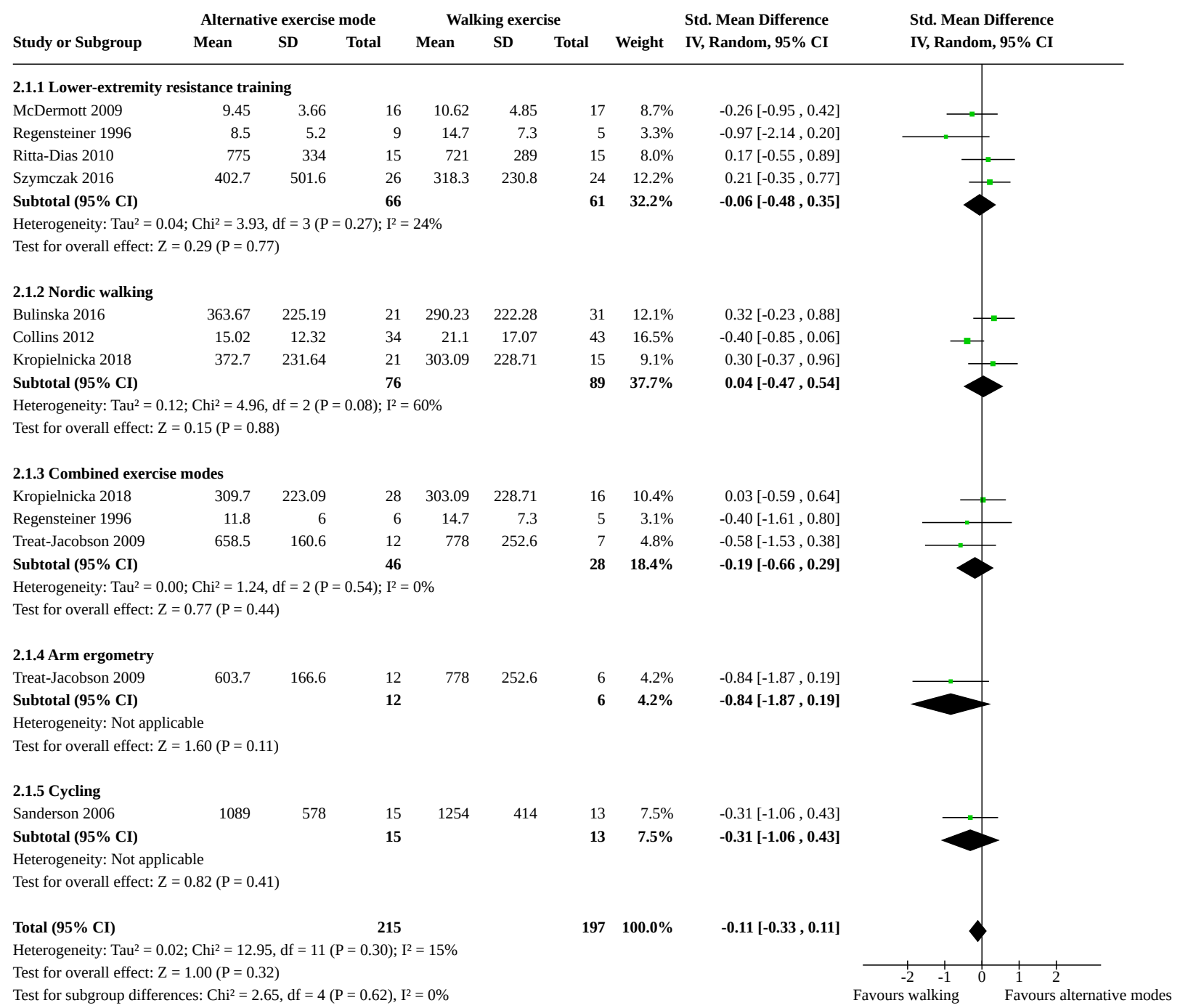


Analysis 2.2. Comparison 2: Alternative modes of exercise versus walking exercise at the end of training, Outcome 2: Pain-free walking distance

\begin{tabular}{|c|c|c|c|c|c|c|c|c|c|}
\hline \multirow{2}{*}{ Study or Subgroup } & \multicolumn{3}{|c|}{ Alternative exercise mode } & \multicolumn{3}{|c|}{ Walking exercise } & \multirow[b]{2}{*}{ Weight } & \multirow{2}{*}{$\begin{array}{l}\text { Std. Mean Difference } \\
\text { IV, Random, 95\% CI }\end{array}$} & \multirow{2}{*}{$\begin{array}{l}\text { Std. Mean Difference } \\
\text { IV, Random, } 95 \% \text { CI }\end{array}$} \\
\hline & Mean & SD & Total & Mean & SD & Total & & & \\
\hline \multicolumn{10}{|c|}{ 2.2.1 Lower-extremity resistance training } \\
\hline McDermott 2009 & 4.59 & 2.63 & 13 & 5.62 & 3.66 & 15 & $8.3 \%$ & $-0.31[-1.06,0.44]$ & \\
\hline Ritta-Dias 2010 & 504 & 276 & 15 & 469 & 237 & 15 & $8.9 \%$ & $0.13[-0.58,0.85]$ & \\
\hline Szymczak 2016 & 186.7 & 211.9 & 26 & 168.5 & 113.2 & 24 & $13.1 \%$ & $0.10[-0.45,0.66]$ & \\
\hline Subtotal (95\% CI) & & & 54 & & & 54 & $30.3 \%$ & $0.01[-0.37,0.38]$ & \\
\hline \multicolumn{10}{|c|}{ Heterogeneity: $\mathrm{Tau}^{2}=0.00 ; \mathrm{Chi}^{2}=0.93, \mathrm{df}=2(\mathrm{P}=0.63) ; \mathrm{I}^{2}=0 \%$} \\
\hline \multicolumn{10}{|c|}{ Test for overall effect: $\mathrm{Z}=0.03(\mathrm{P}=0.98)$} \\
\hline \multicolumn{10}{|l|}{ 2.2.2 Nordic walking } \\
\hline Bulinska 2016 & 166.05 & 97.53 & 21 & 151.38 & 95.3 & 31 & $13.1 \%$ & $0.15[-0.40,0.70]$ & $-1-$ \\
\hline Collins 2012 & 9.3 & 12.1 & 34 & 6.8 & 4.8 & 43 & $17.3 \%$ & $0.28[-0.17,0.73]$ & - \\
\hline Kropielnicka 2018 & 169.21 & 98.63 & 21 & 155.96 & 96.83 & 15 & $10.0 \%$ & $0.13[-0.53,0.80]$ & \\
\hline Subtotal (95\% CI) & & & 76 & & & 89 & $40.5 \%$ & $0.21[-0.10,0.52]$ & \\
\hline \multicolumn{10}{|c|}{ Heterogeneity: $\mathrm{Tau}^{2}=0.00 ; \mathrm{Chi}^{2}=0.19, \mathrm{df}=2(\mathrm{P}=0.91) ; \mathrm{I}^{2}=0 \%$} \\
\hline \multicolumn{10}{|c|}{ Test for overall effect: $\mathrm{Z}=1.32(\mathrm{P}=0.19)$} \\
\hline \multicolumn{10}{|c|}{ 2.2.3 Combined exercise modes } \\
\hline Kropielnicka 2018 & 143.02 & 101.38 & 28 & 155.96 & 96.83 & 16 & $11.3 \%$ & $-0.13[-0.74,0.49]$ & \\
\hline Treat-Jacobson 2009 & 235.54 & 105.5 & 12 & 292 & 149.9 & 7 & $5.6 \%$ & $-0.44[-1.38,0.51]$ & \\
\hline Subtotal (95\% CI) & & & 40 & & & 23 & $16.8 \%$ & $-0.22[-0.74,0.30]$ & \\
\hline \multicolumn{10}{|c|}{ Heterogeneity: $\mathrm{Tau}^{2}=0.00 ; \mathrm{Chi}^{2}=0.29, \mathrm{df}=1(\mathrm{P}=0.59) ; \mathrm{I}^{2}=0 \%$} \\
\hline \multicolumn{10}{|c|}{ Test for overall effect: $\mathrm{Z}=0.84(\mathrm{P}=0.40)$} \\
\hline \multicolumn{10}{|l|}{ 2.2.4 Arm ergometry } \\
\hline Treat-Jacobson 2009 & 222.7 & 69.6 & 12 & 292 & 149.9 & 6 & $4.9 \%$ & $-0.65[-1.66,0.36]$ & \\
\hline Subtotal (95\% CI) & & & 12 & & & 6 & $4.9 \%$ & $-0.65[-1.66,0.36]$ & \\
\hline \multicolumn{10}{|c|}{ Heterogeneity: Not applicable } \\
\hline \multicolumn{10}{|c|}{ Test for overall effect: $\mathrm{Z}=1.26(\mathrm{P}=0.21)$} \\
\hline \multicolumn{10}{|l|}{ 2.2.5 Cycling } \\
\hline Sanderson 2006 & 263 & 293 & 15 & 607 & 369 & 13 & $7.5 \%$ & $-1.01[-1.81,-0.22]$ & . \\
\hline Subtotal (95\% CI) & & & 15 & & & 13 & $7.5 \%$ & $-1.01[-1.81,-0.22]$ & \\
\hline \multicolumn{10}{|c|}{ Heterogeneity: Not applicable } \\
\hline \multicolumn{10}{|c|}{ Test for overall effect: $\mathrm{Z}=2.49(\mathrm{P}=0.01)$} \\
\hline Total $(95 \%$ CI) & & & 197 & & & 185 & $100.0 \%$ & $-0.06[-0.30,0.17]$ & \\
\hline \multicolumn{10}{|c|}{ Heterogeneity: $\mathrm{Tau}^{2}=0.03 ; \mathrm{Chi}^{2}=11.51, \mathrm{df}=9(\mathrm{P}=0.24) ; \mathrm{I}^{2}=22 \%$} \\
\hline Test for overall effect: & $0.54(\mathrm{P}=0$ & & & & & & & & $\begin{array}{cc}1 & 1 \\
-2 & -1\end{array}$ \\
\hline Test for subgroup diff & es: $\mathrm{Chi}^{2}=1$ & $10, \mathrm{df}=4$ & $=0.04)$, & $\mathrm{I}^{2}=60.4 \%$ & & & & & Favours walking \\
\hline
\end{tabular}

\section{Analysis 2.3. Comparison 2: Alternative modes of exercise versus walking exercise at the end of training, Outcome 3: Functional impairment (WIQ distance score)}

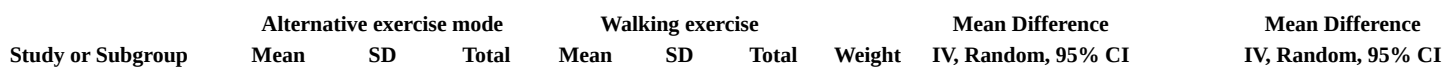

2.3.1 Lower-extremity resistance training

Regensteiner $1996 \quad 42.5 \quad 22.6$

Subtotal (95\% CI)

Heterogeneity: Not applicable

Test for overall effect: $\mathrm{Z}=1.21(\mathrm{P}=0.23)$

2.3.2 Nordic walking

Collins 2012

Subtotal (95\% CI)

$45.5 \quad 31.7$

34
34

$47.8 \quad 30.2$

$43 \quad 72.4 \%$

$43 \quad 72.4 \%$

eterogeneity: Not applicable

Test for overall effect: $\mathrm{Z}=0.32(\mathrm{P}=0.75)$

Total (95\% CI)

43

Heterogeneity: $\mathrm{Tau}^{2}=0.00 ; \mathrm{Chi}^{2}=0.74, \mathrm{df}=1(\mathrm{P}=0.39) ; \mathrm{I}^{2}=0 \%$

Test for overall effect: $\mathrm{Z}=0.91(\mathrm{P}=0.36)$

Test for subgroup differences: $\mathrm{Chi}^{2}=0.74, \mathrm{df}=1(\mathrm{P}=0.39), \mathrm{I}^{2}=0 \%$
$-2.30[-16.26,11.66]$

$-14.00[-36.64,8.64]$ $-14.00[-36.64,8.64]$

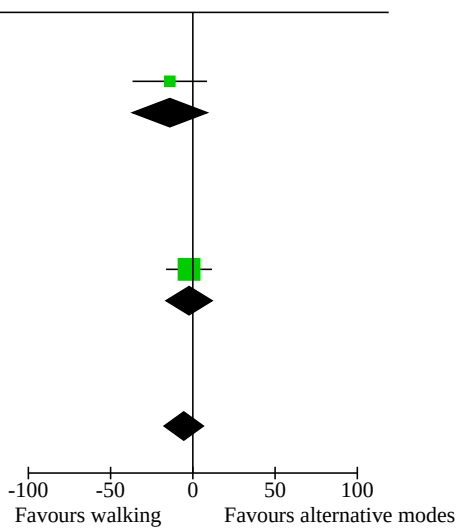




\section{ADDITIONAL TABLES}

Table 1. Glossary of abbreviations and definitions

\begin{tabular}{ll}
\hline Abbreviations & Confidence interval \\
\hline CI & Health-related quality of life \\
\hline IC & Intermittent claudication \\
\hline MD & Mean difference \\
\hline MWD & Maximum walking distance \\
\hline PFWD & Pain-free walking distance \\
\hline PAD & Peripheral arterial disease \\
\hline RCT & Randomised controlled trial \\
\hline SD & Standard deviation \\
\hline SMD & Standardised mean difference \\
\hline WIQ & Walking impairment questionnaire \\
\hline
\end{tabular}

\section{Definitions}

Arm-ergometry

Ergometry is a heart rate increasing activity. In arm-ergometry, an arm ergometer is used (also referred to as an arm cycle or arm crank), which is an alternative to the treadmill or leg cycle.

Endothelial and mitochondrial This means that the endothelial cells and mitochondria do not function as well as they should due dysfunction to a disease or condition. Endothelial cells form a thin layer that line the interior surface of blood vessels. Mitochondria lay within a cell and produce the energy necessary for the cell's survival and functioning.

\section{Endothelial flow-mediated} dilatation
Flow-mediated dilatation refers to dilatation (widening) of a blood vessel when blood flow increases in that vessel. This process is primarily regulated by endothelial cells, which form a thin layer that line the interior surface of blood vessels.

Metabolic adaptation

This is the process by which the body (e.g. the skeletal muscle) alters how efficient it is at obtaining energy and this increases capacity.

Pain tolerance

Pain tolerance is the maximum level of pain that a person is able to tolerate. 


\section{APPENDICES}

\section{Appendix 1. Database search strategies}

\begin{tabular}{|c|c|c|}
\hline Source & Search strategy & Hits retrieved \\
\hline \multirow[t]{30}{*}{ CENTRAL (2013 - 2019) } & \#1 MESH DESCRIPTOR Arteriosclerosis 948 & 1766 \\
\hline & \#2 MESH DESCRIPTOR Arteriolosclerosis EXPLODE ALL TREES 0 & \\
\hline & \#3 MESH DESCRIPTOR Arteriosclerosis Obliterans EXPLODE ALL TREES 81 & \\
\hline & \#4 MESH DESCRIPTOR Atherosclerosis 1092 & \\
\hline & \#5 MESH DESCRIPTOR Arterial Occlusive Diseases 831 & \\
\hline & \#6 MESH DESCRIPTOR Intermittent Claudication EXPLODE ALL TREES 839 & \\
\hline & \#7 MESH DESCRIPTOR Peripheral Vascular Diseases EXPLODE ALL TREES 2835 & \\
\hline & \#8 (atherosclero* or arteriosclero* or PVD or PAOD or PAD):TI,AB,KY 11697 & \\
\hline & \#9 ((arter ${ }^{\star}$ or vascular or vein ${ }^{\star}$ or veno* or peripher $\left.^{\star}\right)$ adj3 (occlus ${ }^{\star}$ or steno* or & \\
\hline & obstruct $^{\star}$ or lesio* or block* or harden* or stiffen* or obliter*)):TI,AB,KY 10266 & \\
\hline & \#10 (peripheral adj3 dis*):TI,AB,KY 4857 & \\
\hline & \#11 (claudic* or IC):TI,AB,KY 3745 & \\
\hline & $\# 12$ arteriopathic: $\mathrm{TI}, \mathrm{AB}, \mathrm{KY} 7$ & \\
\hline & $\# 13$ dysvascular*:TI,AB,KY 23 & \\
\hline & $\begin{array}{l}\# 14\left(\text { leg adj3 }\left(\text { occlus }^{\star} \text { or steno* or obstruct }{ }^{\star} \text { or lesio* } \text { or block }^{*} \text { or harden }{ }^{\star} \text { or }\right.\right. \\
\left.\text { stiffen }^{\star} \text { or obliter }{ }^{\star}\right) \text { :TI,AB,KY } 128\end{array}$ & \\
\hline & $\begin{array}{l}\# 15 \text { (limb adj3 (occlus* or steno* or obstruct }{ }^{\star} \text { or lesio* or block* or harden* or } \\
\left.\left.\text { stiffen* or obliter }{ }^{\star}\right)\right): T I, A B, K Y 220\end{array}$ & \\
\hline & $\begin{array}{l}\# 16 \text { (lower adj3 extrem* adj3 }\left(\text { occlus }^{\star} \text { or steno* } \text { or obstruct* }^{\star} \text { or lesio* or block* }\right. \\
\left.\left.\text { or harden }{ }^{\star} \text { or stiffen* or obliter }{ }^{\star}\right)\right): T I, A B, K Y 93\end{array}$ & \\
\hline & \#17 ((iliac or femoral or popliteal or femoro* or fempop* or crural or tibial) & \\
\hline & $\operatorname{adj}\left(\right.$ occlus $^{\star}$ or steno* or obstruct ${ }^{\star}$ or lesio* or block ${ }^{*}$ or harden ${ }^{\star}$ or stiffen ${ }^{\star}$ or & \\
\hline & \#18 MECH RECCPIPTOP Ulias Artery EYDI ORE A I TPEEC 150 & \\
\hline & & \\
\hline & \#19 MESH DESCRIPTOR Popliteal Artery EXPLODE ALL TREES 314 & \\
\hline & \#20 MESH DESCRIPTOR Femoral Artery EXPLODE ALL TREES 927 & \\
\hline & \#21 MESH DESCRIPTOR Tibial Arteries EXPLODE ALL TREES 40 & \\
\hline & \#22 \#1 OR \#2 OR \#3 OR \#4 OR \#5 OR \#6 OR \#7 OR \#8 OR \#9 OR \#10 OR \#11 OR & \\
\hline & \#12 OR \#13 OR \#14 OR \#15 OR \#16 OR \#17 OR \#18 OR \#19 OR \#20 OR \#21 29244 & \\
\hline & \#23 MESH DESCRIPTOR Exercise EXPLODE ALL TREES 21271 & \\
\hline & \#24 MESH DESCRIPTOR Dancing 152 & \\
\hline & \#25 MESH DESCRIPTOR Sports EXPLODE ALL TREES 14172 & \\
\hline & \#26 MESH DESCRIPTOR Exercise Therapy EXPLODE ALL TREES 11534 & \\
\hline
\end{tabular}


\#27 (physical adj (exercise* or exertion or endurance or therapy or conditioning or activity or activities or fitness or training)):TI,AB, KY 38005

\#28 (exercise adj (training or intervention or programme or therapy or activity or regime)):TI,AB,KY 22027

\#29 (fitness adj (training or intervention or protocol or programme or therapy or activity or regime)):TI,AB,KY 1383

\#30 ((training or conditioning) adj (circuit or intervention or protocol or programme or activity or regime)):TI,AB,KY 5603

\#31 (walk or walking or run or running or treadmill or aerobic or swim or swimming or dance or dancing or cycling or cyclist):TI,AB,KY 43589

\#32 kinesiotherap*:TI,AB,KY 2187

\#33 ((endurance or aerobic or cardio*) adj (fitness or training or intervention or protocol or program* or therapy or activity or regime)):TI,AB,KY 14421

\#34 \#23 OR \#24 OR \#25 OR \#26 OR \#27 OR \#28 OR \#29 OR \#30 OR \#31 OR \#32 OR \#33 94718

\#35 \#22 AND \#34 3281

\#36 01/01/2013 TO 04/03/2019:CD 629526

\#37 \#35 AND \#36 1766

Clinicaltrials.gov (2013 - 2019)

\section{ICTRP Search Portal} (2013 - 2019)
Intermittent Claudication OR Peripheral Vascular Diseases OR Peripheral Arterial Disease OR Arterial Occlusive Diseases | Exercise Therapy OR Exercise OR Resistance Training OR walking OR dancing OR running OR run OR cycling OR cyclist OR treadmill OR aerobic OR kinesiotherap* $\mid$ Start date on or after $01 / 01 / 2013$ | Last update posted on or before $03 / 04 / 2019$
Intermittent Claudication OR Peripheral Vascular Diseases OR Peripheral Arterial Disease OR Arterial Occlusive Diseases | Exercise Therapy OR Exercise OR Resistance Training OR walking OR dancing OR running OR run OR cycling OR cyclist OR treadmill OR aerobic OR kinesiotherap*
1 Intermittent Claudication/

Medline (Ovid
MEDLINE ${ }^{\circledR}$ Epub Ahead
of Print, In-Process
\& Other Non-In-
dexed Citations, Ovid
MEDLINE ${ }^{\circledR}$ Daily and
Ovid MEDLINE ${ }^{\circledR}$ ) (2013-
2019)

2 exp Peripheral Vascular Diseases/

3 exp Peripheral Arterial Disease/

4 exp Arterial Occlusive Diseases/

5 exp Leg/bs [Blood Supply]

6 Iliac Artery/

7 Popliteal Artery/

8 Femoral Artery/

9 Tibial Arteries/

10 (PVD or PAOD or PAD).ti,ab.

11 ((arter* or vascular or vein ${ }^{\star}$ or veno* or peripher $^{\star}$ ) adj3 (occlus ${ }^{\star}$ or steno* or obstruct $^{\star}$ or lesio* or block $^{\star}$ or harden ${ }^{\star}$ or stiffen ${ }^{\star}$ or obliter $\left.\left.{ }^{\star}\right)\right)$.ti,ab.

12 (peripheral adj3 dis*).ti,ab. 
13 claudic $^{\star} . \mathrm{ti}, \mathrm{ab}$.

14 arteriopathic.ti,ab.

15 dysvascular*.ti,ab.

16 (leg adj3 (occlus ${ }^{*}$ or steno* or obstruct* or lesio* or block ${ }^{\star}$ or harden ${ }^{\star}$ or stiffen* ${ }^{\star}$ or obliter $\left.\left.{ }^{\star}\right)\right)$. ti,ab.

17 (limb adj3 (occlus* or steno* or obstruct* or lesio* or block* or harden* or stiffen* or obliter $\left.\left.{ }^{\star}\right)\right)$. ti,ab.

18 (lower adj3 extrem*) adj3 (occlus* or steno* or obstruct* or lesio* or block ${ }^{\star}$ or harden* or stiffen* or obliter $\left.\left.{ }^{\star}\right)\right) . t i, a b$.

19 ((iliac or femoral or popliteal or femoro* or fempop* or crural or tibial) adj3 (occlus* or steno* or obstruct* or lesio* or block* or harden* or stiffen* or obliter $\left.\left.{ }^{\star}\right)\right) . t i, a b$.

20 or/1-19

21 exp Exercise/

22 exp Exercise Therapy/

23 exp Resistance Training/

24 exp Walking/

25 Dancing/

26 (physical adj (exercise* or exertion or endurance or therapy or conditioning or activity or activities or fitness or training)).ti,ab.

27 (exercise adj (training or intervention or programme or therapy or activity or regime)).ti,ab.

28 (fitness adj (training or intervention or protocol or programme or therapy or activity or regime)).ti,ab.

29 ((training or conditioning) adj (circuit or intervention or protocol or programme or activity or regime)).ti,ab.

30 (walk or walking or run or running or treadmill or aerobic or swim or swimming or dance or dancing or cycling or cyclist).ti,ab.

31 kinesiotherap ${ }^{\star} . t i, a b$.

32 ((endurance or aerobic or cardio*) adj (fitness or training or intervention or protocol or program* or therapy or activity or regime)).ti,ab.

33 or/21-32

3420 and 33

35 randomized controlled trial.pt.

36 controlled clinical trial.pt.

37 randomized.ab.

38 placebo.ab.

39 drug therapy.fs.

40 randomly.ab. 
41 trial.ab.

42 groups.ab.

43 or $/ 35-42$

44 exp animals/ not humans.sh.

4543 not 44

4634 and 45

$47\left(2013^{\star}\right.$ or $2014^{\star}$ or $2015^{\star}$ or $2016^{\star}$ or $2017^{\star}$ or $2018^{\star}$ or $\left.2019^{\star}\right)$.ed.

4846 and 47

2 peripheral vascular disease/

3 peripheral occlusive artery disease/

4 iliac artery/

5 popliteal artery/

6 femoral artery/

7 tibial artery/

8 (PVD or PAOD).ti,ab.

9 ((arter ${ }^{\star}$ or vascular or vein* or veno* or peripher $\left.{ }^{\star}\right)$ adj3 (occlus* or steno* or obstruct $^{\star}$ or lesio* or block ${ }^{\star}$ or harden* or stiffen ${ }^{\star}$ or obliter $\left.\left.{ }^{\star}\right)\right)$. ti,ab.

10 (peripheral adj3 dis $\left.{ }^{\star}\right) . t i, a b$.

11 claudic ${ }^{\star}$.ti,ab.

12 arteriopathic.ti,ab.

13 dysvascular*.ti,ab.

14 (leg adj3 (occlus ${ }^{*}$ or steno* or obstruct* or lesio* or block ${ }^{*}$ or harden ${ }^{\star}$ or stiffen* ${ }^{\star}$ or obliter $\left.{ }^{\star}\right)$ ).ti,ab.

15 (limb adj3 (occlus* or steno* or obstruct* or lesio* or block ${ }^{\star}$ or harden* or stiffen ${ }^{\star}$ or obliter $\left.\left.{ }^{\star}\right)\right) . t i, a b$.

16 (lower adj3 extrem* adj3 (occlus* or steno* or obstruct* or lesio* or block ${ }^{*}$ or harden* or stiffen* or obliter $\left.\left.{ }^{\star}\right)\right) . t i, a b$.

17 ((iliac or femoral or popliteal or femoro* or fempop* or crural or tibial) adj3 (occlus* or steno* or obstruct* or lesio* or block* or harden* or stiffen* or obliter $\left.{ }^{\star}\right)$.ti,ab.

18 or $/ 1-17$

19 exp exercise/

20 exp kinesiotherapy/

21 exp resistance training/

22 exp walking/

23 exp dancing/ 
24 (physical adj (exercise* or exertion or endurance or therapy or conditioning or activity or activities or fitness or training)).ti,ab.

25 (exercise adj (training or intervention or programme or therapy or activity or regime)).ti,ab.

26 (fitness adj (training or intervention or protocol or programme or therapy or activity or regime)).ti,ab.

27 ((training or conditioning) adj (circuit or intervention or protocol or programme or activity or regime)).ti,ab.

28 (walk or walking or run or running or treadmill or aerobic or swim or swimming or dance or dancing or cycling or cyclist).ti,ab.

29 kinesiotherap*.ti,ab.

30 ((endurance or aerobic or cardio*) adj (fitness or training or intervention or protocol or program* or therapy or activity or regime)).ti,ab.

31 or/19-30

3218 and 31

33 randomized controlled trial/

34 controlled clinical trial/

35 random\$.ti,ab.

36 randomization/

37 intermethod comparison/

38 placebo.ti,ab.

39 (compare or compared or comparison).ti.

40 ((evaluated or evaluate or evaluating or assessed or assess) and (compare or compared or comparing or comparison)).ab.

41 (open adj label).ti,ab.

42 ((double or single or doubly or singly) adj (blind or blinded or blindly)).ti,ab.

43 double blind procedure/

44 parallel group $\$ 1 . t i, a b$.

45 (crossover or cross over).ti,ab.

46 ((assign\$ or match or matched or allocation) adj5 (alternate or group\$1 or intervention $\$ 1$ or patient $\$ 1$ or subject $\$ 1$ or participant $\$ 1)) . t i, a b$.

47 (assigned or allocated).ti,ab.

48 (controlled adj7 (study or design or trial)).ti,ab.

49 (volunteer or volunteers).ti,ab.

50 trial.ti.

51 or $/ 33-50$

5232 and 51

$53\left(2013^{\star}\right.$ or $2014^{\star}$ or $2015^{\star}$ or $2016^{\star}$ or $2017^{\star}$ or $2018^{\star}$ or $\left.2019^{\star}\right)$.em. 
S49 EM 2017 OR EM 2018 OR EM 2019

S48 S34 AND S47

S47 S35 OR S36 OR S37 OR S38 OR S39 OR S40 OR S41 OR S42 OR S43 OR S44 OR S45 OR S46

S46 MH "Random Assignment"

S45 MH "Single-Blind Studies" or MH "Double-Blind Studies" or MH "TripleBlind Studies"

S44 MH "Crossover Design"

S43 MH "Factorial Design"

S42 MH "Placebos"

S41 MH "Clinical Trials"

S40 TX "multi-centre study" OR "multi-center study" OR "multicentre study" OR "multicenter study" OR "multi-site study"

S39 TX crossover OR "cross-over"

S38 AB placebo*

S37 TX random*

S36 TX trial*

S35 TX "latin square"

S34 S19 AND S33

S33 S20 OR S21 OR S22 OR S23 OR S24 OR S25 OR S26 OR S27 OR S28 OR S29 OR S30 OR S31 OR S32

S32 TX (endurance or aerobic or cardio*) N (fitness or training or intervention or protocol or program* or therapy or activity or regime)

\section{S31 TX kinesiotherap*}

S30 TX walk or walking or run or running or treadmill or aerobic or swim or swimming or dance or dancing or cycling or cyclist

S29 TX training or conditioning) N (circuit or intervention or protocol or programme or activity or regime)

S28 TX fitness N (training or intervention or protocol or programme or therapy or activity or regime)

S27 TX exercise N (training or intervention or programme or therapy or activity or regime)

S26 TX physical N (exercise* or exertion or endurance or therapy or conditioning or activity or activities or fitness or training))

S25 (MH "Dancing+")

S24 (MH "Nordic Walking") 


\author{
S23 (MH "Walking+") \\ S22 (MH "Resistance Training") \\ S21 (MH "Therapeutic Exercise+") \\ S20 (MH "Exercise+")
}

S19 S1 OR S2 OR S3 OR S4 OR S5 OR S6 OR S7 OR S8 OR S9 OR S10 OR S11 OR S12 OR S13 OR S14 OR S15 OR S16 OR S17 OR S18

S18 TX (iliac or femoral or popliteal or femoro* or fempop* or crural or tibial) N3 (occlus* or steno* or obstruct* or lesio* or block* or harden ${ }^{\star}$ or stiffen* or obliter $\left.{ }^{\star}\right)$

S17 TX (lower N3 extrem*) N3 (occlus * or steno* or obstruct* or lesio* or block ${ }^{*}$ or harden* or stiffen* or obliter $\left.^{\star}\right)$ )

S16 TX limb N3 (occlus* or steno* or obstruct* or lesio* or block ${ }^{\star}$ or harden ${ }^{\star}$ or stiffen ${ }^{\star}$ or obliter $\left.{ }^{\star}\right)$

S15 TX leg N3 (occlus* or steno* or obstruct* or lesio* or block* or harden* or stiffen $^{\star}$ or obliter $\left.^{\star}\right)$

S14 TX dysvascular*

S13 TX arteriopathic

S12 TX claudic*

S11 TX peripheral N3 dis*

S10 TX (arter* or vascular or vein* or veno* or peripher ${ }^{\star}$ ) N3 (occlus* or steno* or obstruct* or lesio* or block* or harden ${ }^{\star}$ or stiffen ${ }^{\star}$ or obliter $^{\star}$ )

S9 TX PVD or PAOD

S8 (MH "Tibial Arteries")

S7 (MH "Femoral Artery")

S6 (MH "Popliteal Artery")

S5 (MH "Iliac Artery")

S4 (MH "Leg/BS")

S3 (MH "Arterial Occlusive Diseases+")

S2 (MH "Peripheral Vascular Diseases+")

S1 (MH "Intermittent Claudication")

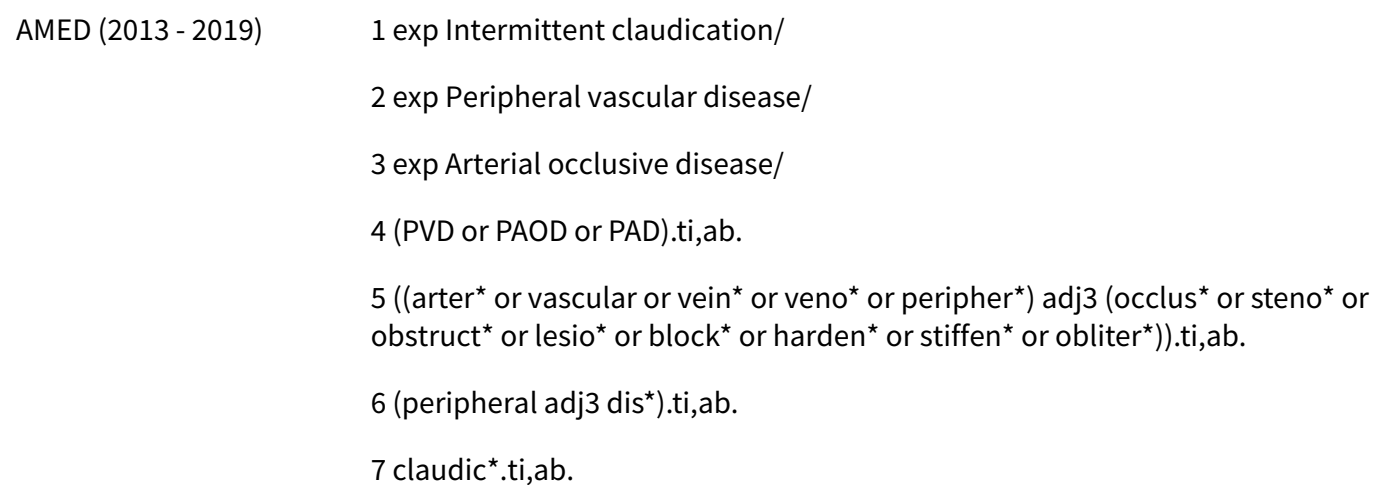

Modes of exercise training for intermittent claudication (Review)

Copyright (c) 2020 The Cochrane Collaboration. Published by John Wiley \& Sons, Ltd. 


\author{
8 arteriopathic.ti,ab. \\ 9 dysvascular*.ti,ab. \\ 10 (leg adj3 (occlus* or steno* or obstruct* or lesio* or block ${ }^{\star}$ or harden ${ }^{\star}$ or \\ stiffen* or obliter $\left.\left.{ }^{\star}\right)\right)$. ti,ab.
}

11 (limb adj3 (occlus* or steno* or obstruct* or lesio* or block* or harden* or stiffen* ${ }^{\star}$ or obliter $\left.\left.{ }^{\star}\right)\right)$. ti,ab.

12 (lower adj3 extrem* adj3 (occlus ${ }^{\star}$ or steno* or obstruct* or lesio* or block $^{\star}$ or harden* or stiffen ${ }^{\star}$ or obliter $\left.\left.{ }^{\star}\right)\right)$. .ti,ab.

13 ((iliac or femoral or popliteal or femoro* or fempop* or crural or tibial) adj3 (occlus ${ }^{\star}$ or steno* ${ }^{\star}$ or obstruct* or lesio* or block* or harden ${ }^{\star}$ or stiffen* or obliter $\left.{ }^{\star}\right)$.ti,ab.

14 or/1-13

15 exp Exercise/

16 exp Exercise therapy/

17 exp Resistance training/

18 exp Walking/

19 exp Dancing/

20 (physical adj (exercise* or exertion or endurance or therapy or conditioning or activity or activities or fitness or training)).ti,ab.

21 (exercise adj (training or intervention or programme or therapy or activity or regime)).ti,ab.

22 (fitness adj (training or intervention or protocol or programme or therapy or activity or regime)).ti,ab.

23 ((training or conditioning) adj (circuit or intervention or protocol or programme or activity or regime)).ti,ab.

24 (walk or walking or run or running or treadmill or aerobic or swim or swimming or dance or dancing or cycling or cyclist).ti,ab.

25 kinesiotherap*.ti,ab.

26 ((endurance or aerobic or cardio*) adj (fitness or training or intervention or protocol or program or therapy or activity or regime)).ti,ab.

27 or/15-26

2814 and 27

$29 \exp$ CLINICAL TRIALS/

30 RANDOM ALLOCATION/

31 DOUBLE BLIND METHOD/

32 Clinical trial.pt.

33 (clinic $^{\star}$ adj trial $\left.{ }^{\star}\right)$. tw.

$34\left(\left(\right.\right.$ singl ${ }^{\star}$ or doubl* or trebl ${ }^{\star}$ or tripl $\left.{ }^{\star}\right)$ adj $\left(b_{\text {lind }}{ }^{\star}\right.$ or mask $\left.\left.^{\star}\right)\right)$. tw.

35 PLACEBOS/ 
(Continued)

$$
\begin{aligned}
& 36 \text { placebo }^{*} \text {.tw. } \\
& 37 \text { random* }{ }^{\star} \text { tw. }
\end{aligned}
$$

38 PROSPECTIVE STUDIES/

39 or/29-38

4028 and 39

41 ("2017" or "2018" or "2019").yr.

4240 and 41

WHAT'S NEW

\begin{tabular}{lll}
\hline Date & Event & Description \\
\hline 29 October 2019 & $\begin{array}{l}\text { New citation required but conclusions } \\
\text { have not changed }\end{array}$ & $\begin{array}{l}\text { Searches updated. Five new studies included and two ongoing } \\
\text { studies identified. Six new studies excluded. New authors joined } \\
\text { team. Text updated to reflect current Cochrane standards includ- } \\
\text { ing addition of 'Summary of findings' table. No change to conclu- } \\
\text { sions. }\end{array}$ \\
\hline 29 October 2019 & New search has been performed & $\begin{array}{l}\text { Searches updated. Five new studies included and two ongoing } \\
\text { studies identified. Six new studies excluded. }\end{array}$ \\
\hline
\end{tabular}

\section{H I S T O R Y}

Protocol first published: Issue 2, 2012

Review first published: Issue 7, 2014

\section{CONTRIBUTIONS OF AUTHORS}

SJ: updated the protocol, selected relevant studies, assessed study quality, extracted data, performed data analysis, and wrote the text of this update.

UA: contributed to updating the protocol, selected studies, assessed study quality, extracted data, checked data for accuracy, and contributed to the text of the review.

GJL: contributed to updating the protocol, confirmed suitability of selected studies for inclusion, was consulted where disagreements occurred, checked data for accuracy, and revised the text of the review. In the previous version, he wrote the protocol, selected relevant studies, assessed study quality, extracted data, and wrote the review.

FF: contributed to updating the protocol, confirmed suitability of selected studies for inclusion, and revised the text. In the previous version, he contributed to the protocol, selected relevant studies, assessed study quality, and extracted data.

HF: contributed to updating the protocol, confirmed suitability of selected studies for inclusion, and revised the text. In the previous version, he contributed to the protocol and to the text of the review.

$\mathrm{JT}$ : contributed to the protocol, confirmed suitability of selected studies for inclusion, and contributed to the text of the review (both in the updated and previous version of the review).

\section{DECLARATIONSOF INTEREST}

SJ: none known

UA: none known

GJL: none known

FF: none known

HF: none known

JT: declares that he is Chairman of ClaudicatioNet, a network of specialised physiotherapists and foundation that implemented SET in the Netherlands 


\section{SOURCES OF SUPPORT}

\section{Internal sources}

- No sources of support supplied

\section{External sources}

- Chief Scientist Office, Scottish Government Health Directorates, the Scottish Government, UK

Cochrane Vascular's editorial base is supported by the Chief Scientist Office.

\section{DIFFERENCES BETWEEN PROTOCOLANDREVIEW}

For this update, in the Types of interventions section, 'Nordic walking' was added as an alternative mode of exercise. In the original protocol and review, studies comparing different types of walking exercise were not included, and Nordic walking was considered a different type of walking exercise. Recent publications have led to a different insight, as Nordic walking is different from standard walking because it uses a core-focused walking technique which engages the muscles of the arms and trunk to reduce the load on the legs during walking. Therefore, the criterion for not including studies was changed to 'different settings of walking exercise' (supervised versus unsupervised, communitybased versus hospital), and Nordic walking was included as an alternative mode of exercise. In the Data collection and analysis section, a different method to analyse treatment effect was used in this update. In the case of different treadmill test protocols, the standardised mean difference approach was used for summary statistics. Therefore, it was no longer necessary to convert times or distances to metabolic equivalent of tasks (METs).

In the previous version, we altered the primary outcome from mean change in maximum or pain-free walking distance to a postintervention maximum or pain-free walking distance. After extracting the data, most of the included trials only reported pre-intervention and post-intervention walking distances and their variances. No data on mean change were reported. Although calculating the mean change in walking distance from the pre-intervention and post-intervention data was possible, calculating a variance (standard deviation) of the mean change without having individual participant data was more challenging. To calculate a variance of the mean change from the reported summary pre-intervention and post-intervention variances, we needed at least the correlation between the pre-intervention and post-intervention variance (Higgins 2019), which was not reported. Furthermore, as we only included randomised trials and no significant difference in walking distance between the intervention and control group in each trial existed at baseline, we did not have any indication that our main outcome, the mean difference in post-intervention walking distance between the intervention and control group might be biased. We changed the $P$ value that was considered statistically significant in case of heterogeneity from 0.05 in our protocol to 0.10 in our full review. In the Background, we adjusted the description of the systematic review by Parmenter and colleagues (Parmenter 2011) after they contacted us and added why no meta-analysis was performed in this systematic review.

\section{NDEX TERMS}

\section{Medical Subject Headings (MeSH)}

Bias; Bicycling; Cardiovascular Diseases [therapy]; 'Exercise Test; Exercise Therapy [ ${ }^{\star}$ methods]; Intermittent Claudication [ ${ }^{\star}$ therapy]; Randomized Controlled Trials as Topic; Resistance Training; Skiing; Walk Test; *Walking

\section{MeSH check words}

Adult; Humans 